\title{
Effect of 1-Substitution on Tetrahydroisoquinolines as Selective Antagonists for the Orexin-1 Receptor
}

\author{
David A. Perrey ${ }^{\dagger}$, Nadezhda A. German ${ }^{\dagger}$, Ann M. Decker ${ }^{\dagger}$, David Thorn ${ }^{\ddagger}$, Jun-Xu Li ${ }^{\ddagger}$, Brian \\ P. Gilmour ${ }^{\dagger}$, Brian F. Thomas ${ }^{\dagger}$, Danni L. Harris ${ }^{\dagger}$, Scott P. Runyon ${ }^{\dagger}$, and Yanan Zhang ${ }^{\dagger},{ }^{*}$ \\ †Research Triangle Institute, Research Triangle Park, North Carolina 27709, United States \\ ‡Department of Pharmacology and Toxicology, University at Buffalo, the State University of New \\ York, Buffalo, New York 14214, United States
}

\begin{abstract}
Selective blockade of the Orexin-1 receptor has been suggested as a potential approach to drug addiction therapy because of its role in modulating the brain's reward system. We have recently reported a series of tetrahydroisoquinoline-based $\mathrm{OX}_{1}$ selective antagonists. Aimed at elucidating SAR requirements in other regions of the molecule and further enhancing $\mathrm{OX}_{1}$ potency and selectivity, we have designed and synthesized a series of analogs bearing a variety of substituents at the 1-position of the tetrahydroisoquinoline. The results show that an optimally substituted benzyl group is required for activity at the $\mathrm{OX}_{1}$ receptor. Several compounds with improved potency and/or selectivity have been identified. When combined with structural modifications that were previously found to improve selectivity, we have identified compound 73 (RTIOX-251) with an apparent dissociation constant $(\mathrm{Ke})$ of $16.1 \mathrm{nM}$ at the $\mathrm{OX}_{1}$ receptor and $>620$-fold selectivity over the $\mathrm{OX}_{2}$ receptor. In vivo, compound $\mathbf{7 3}$ was shown to block the development of locomotor sensitization to cocaine in rats.
\end{abstract}

\section{Keywords}

Orexin; antagonist; selective; tetrahydroisoquinoline

\section{Introduction}

Orexins (hypocretins), including orexin A and orexin B, are neuropeptides exclusively produced in hypothalamic neurons arising in the dorsomedial hypothalamus (DMH), perifornical area (PFA), and lateral hypothalamus (LH). ${ }^{1,2}$ The orexin-producing neurons in the hypothalamus project widely to key areas of the central nervous system (CNS) that are commonly thought to control sleep-wake states, modulation of food intake, panic, anxiety,

\footnotetext{
*Corresponding Authoryzhang@ rti.org; Tel: 919-541-1235; Fax: 919-541-6499.

Author Contributions

The manuscript was written through contributions of all authors. All authors have given approval to the final version of the manuscript.

Supporting Information. HPLC analysis of target compounds. This material is available free of charge via the Internet at http:// pubs.acs.org.
} 
reward and addictive behaviors, suggesting diverse roles for these peptides. ${ }^{3-5}$ Orexin A and $B$ bind and activate two $\mathrm{G}$ protein-coupled receptors (GPCRs), orexin-1 $\left(\mathrm{OX}_{1}\right)$ and orexin-2 $\left(\mathrm{OX}_{2}\right)$, with $\mathrm{OX}_{1}$ signaling via $\mathrm{G}_{\mathrm{q}}$ proteins and $\mathrm{OX}_{2}$ signaling via $\mathrm{G}_{\mathrm{q}}$ or $\mathrm{G}_{\mathrm{i} / \mathrm{o}}$ proteins. ${ }^{6,7}$ The $\mathrm{OX}_{1}$ receptor has 10-fold higher affinity for orexin $\mathrm{A}$ than for orexin $\mathrm{B}$; whereas $\mathrm{OX}_{2}$ has equal affinity for both peptides. Interestingly, these receptors are differentially distributed throughout the brain, suggesting different physiological roles for each receptor. ${ }^{1,8,9}$ Originally known for regulation of metabolic, circadian and stress systems, the orexin system has recently been associated with drug addiction. ${ }^{10-13}$ The fact that orexin neurons project to the ventral tegmental area (VTA) and other brain regions involved in reward processing supports this notion. Selective blockade of the $\mathrm{OX}_{1}$ receptor has been shown to attenuate stress- and cue-induced reinstatement of previously extinguished cocaine-, morphine-, and alcohol-seeking behavior. ${ }^{14-18}$ Together, these findings suggest that $\mathrm{OX}_{1}$ antagonists may have therapeutic utility for the treatment of drug addiction.

In order to elucidate the physiological role of the orexin receptors and explore the potential of orexin receptor antagonists as therapeutics, a number of groups, mostly from the pharmaceutical industry, have developed orexin receptor antagonists. ${ }^{19-23}$ In these endeavors, the majority of research has focused on dual orexin receptor antagonists for new sleep medications development. ${ }^{24,}{ }^{25}$ Several dual antagonists, including almorexant (1) and SB-649828 (2), have been advanced into clinical trials, but their development was later halted because of tolerability and toxicity concerns, respectively. The most success was seen with suvorexant (3), a dual orexin antagonist developed by Merck. Recently, suvorexant was approved at a lower dose $(20 \mathrm{mg})$ than initially proposed for the treatment of insomnia, and is currently marketed under the trade name Belsomra. ${ }^{26}$ Several $\mathrm{OX}_{1}$ receptor selective antagonists have also been developed to probe the importance of this receptor. ${ }^{27}$ Among these, the $\mathrm{OX}_{1}$ antagonist SB-334867 (4) was the first $\mathrm{OX}_{1}$ selective antagonist reported and has been extensively studied because it has favorable preclinical pharmacokinetics. ${ }^{28}$ Its affinity for $\mathrm{OX}_{1}$ is $\sim 50$-fold higher than for $\mathrm{OX}_{2}$, but some in vivo studies using high doses should be viewed cautiously because those doses may block both receptors. Additionally, Rottapharm Madaus has reported a series of azaspiro compounds as selective $\mathrm{OX}_{1}$ antagonists, and identified the spiro moiety as a key structural feature for $\mathrm{OX}_{1}$ receptor selectivity. ${ }^{29,}{ }^{30}$ Several other OX $_{1}$ selective antagonists have also been reported, including GSK-1059865 and its analogs, as well as ACT-335827, although these compounds mostly retained a significant amount of $\mathrm{OX}_{2}$ activity. ${ }^{31-33}$

Our group has been developing $\mathrm{OX}_{1}$ selective antagonists for the potential treatment of drug addiction and related disorders. ${ }^{34-36} \mathrm{We}$ recently described our progress toward selective OX antagonists based on the tetrahydroisoquinoline scaffold, which is found both in $\mathbf{1}$ and the $\mathrm{OX}_{2}$ receptor selective antagonist TCS-OX2-29 (5). ${ }^{37}$ The structural modifications focused on the 7-position of the tetrahydroisoquinoline ring and the acetamide positions, resulting in several potent and selective $\mathrm{OX}_{1}$ antagonists. In particular, RTIOX-276 (6) showed excellent $\mathrm{OX}_{1}$ potency and selectivity, and attenuated cocaine-induced conditioned place preference (CPP) in rats. ${ }^{34}$ However, the structure-activity relationship (SAR) requirements in other regions of the structure have yet to be explored. Interestingly, at the 1position of the tetrahydroisoquinoline, the dual orexin antagonist $\mathbf{1}$ has a 4 - 
trifluoromethylphenylethyl group, whereas the $\mathrm{OX}_{2}$ selective antagonist 5 does not bear any substitution, suggesting that this position may play an important role in receptor subtype selectivity. Therefore, we have examined a series of analogs bearing a variety of modifications at the 1-position of the tetrahydroisoquinoline. Herein, we report our effort in the design, synthesis, and in vitro and in vivo characterization of these 1-substituted analogs.

\section{Results and Discussion}

\section{Chemistry}

The overall approach to the synthesis followed methods detailed in our earlier work (Scheme 1). ${ }^{34,36}$ Briefly, commercially available 3,4-dimethoxyphenethylamine (7) and phenylacetic acid 8a were coupled using HBTU or BOP to give the amide 9. Cyclization of 9 via the Bischler-Napieralski reaction using phosphorus oxychloride in toluene afforded the dihydroisoquinoline, which was readily reduced to the tetrahydroisoquinoline $\mathbf{1 0}$ with sodium borohydride. The nitrogen was alkylated using N-benzyl bromoacetamide with diisopropylethylamine as base to give final product 11. Similarly, compound $\mathbf{1 2}$ was synthesized from $\mathbf{8 b}(\mathrm{R}=\mathrm{H})$. Elaboration of the phenol $\mathbf{1 2}$ was achieved by alkylation using the appropriate alkyl bromide in the presence of $\mathrm{K}_{2} \mathrm{CO}_{3}$, esterification via BOP-mediated coupling, or by sulfonylation using the sulfonyl chloride with triethylamine as base, to afford target compounds 13-23.

Aniline derivatives were synthesized following a similar route (Scheme 2). Amide coupling of $\mathbf{2 4}$ with the amine $\mathbf{7}$ followed by alkylation of the hydroxyl group afforded intermediate 25, which was converted to $\mathbf{2 7}$ via Bischler-Napieralski reaction, alkylation of the nitrogen and reduction of the nitro group. The free aniline in $\mathbf{2 7}$ was then modified by reductive amination using sodium triacetoxyborohydride or sodium cyanoborohydride, alkylation via an alkyl bromide or by amide coupling using BOP in DMF to provide final compounds 28-35. Similarly, the benzoxazole 38 was prepared from $\mathbf{2 4}$ via the 4-hydroxy-3-amino intermediate 37 by condensation with ethyl acetimidate. In addition to the 3,4-disubstituted, several monosubstituted analogs were prepared in analogous fashion (Scheme 3), starting from acid 39, via the tetrahydroisoquinoline $\mathbf{4 0}$ with further elaboration at phenol or aniline. Urea $\mathbf{5 0}$ was prepared by reaction with $\mathrm{n}$-hexyl isocyanate in toluene.

Compounds with substituents other than the benzyl group at the 1-position were made via Pictet-Spengler condensation between $\mathbf{7}$ and the corresponding aldehydes in toluene and trifluoroacetic acid at $140{ }^{\circ} \mathrm{C}$ for 30 minutes in the microwave, followed by $\mathrm{N}$-alkylation as described above (Scheme 4). The olefin $\mathbf{6 1}$ was reduced by hydrogenation on $\mathrm{Pd} / \mathrm{C}$ in ethanol to give the saturated analog 62. Non-commercial aldehydes in the Pictet-Spengler reaction were prepared via pyridinium chlorochromate oxidation of the appropriate alcohols.

The 7-propoxy derivative $\mathbf{7 3}$ was prepared in a similar fashion as described above (Scheme 5), starting from 4-hydroxy-3-methoxy-phenethylamine (70). Amide coupling between 70 and $\mathbf{8 b}$, followed by alkylation of the two hydroxyl groups afforded intermediate $\mathbf{7 1}$. Cyclization followed by reduction provided amine $\mathbf{7 2}$ and then a final $\mathrm{N}$-alkylation with the bromoacetamide gave $\mathbf{7 3}$. 


\section{Biological Evaluation}

Activity of the target compounds at the human $\mathrm{OX}_{1}$ and $\mathrm{OX}_{2}$ receptors was evaluated using Fluorescent Imaging Plate Reader technology (FLIPR ${ }^{\mathrm{TM}}$, Molecular Devices), which measures intracellular calcium mobilization in live cells. The apparent dissociation constant Ke was calculated from compound-mediated inhibition of orexin A activity as previously described. ${ }^{34-36}$ In these assays, the $\mathrm{EC}_{50}$ for orexin $\mathrm{A}$ at $\mathrm{OX}_{1}$ and $\mathrm{OX}_{2}$ is $0.13 \pm 0.02 \mathrm{nM}$ and $4.2 \pm 0.2 \mathrm{nM}$, respectively. All the compounds that had $\mathrm{OX}_{1}$ Ke values $<1 \mu \mathrm{M}$ were also tested for agonist activity at $10 \mu \mathrm{M}$; none of them were active.

Our studies aimed at mapping out the SAR requirements at the 1-positon based on both the steric and electronic considerations. An examination of several reported orexin antagonists based on the tetrahydroisoquinoline scaffold revealed the importance of the 1-postion. The dual orexin antagonist $\mathbf{1}$ has a 4-trifluoromethylphenylethyl group at the 1-position.

Conversely, the $\mathrm{OX}_{2}$ selective antagonist 5 does not bear any substitution at the 1-position. Compound 11, the hit identified in a high-throughput screening campaign by Actelion, has a 3,4-dimethoxybenzyl group at the 1-position of the tetrahydroisoquinoline, and showed some selectivity for the $\mathrm{OX}_{1}$ receptor (Table 1). ${ }^{34,38}$ The $\mathrm{OX}_{1}$ receptor selective antagonist 6 developed in our lab also has the 3,4-dimethoxy substitution. Taken together, these results suggest that the 1-position substituents may have differential effects on the activity of ligands at the two orexin receptors.

The small set of analogs of $\mathbf{1 1}$ reported by Actelion suggests that the substitution pattern on the 1-benzyl group may have a significant effect on the activity at the orexin receptors. ${ }^{38}$ For instance, the corresponding phenyl analog which lacked the dimethoxy groups at the 3 and 4-positons, showed little activity at either receptor. Removing one of the methoxy groups also resulted in significant loss of activity at both receptors. Therefore, we first evaluated a series of 3,4-disubstituted benzyl analogs that retained the 3-methyoxy group but had different alkyl-substituted groups at the 4-position of the benzyl group (Table 1). All of the target compounds were prepared racemically, although the 1-position stereochemistry is undoubtedly important, as evidenced by both $\mathbf{1}$ and our own findings. ${ }^{34,} 39$ While removing the methyl group at the 4-methoxy position gave a slight drop in potency in phenol 12, the potency was regained and even increased by substituting with a larger alkyl group such as butyl 13 or hexyl 14, with 13 having slightly higher potency. Further increasing the size to a piperidinylethyl group, which may provide improved drug-like properties due to the basic nitrogen, resulted in a total loss of activity, suggesting limited size tolerance at this site. Interestingly, the butyric ester 16 was equally potent to the butyl analog 13 , suggesting polar groups can be tolerated at this site. Analog 17 with a mesyl group, which has the size between a methyl (11) and butyl groups (13) but a high electron deficiency, had a Ke $=485$ $\mathrm{nM}$, only slightly less potent than $\mathbf{1 1}$. These findings indicate that steric bulk may play a more prominent role at this position than electronic effects. A series of aromatic substituents at the 4-alkoxy position were then examined (18-22). The O-benzyl analog 18 was 2-fold less potent than 11. Extending the phenyl group away from the ring system had no effect on potency (19). The corresponding sulfonyl analog (20) showed no potency at the $\mathrm{OX}_{1}$ receptor. The two pyridylmethyl derivatives $\mathbf{2 1}$ and $\mathbf{2 2}$ showed similar potency to compound 11. Finally, the phenylsulfonyl analog $(\mathbf{2 3})$ had a $\sim 9$-fold decrease in potency. 
We next synthesized a series of compounds that had modifications at the 3-position of the 1benzyl group, while retaining the 4-methoxy group (Table 1). Replacement of the oxygen moiety with a series of nitrogen-containing groups, with the aim of reducing $\log \mathrm{P}$ and improving the drug-likeness, gave some interesting results. The 3-nitro analog (26) showed $\sim 7$-fold reduced potency, whereas dimethylamino analog $\mathbf{2 8}$ gave a significant improvement of potency at the $\mathrm{OX}_{1}$ receptor $(\mathrm{Ke}=13 \mathrm{nM})$ but also increased the $\mathrm{OX}_{2}$ receptor potency. However, larger $\mathrm{N}$-alkyl groups were not as well tolerated and the potency decreased with the increase of the size of the alkyl groups (29-33), with the benzyl analog (33) having no activity at concentrations up to $10 \mu \mathrm{M}$. Interestingly, while the acetyl derivatives $\mathbf{3 4}$ had a significant drop in potency, $\mathbf{3 5}$, which had a larger acyl group, regained most of the potency. Finally, the corresponding 4-hydroxyl substituent had a significant potency reduction compared to its 4-methoxy analog ( $\mathbf{3 6}$ vs. 26). The benzoxazole $\mathbf{3 8}$ had a Ke in the micromolar range.

All of the 1-benzyl analogs discussed thus far have a 3,4-substitution pattern. The relative importance of each of those positions was then examined by preparing a series of 3substituted and 4-substituted analogs (Table 2). As previously reported, analogs singly substituted with a methoxyl group at either the 3- or 4-position had diminished activity at both $\mathrm{OX}_{1}$ and $\mathrm{OX}_{2}$ receptors. ${ }^{38}$ Therefore, we have examined a series of analogs that bear substituents other than a methoxyl group at these positions. The 3-isopropoxyl analog (41) had a $\sim 7$-fold drop in $\mathrm{OX}_{1}$ potency. In the 3-nitrogen containing analogs, the 3-nitro 42 showed activity only at $\mathrm{OX}_{2}(1200 \mathrm{nM})$, whereas the aniline $\mathbf{4 3}$ showed modest potency at the $\mathrm{OX}_{1}$ receptor and no activity at $\mathrm{OX}_{2}$. Potency at the $\mathrm{OX}_{1}$ receptor was further increased by dimethylation (44), which was the most potent mono-substituted compound in the series. However, 44 also showed significant potency at the $\mathrm{OX}_{2}$ receptor $(\mathrm{Ke}=660 \mathrm{nM})$. It appears that the 4-position may contribute more to the $\mathrm{OX}_{1}$ potency as the 4-substituted mono isopropoxy derivative (46) showed increased potency compared to the corresponding 3substituted derivative (41). The differences in $\mathrm{OX}_{1}$ potency between the n-propyl 45 and the isopropyl $\mathbf{4 6}$ were modest and both were slightly less potent than 11. In the 4-nitrogen series, the 4-aniline $\mathbf{4 7}$ showed no $\mathrm{OX}_{1}$ activity and again this was restored with the 4dimethylamino analog 48, which had similar potency to compound $11(253 \mathrm{v} 199 \mathrm{nM})$. As with the disubstituted analogs, acylation as the acetamide $\mathbf{4 9}$ or the urea $\mathbf{5 0}$ caused a significant drop in potency. Finally, the isopropyl analog $\mathbf{5 1}$ had good potency, with a Ke of $85 \mathrm{nM}$, further reinforcing the idea that steric factors are the overriding factor in potency. The $\mathrm{OX}_{2}$ selectivity of the nitro $\mathbf{4 2}$ indicates some preference for electron-withdrawing substituents for $\mathrm{OX}_{2}$ potency and indeed a trifluoromethyl substituent may contribute to the $\mathrm{OX}_{2}$ potency of 1 .

We then investigated a series of alternate substituents, including differentially substituted benzylic and non-aromatic systems to further examine the SAR requirements at this position (Table 3). Surprisingly, the 3,4,5-trimethoxy analog $\mathbf{5 2}$ was mostly inactive at both receptors. This clearly shows that the 1-benzyl substituent is highly sensitive to substitutions, confirming the earlier observations. The 3,4-dimethylbenzyl analog $\mathbf{5 3}$ showed higher potency than 11, further illustrating the importance of steric effects on potency. The naphthyl (54) and quinoline (55) analogs showed a modest reduction in potency compared to 
11. Interestingly, removing the methylene group resulted in a total loss of activity (59 vs. 11). Elongation of the methylene group $(\mathbf{6 0}, \mathbf{6 2}, \mathbf{6 3})$ also led to significant loss of activity at the $\mathrm{OX}_{1}$ receptor. This is somewhat surprising as the dual orexin antagonist $\mathbf{1}$ has a phenethyl group and has high potency at both receptors. Introduction of rigidity (61) led to diminished activity. The requirement for an aromatic system was then examined with the replacement of the 1-benzyl with nonaromatic systems (Table 3). A series of alkyl analogs were prepared and their OX potency evaluated; however, none of them (64-69) showed detectable antagonism in our assay at concentrations of $10 \mu \mathrm{M}$. Taken together, these findings clearly confirm that an optimally substituted benzyl group is required for $\mathrm{OX}_{1}$ potency.

The structural modifications at the 1-position have led to the identification of several compounds that have improved $\mathrm{OX}_{1}$ potency compared to the 3,4-dimethoxy analog $\mathbf{1 1}$. Several compounds also showed improved $\mathrm{OX}_{1}$ selectivity, greater than 50 -fold (e.g. 16, 28, 51), even though this improvement is only modest. As previously reported by our group, introducing larger alkyl groups such as a 7-propoxy at the 7-methoxy position led to improved potency and selectivity. Therefore, we synthesized a dipropoxy analog which has a propoxy group at the 7-position of the tetrahydroisoquinoline and the 4-position of the 1benzyl group, respectively (73, RTIOX-251, Figure 2). Indeed, these modifications resulted in an analog that showed improvement in both $\mathrm{OX}_{1}$ potency and selectivity (73). Compound $73 \mathrm{had}$ a Ke of $16.1 \mathrm{nM}$ (vs. $48 \mathrm{nM}$ for the close analog 13), but it was selectivity where the greatest improvement was seen in $\mathbf{7 3}$, which increased to approximately $>620$-fold.

\section{Cocaine-induced Behavioral Sensitization}

$\mathrm{OX}_{1}$ receptor selective antagonist SB334867 has been reported to block the development of locomotor sensitization to cocaine when administrated i.p. ${ }^{40}$ We next moved on to test one of the compounds that showed the highest potency and selectivity in this series of compounds, compound $\mathbf{7 3}$, on the development of behavioral sensitization to cocaine in rats. As expected, acute cocaine treatment induced a dose-dependent hyperactivity (open circles, left panel, Fig. 3). Daily treatment with $15 \mathrm{mg} / \mathrm{kg}$ cocaine for 7 days induced a significant locomotor sensitization, as demonstrated by a leftward shift of the cocaine dose-effect curve on day 15 as compared to day 1 (compare gray circles with open circles, right panel, Fig. 3). Two way ANOVA revealed significant main effects of repeated treatment $(F[2,14]=24.7$, $\mathrm{P}<0.0001)$ and repeated treatment $\times$ cocaine dose interactions $(\mathrm{F}[2,14]=35.2, \mathrm{P}<$ 0.0001 ). Post hoc analysis indicated that on day 15 , the effects of 3.2 and $10 \mathrm{mg} / \mathrm{kg}$ cocaine were significantly increased while the effect of $32 \mathrm{mg} / \mathrm{kg}$ cocaine was significantly decreased. Although $10 \mathrm{mg} / \mathrm{kg}$ compound 73, a dose that alone did not significantly alter the spontaneous activity in rats (data not shown), did not alter acute cocaine-induced hyperactivity when given acutely (left panel, Fig. 3), repeated treatment with compound $\mathbf{7 3}$ significantly blocked the development of cocaine sensitization (compare open circles with open squares, right panel, Fig. 3). Two way ANOVA revealed significant main effects of repeated treatment $(\mathrm{F}[2,14]=7.2, \mathrm{P}<0.01)$ and repeated treatment $\times$ cocaine dose interactions $(\mathrm{F}[2,14]=10.5, \mathrm{P}<0.01)$. Post hoc analysis indicated that on day 15 , the effects of $10 \mathrm{mg} / \mathrm{kg}$ cocaine were significantly lower while the effect of $32 \mathrm{mg} / \mathrm{kg}$ cocaine 
was significantly higher in the compound $\mathbf{7 3}$ treated group as compared to control group, suggesting a significant blockade of cocaine sensitization.

\section{Conclusions}

Recently, the orexin system has been indicated to play an important role in the reward pathway and $\mathrm{OX}_{1}$ receptor selective antagonists have been suggested to hold value for the treatment of addiction to a number of illicit drugs. While several $\mathrm{OX}_{1}$ antagonists have been reported so far, they tend to retain some activity at the $\mathrm{OX}_{2}$ receptor. In our continued effort to investigate the SAR on the tetrahydroisoquinoline scaffold and develop highly potent and selective $\mathrm{OX}_{1}$ antagonists, we have designed and synthesized a series of compounds with a range of substituents at the 1-position. These compounds were then evaluated for the potency at the $\mathrm{OX}_{1}$ and $\mathrm{OX}_{2}$ receptors in FLPR-based calcium mobilization assays. The SAR results indicate that an optimally substituted benzyl group is required for activity at the $\mathrm{OX}_{1}$ receptor. Shortening or elongation of the methylene unit in the benzyl group both led to dramatic decreases in $\mathrm{OX}_{1}$ potency. Other nonaromatic systems including straight chain or cyclic alkyl groups were also not well tolerated. A number of analogs (e.g. 13, 16 and 51) showed improvement on potency at the $\mathrm{OX}_{1}$ receptor compared with the dimethoxy substitution (11). In particular, the 3-dimethylamino-4-methyoxy substitution pattern (28) provided the best $\mathrm{OX}_{1}$ potency $(\mathrm{Ke}=12.7 \mathrm{nM})$ and reasonable selectivity (76.7-fold), although some activity at the $\mathrm{OX}_{2}$ potency remains $(\mathrm{Ke}=970 \mathrm{nM})$. When structural modifications at the 7-position of the tetrahydroisoquinoline that have been shown to improve potency were introduced, $\mathrm{OX}_{1}$ potency and selectivity were further enhanced. Compound 73 (RTIOX-251) is both a potent and highly selective $\mathrm{OX}_{1}$ receptor antagonist. At $10 \mathrm{mg} / \mathrm{kg} 73 \mathrm{did}$ not alter acute cocaine-induced hyperactivity when given acutely, but blocked the development of locomotor sensitization to cocaine in rats when repeatedly administrated.

\section{Experimental Procedures}

\section{General}

All solvents and chemicals were reagent grade. Unless otherwise mentioned, all were purchased from commercial vendors and used as received. Flash column chromatography was done on a Teledyne ISCO CombiFlash Rf system using prepacked columns. Solvents used were hexane, ethyl acetate (EtOAc), dichloromethane (DCM), methanol and chloroform:methanol:ammonium hydroxide (80:18:2) (CMA-80). Purity and characterization of compounds was established by a combination of high pressure liquid chromatography (HPLC), thin layer chromatography (TLC), mass spectrometry (MS) and nuclear magnetic resonance (NMR) analysis. ${ }^{1} \mathrm{H}$ and ${ }^{13} \mathrm{C}$ NMR spectra were recorded on a Bruker Avance DPX-300 (300 MHz) spectrometer and were determined in chloroform-d or methanol-d4 with tetramethylsilane (TMS) $(0.00 \mathrm{ppm})$ or solvent peaks as the internal reference. Chemical shifts are reported in ppm relative to the reference signal, and coupling constant (J) values are reported in Hz. TLC was done on EMD precoated silica gel 60 F254 plates, and spots were visualized with UV light or iodine staining. Low resolution mass spectra were obtained using a Waters Alliance HT/Micromass ZQ system (ESI). High 
resolution mass spectra were obtained using an Agilent 6230 time-of-flight mass spectrometer. Melting points were determined using a Mel Temp II melting point apparatus and are uncorrected. All test compounds were greater than $95 \%$ pure as determined by HPLC on an Agilent 1100 system using an Agilent Zorbax SB-Phenyl, $2.1 \mathrm{~mm}$ x $150 \mathrm{~mm}, 5$ $\mu$ m column with gradient elution using the mobile phases (A) $\mathrm{H}_{2} \mathrm{O}$ containing $0.1 \%$ $\mathrm{CF}_{3} \mathrm{COOH}$ and (B) $\mathrm{MeCN}$, with a flow rate of $1.0 \mathrm{~mL} / \mathrm{min}$.

\section{General procedures}

N-[2-(3,4-Dimethoxyphenyl)ethyl]-2-(3-hydroxy-4-methoxyphenyl)acetamide (9): 3Hydroxy-4-methoxyphenylacetic acid (1.0 g, $5.49 \mathrm{mmol}), 3$,4-dimethoxyphenethylamine $(1.0 \mathrm{~g}, 0.93 \mathrm{~mL}, 5.49 \mathrm{mmol})$ and HBTU $(2.08 \mathrm{~g}, 5.49 \mathrm{mmol})$ were combined in dry DMF $(55 \mathrm{~mL})$ at $\mathrm{RT}$ under $\mathrm{N}_{2}$. Diisopropylethylamine $(1.77 \mathrm{~g}, 2.4 \mathrm{~mL}, 13.72 \mathrm{mmol})$ was added and the reaction stirred at RT overnight. The reaction was diluted with EtOAc, washed with $2 \mathrm{~N} \mathrm{HCl}, \mathrm{NaHCO}_{3}$ solution and brine, dried over $\mathrm{MgSO}_{4}$ and the solvent removed under reduced pressure to give the desired amide as a yellow oil which solidified upon standing (1.50 g, 79\%). ${ }^{1} \mathrm{H}$ NMR (300 MHz, CHLOROFORM-d) $\delta 7.39$ - $7.50(\mathrm{~m}, 1 \mathrm{H}), 6.81$ - 6.88 $(\mathrm{m}, 1 \mathrm{H}), 6.71(\mathrm{~d}, J=8.19 \mathrm{~Hz}, 1 \mathrm{H}), 6.57-6.67(\mathrm{~m}, 3 \mathrm{H}), 6.50(\mathrm{dd}, J=1.98,8.10 \mathrm{~Hz}, 1 \mathrm{H})$, 5.52 (br. s., $1 \mathrm{H}), 3.86$ (s, $3 \mathrm{H}), 3.83$ (s, 3H), 3.82 (s, 3H), 3.47 (s, 2H), 3.43 (t, $J=6.12 \mathrm{~Hz}$, $2 \mathrm{H}), 2.67(\mathrm{t}, J=6.83 \mathrm{~Hz}, 2 \mathrm{H})$.

\section{4-[(6,7-Dimethoxy-1,2,3,4-tetrahydroisoquinolin-1-yl)methyl]-2-methoxyphenol (10):}

Amide $9(1.51 \mathrm{~g}, 4.37 \mathrm{mmol})$ was suspended in anhydrous toluene $(22 \mathrm{~mL})$ and phosphorous oxychloride $(4.02 \mathrm{~g}, 2.45 \mathrm{~mL}, 26.23 \mathrm{mmol})$ added slowly. The reaction was heated to $90{ }^{\circ} \mathrm{C}$ for $2 \mathrm{hr}$, during which the solid went into solution, then a red oil separated. The reaction was cooled, then quenched by slow addition of the reaction mixture to water and heated until a solution formed. The toluene layer was removed, $2 \mathrm{~N}$ sodium hydroxide solution was added until $\mathrm{pH}$ was 8-9, then the solution was extracted 3 times with DCM. The combined extracts were dried over $\mathrm{MgSO}_{4}$ and the solvent removed under reduced pressure.

The crude dihydroisoquinoline was dissolved in methanol $(25 \mathrm{~mL})$ and cooled in an ice bath under $\mathrm{N}_{2}$. Sodium borohydride $(0.83 \mathrm{~g}, 21.99 \mathrm{mmol})$ was added portionwise and the reaction allowed to warm slowly to RT overnight. The reaction was quenched with water then the methanol removed under reduced pressure. The aqueous solution was extracted 3 times with DCM and the combined extracts were dried over $\mathrm{MgSO}_{4}$ and the solvent removed under reduced pressure to give the desired tetrahydroisoquinoline as an off-white foam $(0.73 \mathrm{~g}, 91 \%) .{ }^{1} \mathrm{H}$ NMR (300 MHz, CHLOROFORM-d) $\delta 6.86(\mathrm{~d}, J=7.82 \mathrm{~Hz}, 1 \mathrm{H})$, $6.70-6.79(\mathrm{~m}, 2 \mathrm{H}), 6.66(\mathrm{~s}, 1 \mathrm{H}), 6.60(\mathrm{~s}, 1 \mathrm{H}), 4.13(\mathrm{dd}, J=4.29,9.18 \mathrm{~Hz}, 1 \mathrm{H}), 3.87(\mathrm{~s}, 3 \mathrm{H})$, $3.85(\mathrm{~s}, 3 \mathrm{H}), 3.84(\mathrm{~s}, 3 \mathrm{H}), 3.11-3.27(\mathrm{~m}, 2 \mathrm{H}), 2.83-2.98(\mathrm{~m}, 4 \mathrm{H}), 2.63-2.79(\mathrm{~m}, 2 \mathrm{H})$.

\section{N-Benzyl-2-\{1-[(4-hydroxy-3-methoxyphenyl)methyl]-6,7-dimethoxy-1,2,3,4-} tetrahydroisoquinolin-2-yl\}acetamide (12): Amine 10 (0.20 g, $0.61 \mathrm{mmol})$, N-benzyl-2bromoacetamide $(0.152 \mathrm{~g}, 0.67 \mathrm{mmol})$ and tetrabutylammonium iodide $(0.045 \mathrm{~g}, 0.12$ mmol) were combined in dry DMF $(6 \mathrm{~mL})$ and diisopropylethylamine $(0.196 \mathrm{~g}, 0.26 \mathrm{~mL}$, $1.52 \mathrm{mmol}$ ) was added. The reaction was stirred at $\mathrm{RT}$ overnight under $\mathrm{N}_{2}$. The reaction was diluted with EtOAc, washed with $\mathrm{NaHCO}_{3}$ solution, water and brine (x2), then dried over 
$\mathrm{MgSO}_{4}$ and the solvent removed under reduced pressure. The crude was purified by chromatography on silica (0-60\% EtOAc in hexane) to obtain the desired product as a pale yellow oil (0.097 g, 33\%). ${ }^{1} \mathrm{H}$ NMR (300 MHz, CHLOROFORM-d) $\delta 7.21-7.36$ (m, 3H), $7.14(\mathrm{~d}, J=6.69 \mathrm{~Hz}, 2 \mathrm{H}), 6.93-7.04(\mathrm{~m}, 1 \mathrm{H}), 6.76-6.84(\mathrm{~m}, 1 \mathrm{H}), 6.66-6.73(\mathrm{~m}, 1 \mathrm{H}), 6.64$ $(\mathrm{d}, J=1.51 \mathrm{~Hz}, 1 \mathrm{H}), 6.59(\mathrm{~s}, 1 \mathrm{H}), 6.45(\mathrm{~s}, 1 \mathrm{H}), 5.50(\mathrm{~s}, 1 \mathrm{H}), 4.48(\mathrm{dd}, J=8.01,14.69 \mathrm{~Hz}$, $1 \mathrm{H}), 3.87(\mathrm{~s}, 3 \mathrm{H}), 3.82(\mathrm{~s}, 3 \mathrm{H}), 3.76(\mathrm{~s}, 3 \mathrm{H}), 3.56$ - $3.72(\mathrm{~m}, 2 \mathrm{H}), 3.35$ - $3.49(\mathrm{~m}, 1 \mathrm{H}), 3.09$ $3.34(\mathrm{~m}, 2 \mathrm{H}), 2.79-3.01(\mathrm{~m}, 4 \mathrm{H}), 2.42-2.56(\mathrm{~m}, 1 \mathrm{H}) . \mathrm{m} / z 477(\mathrm{M}+\mathrm{H})$. HRMS (ESI, $\left.\mathrm{CH}_{3} \mathrm{OH}\right) \mathrm{m} / \mathrm{z}$ calcd for $\mathrm{C}_{28} \mathrm{H}_{33} \mathrm{~N}_{2} \mathrm{O}_{5}[\mathrm{M}+\mathrm{H}]^{+} 477.2384, \mathrm{~m} / z$ found 477.2411 .

\section{N-Benzyl-2-\{1-[(4-butoxy-3-methoxyphenyl)methyl]-6,7-dimethoxy-1,2,3,4-}

tetrahydroisoquinolin-2-yl \}acetamide (13): Phenol $12(50 \mathrm{mg}, 0.105 \mathrm{mmol})$, potassium carbonate $(29 \mathrm{mg}, 0.210 \mathrm{mmol})$ and tetrabutylammonium iodide $(8 \mathrm{mg}, 0.021 \mathrm{mmol})$ were combined in DMF ( $1 \mathrm{~mL})$ and 1-bromobutane $(16 \mathrm{mg}, 12 \mu \mathrm{L}, 0.115 \mathrm{mmol})$ was added. The reaction was heated at $50{ }^{\circ} \mathrm{C}$ overnight. It was diluted with EtOAc, washed with water and brine, dried over $\mathrm{MgSO}_{4}$ and the solvent removed under reduced pressure. The crude was purified by chromatography on silica (0-75\% EtOAc in hexane) to give the desired product as a yellow glassy solid (47 mg, 84\%). ${ }^{1} \mathrm{H}$ NMR $(300 \mathrm{MHz}, \mathrm{CHLOROFORM-d)} \delta 7.18$ $7.34(\mathrm{~m}, 3 \mathrm{H}), 7.11(\mathrm{~d}, J=6.50 \mathrm{~Hz}, 2 \mathrm{H}), 6.96-7.06(\mathrm{~m}, 1 \mathrm{H}), 6.63-6.72(\mathrm{~m}, 3 \mathrm{H}), 6.58(\mathrm{~s}$, 1H), $6.44(\mathrm{~s}, 1 \mathrm{H}), 4.49$ (dd, $J=8.05,14.93 \mathrm{~Hz}, 1 \mathrm{H}), 3.83-3.91(\mathrm{~m}, 5 \mathrm{H}), 3.81(\mathrm{~s}, 3 \mathrm{H}), 3.79$ (s, 3H), 3.58 - $3.71(\mathrm{~m}, 2 \mathrm{H}), 3.34-3.51(\mathrm{~m}, 1 \mathrm{H}), 3.10$ - $3.34(\mathrm{~m}, 2 \mathrm{H}), 2.78-3.00(\mathrm{~m}, 4 \mathrm{H})$, $2.41-2.56(\mathrm{~m}, 1 \mathrm{H}), 1.72-1.87(\mathrm{~m}, 2 \mathrm{H}), 1.39-1.53(\mathrm{~m}, 2 \mathrm{H}), 0.97(\mathrm{t}, J=7.35 \mathrm{~Hz}, 3 \mathrm{H}) . \mathrm{m} / z$ $533(\mathrm{M}+\mathrm{H})$. HRMS (ESI, $\left.\mathrm{CH}_{3} \mathrm{OH}\right) \mathrm{m} / z$ calcd for $\mathrm{C}_{32} \mathrm{H}_{41} \mathrm{~N}_{2} \mathrm{O}_{5}[\mathrm{M}+\mathrm{H}]^{+} 533.3010, \mathrm{~m} / z$ found 533.3057.

\section{N-Benzyl-2-(1-\{[4-(hexyloxy)-3-methoxyphenyl]methyl\}-6,7-dimethoxy-1,2,3,4-} tetrahydroisoquinolin-2-yl)acetamide (14): This was made by the general procedure from phenol 12 in 73\% yield. ${ }^{1} \mathrm{H}$ NMR (300 MHz, CHLOROFORM-d) $\delta 7.19-7.34(\mathrm{~m}, 3 \mathrm{H})$, 7.08 - $7.16(\mathrm{~m}, 2 \mathrm{H}), 7.01(\mathrm{dd}, J=5.23,7.49 \mathrm{~Hz}, 1 \mathrm{H}), 6.63-6.73(\mathrm{~m}, 3 \mathrm{H}), 6.59(\mathrm{~s}, 1 \mathrm{H}), 6.44$ (s, 1H), 4.49 (dd, $J=8.01,14.88 \mathrm{~Hz}, 1 \mathrm{H}), 3.84-3.90(\mathrm{~m}, 5 \mathrm{H}), 3.81(\mathrm{~s}, 3 \mathrm{H}), 3.79(\mathrm{~s}, 3 \mathrm{H})$, 3.58 - $3.71(\mathrm{~m}, 2 \mathrm{H}), 3.34$ - $3.49(\mathrm{~m}, 1 \mathrm{H}), 3.10$ - $3.34(\mathrm{~m}, 2 \mathrm{H}), 2.79$ - $2.99(\mathrm{~m}, 4 \mathrm{H}), 2.41$ $2.56(\mathrm{~m}, 1 \mathrm{H}), 1.74-1.88(\mathrm{~m}, 2 \mathrm{H}), 1.29-1.51(\mathrm{~m}, 6 \mathrm{H}), 0.91(\mathrm{t}, J=6.78 \mathrm{~Hz}, 3 \mathrm{H}) . \mathrm{m} / z 561(\mathrm{M}$ $+\mathrm{H}$ ). HRMS (ESI, $\left.\mathrm{CH}_{3} \mathrm{OH}\right) \mathrm{m} / z$ calcd for $\mathrm{C}_{34} \mathrm{H}_{45} \mathrm{~N}_{2} \mathrm{O}_{5}[\mathrm{M}+\mathrm{H}]^{+} 561.3323, \mathrm{~m} / z$ found 561.3362 .

\section{N-Benzyl-2-[6,7-dimethoxy-1-(\{3-methoxy-4-[2-(piperidin-1-} yl)ethoxylphenyl\}methyl)-1,2,3,4-tetrahydroisoquinolin-2-yl]acetamide (15): This was prepared from 12 using the general procedure in $27 \%$ yield. ${ }^{1} \mathrm{H}$ NMR $(300 \mathrm{MHz}$, CHLOROFORM-d) $\delta 7.19$ - 7.35 (m, 3H), 7.12 (d, $J=6.69 \mathrm{~Hz}, 2 \mathrm{H}), 7.03$ (dd, $J=5.09$, $7.44 \mathrm{~Hz}, 1 \mathrm{H}), 6.66-6.73(\mathrm{~m}, 3 \mathrm{H}), 6.59(\mathrm{~s}, 1 \mathrm{H}), 6.43(\mathrm{~s}, 1 \mathrm{H}), 4.48(\mathrm{dd}, J=7.96,14.93 \mathrm{~Hz}$, $1 \mathrm{H}), 4.02(\mathrm{t}, J=6.31 \mathrm{~Hz}, 2 \mathrm{H}), 3.87(\mathrm{~s}, 3 \mathrm{H}), 3.81(\mathrm{~s}, 3 \mathrm{H}), 3.78(\mathrm{~s}, 3 \mathrm{H}), 3.59-3.72(\mathrm{~m}, 2 \mathrm{H})$, 3.34 - $3.48(\mathrm{~m}, 1 \mathrm{H}), 3.11-3.34(\mathrm{~m}, 2 \mathrm{H}), 2.83$ - $2.99(\mathrm{~m}, 4 \mathrm{H}), 2.76$ - $2.82(\mathrm{~m}, 2 \mathrm{H}), 2.42$ $2.56(\mathrm{~m}, 5 \mathrm{H}), 1.61$ (quin, $J=5.49 \mathrm{~Hz}, 4 \mathrm{H}), 1.40-1.51(\mathrm{~m}, 2 \mathrm{H}) . \mathrm{m} / z .588(\mathrm{M}+\mathrm{H})$. HRMS (ESI, $\mathrm{CH}_{3} \mathrm{OH}$ ) $\mathrm{m} / z$ calcd for $\mathrm{C}_{35} \mathrm{H}_{46} \mathrm{~N}_{3} \mathrm{O}_{5}[\mathrm{M}+\mathrm{H}]^{+} 588.3432, \mathrm{~m} / z$ found 588.3489 . 
4-(\{2-[(Benzylcarbamoyl)methyl]-6,7-dimethoxy-1,2,3,4-tetrahydroisoquinolin-1yl\}methyl)-2-methoxyphenyl butanoate (16): To a mixture of phenol $12(50 \mathrm{mg}, 0.105$ $\mathrm{mmol}$ ), butyric acid ( $9 \mathrm{mg}, 10 \mu \mathrm{L}, 0.105 \mathrm{mmol})$ and BOP (46 mg, $0.105 \mathrm{mmol})$ in DCM (1 $\mathrm{mL}$ ) was added diisopropylethylamine $(34 \mathrm{mg}, 46 \mu \mathrm{L}, 0.262 \mathrm{mmol}$ ) and the reaction stirred at RT under $\mathrm{N}_{2}$ overnight. The reaction was diluted with EtOAc, washed with $2 \mathrm{~N} \mathrm{HCl}$, $\mathrm{NaHCO}_{3}$ solution and brine, then dried over $\mathrm{MgSO}_{4}$ and the solvent was removed under reduced pressure. The crude was purified by chromatography on silica (0-75\% EtOAc in hexane) to give the desired ester as a yellow oil (54 mg, 95\%). ${ }^{1} \mathrm{H}$ NMR $(300 \mathrm{MHz}$, CHLOROFORM-d) $\delta 7.23$ - $7.35(\mathrm{~m}, 3 \mathrm{H}), 7.14-7.21(\mathrm{~m}, 2 \mathrm{H}), 7.07(\mathrm{t}, J=6.22 \mathrm{~Hz}, 1 \mathrm{H})$, $6.78-6.85(\mathrm{~m}, 1 \mathrm{H}), 6.66-6.74(\mathrm{~m}, 2 \mathrm{H}), 6.58(\mathrm{~s}, 1 \mathrm{H}), 6.36(\mathrm{~s}, 1 \mathrm{H}), 4.40-4.50(\mathrm{~m}, 1 \mathrm{H}), 3.86$ (s, 3H), $3.79(\mathrm{~s}, 3 \mathrm{H}), 3.70(\mathrm{~s}, 3 \mathrm{H}), 3.63-3.95(\mathrm{~m}, 2 \mathrm{H}), 3.11-3.47(\mathrm{~m}, 3 \mathrm{H}), 2.78-3.04(\mathrm{~m}$, $4 \mathrm{H}), 2.42-2.63(\mathrm{~m}, 3 \mathrm{H}), 1.73-1.89(\mathrm{~m}, 2 \mathrm{H}), 1.07(\mathrm{t}, J=7.39 \mathrm{~Hz}, 3 \mathrm{H}) . \mathrm{m} / z .547(\mathrm{M}+\mathrm{H})$. HRMS (ESI, $\mathrm{CH}_{3} \mathrm{OH}$ ) $\mathrm{m} / z$ calcd for $\mathrm{C}_{32} \mathrm{H}_{39} \mathrm{~N}_{2} \mathrm{O}_{6}[\mathrm{M}+\mathrm{H}]^{+} 547.2803, \mathrm{~m} / z$ found 547.2845.

\section{4-(\{2-[(Benzylcarbamoyl)methyl]-6,7-dimethoxy-1,2,3,4-tetrahydroisoquinolin-1-} yl\}methyl)-2-methoxyphenyl methanesulfonate (17): To a solution of phenol 12 (30 mg, $0.063 \mathrm{mmol})$ in DCM $(0.5 \mathrm{~mL})$ cooled in ice was added methanesulfonyl chloride (14 mg, $10 \mu \mathrm{L}, 0.126 \mathrm{mmol}$ ) and triethylamine $(16 \mathrm{mg}, 22 \mu \mathrm{L}, 0.157 \mathrm{mmol})$. The reaction was allowed to warm to RT overnight. The reaction mixture was applied directly to silica for chromatography (0-100\% EtOAc in hexane) to give the desired sulfonate as a yellow oil (21 $\mathrm{mg}, 60 \%) .{ }^{1} \mathrm{H}$ NMR (300 MHz, CHLOROFORM-d) $87.22-7.37$ (m, 3H), 7.17 (d, $J=6.88$ $\mathrm{Hz}, 2 \mathrm{H}), 7.09(\mathrm{~d}, J=8.29 \mathrm{~Hz}, 2 \mathrm{H}), 6.68-6.77(\mathrm{~m}, 2 \mathrm{H}), 6.60(\mathrm{~s}, 1 \mathrm{H}), 6.32(\mathrm{~s}, 1 \mathrm{H}), 4.44(\mathrm{dd}$, $J=7.25,14.88 \mathrm{~Hz}, 1 \mathrm{H}), 3.95(\mathrm{dd}, J=5.09,14.98 \mathrm{~Hz}, 1 \mathrm{H}), 3.87$ (s, 3H), 3.77 (s, 6H), 3.66 $3.74(\mathrm{~m}, 1 \mathrm{H}), 3.28$ - 3.42 (m, 2H), 3.22 (br. s., 1H), 3.14 (s, 3H), $2.81-3.06$ (m, 4H), 2.53 (d, $J=16.20 \mathrm{~Hz}, 1 \mathrm{H}) . \mathrm{m} / z 555(\mathrm{M}+\mathrm{H})$. HRMS $\left(\mathrm{ESI}, \mathrm{CH}_{3} \mathrm{OH}\right) \mathrm{m} / z$ calcd for $\mathrm{C}_{29} \mathrm{H}_{35} \mathrm{~N}_{2} \mathrm{O}_{7} \mathrm{~S}$ $[\mathrm{M}+\mathrm{H}]^{+}$555.2160, $\mathrm{m} / \mathrm{z}$ found 555.2212 .

\section{N-Benzyl-2-(1-\{[4-(benzyloxy)-3-methoxyphenyl]methyl\}-6,7-dimethoxy-1,2,3,4-} tetrahydroisoquinolin-2-yl)acetamide (18): This was prepared from phenol 12 by the general procedure in $15 \%$ yield. ${ }^{1} \mathrm{H}$ NMR (300 MHz, CHLOROFORM-d) $\delta 7.19-7.45$ (m, $8 \mathrm{H}), 7.12(\mathrm{~d}, J=6.78 \mathrm{~Hz}, 2 \mathrm{H}), 6.98-7.07(\mathrm{~m}, 1 \mathrm{H}), 6.61-6.74(\mathrm{~m}, 3 \mathrm{H}), 6.58(\mathrm{~s}, 1 \mathrm{H}), 6.41$ (s, 1H), $5.00(\mathrm{~s}, 2 \mathrm{H}), 4.45(\mathrm{dd}, J=8.01,14.98 \mathrm{~Hz}, 1 \mathrm{H}), 3.86(\mathrm{~s}, 3 \mathrm{H}), 3.81(\mathrm{~s}, 3 \mathrm{H}), 3.79(\mathrm{~s}$, $3 \mathrm{H}), 3.55$ - $3.76(\mathrm{~m}, 2 \mathrm{H}), 3.34-3.48(\mathrm{~m}, 1 \mathrm{H}), 3.10$ - $3.33(\mathrm{~m}, 2 \mathrm{H}), 2.77-2.99(\mathrm{~m}, 4 \mathrm{H}), 2.41$ - $2.55(\mathrm{~m}, 1 \mathrm{H}) . \mathrm{m} / z 567(\mathrm{M}+\mathrm{H})$. HRMS (ESI, $\left.\mathrm{CH}_{3} \mathrm{OH}\right) \mathrm{m} / z$ calcd for $\mathrm{C}_{35} \mathrm{H}_{39} \mathrm{~N}_{2} \mathrm{O}_{5}[\mathrm{M}+\mathrm{H}]^{+}$ $567.2854, \mathrm{~m} / \mathrm{z}$ found 567.2917 .

N-Benzyl-2-(6,7-dimethoxy-1-\{[3-methoxy-4-(4-phenoxybutoxy)phenyl]methyl\}-1,2,3,4tetrahydroisoquinolin-2-yl)acetamide (19): This was prepared from 12 using the general procedure in $71 \%$ yield. ${ }^{1} \mathrm{H}$ NMR (300 MHz, CHLOROFORM-d) $\delta 7.18-7.35(\mathrm{~m}, 5 \mathrm{H})$, $7.11(\mathrm{~d}, J=6.88 \mathrm{~Hz}, 2 \mathrm{H}), 7.02(\mathrm{dd}, J=5.04,7.39 \mathrm{~Hz}, 1 \mathrm{H}), 6.87-6.98(\mathrm{~m}, 3 \mathrm{H}), 6.65-6.73$ $(\mathrm{m}, 3 \mathrm{H}), 6.60(\mathrm{~s}, 1 \mathrm{H}), 6.45(\mathrm{~s}, 1 \mathrm{H}), 4.50(\mathrm{dd}, J=8.01,14.98 \mathrm{~Hz}, 1 \mathrm{H}), 4.04(\mathrm{t}, J=5.89 \mathrm{~Hz}$, 2H), 3.90 - 3.97 (m, 2H), 3.87 (s, 3H), 3.82 (s, 3H), 3.79 (s, 3H), 3.60 - $3.73(\mathrm{~m}, 2 \mathrm{H}), 3.36$ $3.51(\mathrm{~m}, 1 \mathrm{H}), 3.11-3.35(\mathrm{~m}, 2 \mathrm{H}), 2.80-3.01(\mathrm{~m}, 4 \mathrm{H}), 2.44-2.57(\mathrm{~m}, 1 \mathrm{H}), 1.91-2.04(\mathrm{~m}$, $4 \mathrm{H}$ ). $\mathrm{m} / z 625(\mathrm{M}+\mathrm{H})$. HRMS (ESI, $\left.\mathrm{CH}_{3} \mathrm{OH}\right) \mathrm{m} / z$ calcd for $\mathrm{C}_{38} \mathrm{H}_{45} \mathrm{~N}_{2} \mathrm{O}_{6}[\mathrm{M}+\mathrm{H}]^{+} 625.3272$, $\mathrm{m} / \mathrm{z}$ found 625.3335 . 
4-(\{2-[(Benzylcarbamoyl)methyl]-6,7-dimethoxy-1,2,3,4-tetrahydroisoquinolin-1yl\}methyl)-2-methoxyphenyl 4-methylbenzene-1-sulfonate (20): This was prepared from 12 as sulfonate 17 above. Yield $80 \% .{ }^{1} \mathrm{H}$ NMR $(300 \mathrm{MHz}, \mathrm{CHLOROFORM-d)} \delta 7.76$ (d, $J$ $=8.29 \mathrm{~Hz}, 2 \mathrm{H}), 7.21-7.36(\mathrm{~m}, 5 \mathrm{H}), 7.17(\mathrm{~d}, J=6.97 \mathrm{~Hz}, 2 \mathrm{H}), 7.05$ (br. s., $1 \mathrm{H}), 6.91$ (d, $J=$ $8.10 \mathrm{~Hz}, 1 \mathrm{H}), 6.54-6.67(\mathrm{~m}, 3 \mathrm{H}), 6.31(\mathrm{~s}, 1 \mathrm{H}), 4.44(\mathrm{dd}, J=7.30,14.74 \mathrm{~Hz}, 1 \mathrm{H}), 3.92(\mathrm{~d}, J$ $=4.90 \mathrm{~Hz}, 1 \mathrm{H}), 3.86(\mathrm{~s}, 3 \mathrm{H}), 3.76(\mathrm{~s}, 3 \mathrm{H}), 3.62-3.71(\mathrm{~m}, 1 \mathrm{H}), 3.49(\mathrm{~s}, 3 \mathrm{H}), 3.10-3.39(\mathrm{~m}$, $3 \mathrm{H}), 2.75-3.03(\mathrm{~m}, 4 \mathrm{H}), 2.49-2.57(\mathrm{~m}, 1 \mathrm{H}), 2.46(\mathrm{~s}, 3 \mathrm{H}) . \mathrm{m} / z 631(\mathrm{M}+\mathrm{H})$. HRMS (ESI, $\left.\mathrm{CH}_{3} \mathrm{OH}\right) \mathrm{m} / \mathrm{z}$ calcd for $\mathrm{C}_{35} \mathrm{H}_{39} \mathrm{~N}_{2} \mathrm{O}_{7} \mathrm{~S}[\mathrm{M}+\mathrm{H}]^{+} 631.2473, \mathrm{~m} / z$ found 631.2536 .

\section{N-Benzyl-2-(6,7-dimethoxy-1-\{[3-methoxy-4-(pyridin-2-}

ylmethoxy)phenyl]methyl\}-1,2,3,4-tetrahydroisoquinolin-2-yl)acetamide (21): This was prepared from 12 using the general procedure in $92 \%$ yield. ${ }^{1} \mathrm{H}$ NMR $(300 \mathrm{MHz}$, CHLOROFORM-d) $\delta 8.59(\mathrm{dd}, J=0.85,4.05 \mathrm{~Hz}, 1 \mathrm{H}), 7.61-7.71(\mathrm{~m}, 1 \mathrm{H}), 7.53(\mathrm{~d}, J=$ $7.82 \mathrm{~Hz}, 1 \mathrm{H}), 7.17-7.32(\mathrm{~m}, 4 \mathrm{H}), 7.10(\mathrm{~d}, J=6.59 \mathrm{~Hz}, 2 \mathrm{H}), 6.96-7.05(\mathrm{~m}, 1 \mathrm{H}), 6.69-6.75$ $(\mathrm{m}, 2 \mathrm{H}), 6.62-6.68(\mathrm{~m}, 1 \mathrm{H}), 6.59(\mathrm{~s}, 1 \mathrm{H}), 6.42(\mathrm{~s}, 1 \mathrm{H}), 5.15(\mathrm{~s}, 2 \mathrm{H}), 4.46(\mathrm{dd}, J=7.86$, $14.84 \mathrm{~Hz}, 1 \mathrm{H}), 3.86(\mathrm{~s}, 3 \mathrm{H}), 3.85(\mathrm{~s}, 3 \mathrm{H}), 3.80(\mathrm{~s}, 3 \mathrm{H}), 3.58$ - $3.74(\mathrm{~m}, 2 \mathrm{H}), 3.34$ - $3.48(\mathrm{~m}$, $1 \mathrm{H}), 3.11-3.33(\mathrm{~m}, 2 \mathrm{H}), 2.78-3.00(\mathrm{~m}, 4 \mathrm{H}), 2.50(\mathrm{~d}, J=15.82 \mathrm{~Hz}, 1 \mathrm{H}) . m / z .568(\mathrm{M}+\mathrm{H})$. HRMS (ESI, $\left.\mathrm{CH}_{3} \mathrm{OH}\right) \mathrm{m} / z$ calcd for $\mathrm{C}_{34} \mathrm{H}_{38} \mathrm{~N}_{3} \mathrm{O}_{5}[\mathrm{M}+\mathrm{H}]^{+}$568.2806, $\mathrm{m} / z$ found 568.2869.

\section{N-Benzyl-2-(6,7-dimethoxy-1-\{[3-methoxy-4-(pyridin-3-}

ylmethoxy)phenyl]methyl\}-1,2,3,4-tetrahydroisoquinolin-2-yl)acetamide (22): This was prepared from 12 using the general procedure in $42 \%$ yield. ${ }^{1} \mathrm{H}$ NMR $(300 \mathrm{MHz}$, CHLOROFORM-d) $\delta 8.65(\mathrm{~d}, J=1.60 \mathrm{~Hz}, 1 \mathrm{H}), 8.57$ (dd, $J=1.27,4.76 \mathrm{~Hz}, 1 \mathrm{H}), 7.76(\mathrm{~d}, J$ $=7.82 \mathrm{~Hz}, 1 \mathrm{H}), 7.18-7.34(\mathrm{~m}, 4 \mathrm{H}), 7.12(\mathrm{~d}, J=6.59 \mathrm{~Hz}, 2 \mathrm{H}), 7.04$ (br. s., $1 \mathrm{H}), 6.64-6.74$ $(\mathrm{m}, 3 \mathrm{H}), 6.60(\mathrm{~s}, 1 \mathrm{H}), 6.42(\mathrm{~s}, 1 \mathrm{H}), 4.95(\mathrm{~s}, 2 \mathrm{H}), 4.49(\mathrm{dd}, J=7.91,15.16 \mathrm{~Hz}, 1 \mathrm{H}), 3.87(\mathrm{~s}$, $3 \mathrm{H}), 3.81(\mathrm{~s}, 3 \mathrm{H}), 3.80(\mathrm{~s}, 3 \mathrm{H}), 3.62$ - $3.77(\mathrm{~m}, 2 \mathrm{H}), 3.13$ - $3.50(\mathrm{~m}, 3 \mathrm{H}), 2.80$ - $3.02(\mathrm{~m}, 4 \mathrm{H})$, $2.52(\mathrm{~d}, J=15.73 \mathrm{~Hz}, 1 \mathrm{H}) . \mathrm{m} / z 568(\mathrm{M}+\mathrm{H})$. HRMS (ESI, $\left.\mathrm{CH}_{3} \mathrm{OH}\right) \mathrm{m} / z$ calcd for $\mathrm{C}_{34} \mathrm{H}_{38} \mathrm{~N}_{3} \mathrm{O}_{5}[\mathrm{M}+\mathrm{H}]^{+}$568.2806, $m / z$ found 568.2869.

4-(\{2-[(Benzylcarbamoyl)methyl]-6,7-dimethoxy-1,2,3,4-tetrahydroisoquinolin-1yl\}methyl)-2-methoxyphenyl benzenesulfonate (23): This was prepared from 12 as sulfonate 17 above. Yield 69\%. ${ }^{1} \mathrm{H}$ NMR (300 MHz, CHLOROFORM-d) $\delta 7.85-7.92$ (m, 2H), $7.62-7.71(\mathrm{~m}, 1 \mathrm{H}), 7.48-7.57(\mathrm{~m}, 2 \mathrm{H}), 7.21-7.36(\mathrm{~m}, 3 \mathrm{H}), 7.17(\mathrm{~d}, J=6.78 \mathrm{~Hz}, 2 \mathrm{H})$, $7.04(\mathrm{t}, J=5.93 \mathrm{~Hz}, 1 \mathrm{H}), 6.93(\mathrm{~d}, J=8.10 \mathrm{~Hz}, 1 \mathrm{H}), 6.64(\mathrm{~d}, J=8.19 \mathrm{~Hz}, 1 \mathrm{H}), 6.55-6.60$ (m, 2H), $6.31(\mathrm{~s}, 1 \mathrm{H}), 4.44(\mathrm{dd}, J=7.39,14.74 \mathrm{~Hz}, 1 \mathrm{H}), 3.86(\mathrm{~s}, 3 \mathrm{H}), 3.84-3.96(\mathrm{~m}, 1 \mathrm{H})$, $3.76(\mathrm{~s}, 3 \mathrm{H}), 3.63-3.72(\mathrm{~m}, 1 \mathrm{H}), 3.45(\mathrm{~s}, 3 \mathrm{H}), 3.11-3.38(\mathrm{~m}, 3 \mathrm{H}), 2.76-3.03(\mathrm{~m}, 4 \mathrm{H}), 2.41$ - $2.55(\mathrm{~m}, 1 \mathrm{H}) . \mathrm{m} / \mathrm{z} 617(\mathrm{M}+\mathrm{H})$. HRMS (ESI, $\left.\mathrm{CH}_{3} \mathrm{OH}\right) \mathrm{m} / z$ calcd for $\mathrm{C}_{34} \mathrm{H}_{37} \mathrm{~N}_{2} \mathrm{O}_{7} \mathrm{~S}[\mathrm{M}+\mathrm{H}]^{+}$ $617.2316, \mathrm{~m} / \mathrm{z}$ found 617.2377 .

\section{N-Benzyl-2-\{6,7-dimethoxy-1-[(4-methoxy-3-nitrophenyl)methyl]-1,2,3,4-}

tetrahydroisoquinolin-2-yl\}acetamide (26): Phenol 36 (40 mg, $0.08 \mathrm{mmol})$ and potassium carbonate $(17 \mathrm{mg}, 0.12 \mathrm{mmol})$ were combined in DMF $(2 \mathrm{~mL})$ and iodomethane $(14 \mathrm{mg}, 6$ $\mu \mathrm{L}, 0.097 \mathrm{mmol}$ ) was added. The reaction was heated to $50{ }^{\circ} \mathrm{C}$ for $2 \mathrm{hr}$. The reaction was diluted with EtOAc, washed with $\mathrm{NaHCO}_{3}$ solution and brine, dried over $\mathrm{MgSO}_{4}$ and the solvent was removed under reduced pressure. The crude was purified by chromatography on 
silica (0-100\% EtOAc in hexane) to give the desired product (30 mg, 75\%). ${ }^{1} \mathrm{H}$ NMR (300 MHz, CHLOROFORM-d) $\delta 7.99$ (s, 1H), 7.68 (d, $J=2.26 \mathrm{~Hz}, 1 \mathrm{H}), 7.28-7.39$ (m, 4H), $7.02-7.14(\mathrm{~m}, 1 \mathrm{H}), 6.75(\mathrm{~d}, J=8.29 \mathrm{~Hz}, 1 \mathrm{H}), 6.60(\mathrm{~s}, 1 \mathrm{H}), 6.44(\mathrm{~s}, 1 \mathrm{H}), 4.37$ - $4.54(\mathrm{~m}$, $1 \mathrm{H}), 3.90-3.96(\mathrm{~m}, 1 \mathrm{H}), 3.85-3.88(\mathrm{~m}, 3 \mathrm{H}), 3.82(\mathrm{~s}, 3 \mathrm{H}), 3.76(\mathrm{~s}, 3 \mathrm{H}), 3.65(\mathrm{dd}, J=5.46$, $9.23 \mathrm{~Hz}, 1 \mathrm{H}), 3.38$ - $3.47(\mathrm{~m}, 2 \mathrm{H}), 3.11-3.22(\mathrm{~m}, 1 \mathrm{H}), 2.90$ - $3.00(\mathrm{~m}, 4 \mathrm{H}), 2.46$ - $2.58(\mathrm{~m}$, $1 \mathrm{H}) . \mathrm{m} / \mathrm{z} 506(\mathrm{M}+\mathrm{H})$. HRMS (ESI, $\left.\mathrm{CH}_{3} \mathrm{OH}\right) \mathrm{m} / \mathrm{z}$ calcd for $\mathrm{C}_{28} \mathrm{H}_{32} \mathrm{~N}_{3} \mathrm{O}_{6}[\mathrm{M}+\mathrm{H}]^{+}$506.2286, $\mathrm{m} / \mathrm{z}$ found 506.2327 .

\section{2-\{1-[(3-Amino-4-methoxyphenyl)methyl]-6,7-dimethoxy-1,2,3,4-}

tetrahydroisoquinolin-2-yl\}-N-benzylacetamide (27): To the nitro derivative $\mathbf{2 6}$ (200 $\mathrm{mg}$, $0.4 \mathrm{mmol})$ in ethanol $(20 \mathrm{~mL})$ was added hydrazine monohydrate $(198 \mathrm{mg}, 0.19 \mathrm{~mL}, 4.0$ $\mathrm{mmol}$ ) and then heated to $50{ }^{\circ} \mathrm{C}$ for $15 \mathrm{~min}$. Raney nickel (2800 type as a slurry in water, $232 \mathrm{mg}, 4.0 \mathrm{mmol}$ ) was added and heating continued for $1 \mathrm{hr}$. The reaction was filtered through Celite, rinsed with ethanol then the solvent was removed under reduced pressure to give the desired amine as a clear oil (100 mg, 53\%). ${ }^{1} \mathrm{H}$ NMR $(300 \mathrm{MHz}, \mathrm{CHLOROFORM-}$ d) $\delta 7.68(\mathrm{~s}, 2 \mathrm{H}), 7.20-7.35(\mathrm{~m}, 5 \mathrm{H}), 7.09(\mathrm{~d}, J=6.78 \mathrm{~Hz}, 2 \mathrm{H}), 6.85$ (br. s., $1 \mathrm{H}), 6.75$ (d, $J$ $=8.48 \mathrm{~Hz}, 1 \mathrm{H}), 6.59(\mathrm{~s}, 1 \mathrm{H}), 6.43(\mathrm{~s}, 1 \mathrm{H}), 4.47(\mathrm{dd}, J=7.44,15.16 \mathrm{~Hz}, 1 \mathrm{H}), 3.87(\mathrm{~s}, 3 \mathrm{H})$, 3.85 - $3.98(\mathrm{~m}, 1 \mathrm{H}), 3.82(\mathrm{~s}, 3 \mathrm{H}), 3.77$ (s, 3H), 3.60 - $3.71(\mathrm{~m}, 1 \mathrm{H}), 3.11-3.48(\mathrm{~m}, 3 \mathrm{H}), 2.83$ - $3.05(\mathrm{~m}, 4 \mathrm{H}), 2.51(\mathrm{~d}, J=16.77 \mathrm{~Hz}, 1 \mathrm{H}) . \mathrm{m} / \mathrm{z}, 476(\mathrm{M}+\mathrm{H})$.

N-Benzyl-2-(1-\{[3-(dimethylamino)-4-methoxyphenyl]methyl\}-6,7-dimethoxy-1,2,3,4tetrahydroisoquinolin-2-yl)acetamide (28): To a solution of amine $27(50 \mathrm{mg}, 0.10 \mathrm{mmol})$ in methanol $(1 \mathrm{~mL})$ was added formaldehyde $(37 \%$ solution in water, $1 \mathrm{~mL})$ and glacial acetic acid ( $21 \mathrm{mg}, 20 \mu \mathrm{L}, 0.35 \mathrm{mmol})$. To this was then added sodium cyanoborohydride (31 mg, $0.5 \mathrm{mmol})$ and the reaction stirred at RT for $2 \mathrm{hr}$. $1 \mathrm{~N} \mathrm{HCl}(0.1 \mathrm{~mL})$ was added then the reaction was diluted with EtOAc, washed with $\mathrm{NaHCO}_{3}$ solution and brine, dried over $\mathrm{MgSO}_{4}$ and the solvent was removed under reduced pressure. The crude was purified by chromatography on silica (0-50\% EtOAc in hexane) to give the desired dimethylamine (26 $\mathrm{mg}, 52 \%) .{ }^{1} \mathrm{H}$ NMR (300 MHz, CHLOROFORM-d) $\delta 7.18$ - 7.34 (m, 3H), 7.01 - 7.14 (m, $3 \mathrm{H}), 6.70-6.78(\mathrm{~m}, 2 \mathrm{H}), 6.55-6.65(\mathrm{~m}, 2 \mathrm{H}), 6.41(\mathrm{~s}, 1 \mathrm{H}), 4.48(\mathrm{dd}, J=7.82,14.98 \mathrm{~Hz}$, $1 \mathrm{H}), 3.86(\mathrm{~s}, 3 \mathrm{H}), 3.80(\mathrm{~s}, 3 \mathrm{H}), 3.75(\mathrm{~s}, 3 \mathrm{H}), 3.59-3.72(\mathrm{~m}, 2 \mathrm{H}), 3.37-3.51(\mathrm{~m}, 1 \mathrm{H}), 3.13-$ $3.35(\mathrm{~m}, 2 \mathrm{H}), 2.79-3.00(\mathrm{~m}, 4 \mathrm{H}), 2.75(\mathrm{~s}, 6 \mathrm{H}), 2.44-2.56(\mathrm{~m}, 1 \mathrm{H}) . \mathrm{m} / z 504(\mathrm{M}+\mathrm{H})$. HRMS (ESI, $\mathrm{CH}_{3} \mathrm{OH}$ ) $\mathrm{m} / z$ calcd for $\mathrm{C}_{30} \mathrm{H}_{38} \mathrm{~N}_{3} \mathrm{O}_{4}[\mathrm{M}+\mathrm{H}]^{+} 504.2857, \mathrm{~m} / z$ found 504.2906.

\section{N-Benzyl-2-(1-\{[3-(ethylamino)-4-methoxyphenyl]methyl\}-6,7-dimethoxy-1,2,3,4-} tetrahydroisoquinolin-2-yl)acetamide (29): To amine 27 (30 mg, $0.06 \mathrm{mmol}$ ) in DMF (3 $\mathrm{mL}$ ) was added 1-iodoethane ( $20 \mathrm{mg}, 10 \mu \mathrm{L}, 0.13 \mathrm{mmol}$ ) then diisopropylethylamine (20 $\mathrm{mg}, 26 \mu \mathrm{L}, 0.16 \mathrm{mmol}$ ) and the reaction stirred at RT under $\mathrm{N}_{2}$ overnight. The reaction was diluted with EtOAc, washed with $\mathrm{NaHCO}_{3}$ solution and brine, dried over $\mathrm{MgSO}_{4}$ and the solvent was removed under reduced pressure. The crude was purified by chromatography on silica (0-15\% methanol in DCM) to give the desired amine as a white solid (15 $\mathrm{mg}, 47 \%)$ : mp 122-125 ${ }^{\circ} \mathrm{C} .{ }^{1} \mathrm{H}$ NMR (300 MHz, CHLOROFORM-d) $\delta 7.17$ - $7.32(\mathrm{~m}, 3 \mathrm{H}), 7.01$ - 7.11 (m, 3H), $6.41-6.61(\mathrm{~m}, 5 \mathrm{H}), 4.50(\mathrm{dd}, J=8.29,14.88 \mathrm{~Hz}, 1 \mathrm{H}), 3.86(\mathrm{~s}, 3 \mathrm{H}), 3.84(\mathrm{~s}, 3 \mathrm{H})$, $3.71(\mathrm{~s}, 3 \mathrm{H}), 3.39$ - $3.66(\mathrm{~m}, 3 \mathrm{H}), 3.02$ - $3.32(\mathrm{~m}, 4 \mathrm{H}), 2.78$ - $2.99(\mathrm{~m}, 4 \mathrm{H}), 2.42$ - $2.54(\mathrm{~m}$, 
$1 \mathrm{H}), 1.26(\mathrm{t}, J=7.16 \mathrm{~Hz}, 3 \mathrm{H}) . \mathrm{m} / z 504(\mathrm{M}+\mathrm{H})$. HRMS (ESI, $\left.\mathrm{CH}_{3} \mathrm{OH}\right) \mathrm{m} / z$ calcd for $\mathrm{C}_{30} \mathrm{H}_{38} \mathrm{~N}_{3} \mathrm{O}_{4}[\mathrm{M}+\mathrm{H}]^{+}$504.2857, $\mathrm{m} / z$ found 504.2914.

N-Benzyl-2-(1-\{[3-(diethylamino)-4-methoxyphenyl]methyl\}-6,7-dimethoxy-1,2,3,4tetrahydroisoquinolin-2-yl)acetamide (30): This was prepared as per 29 using 1iodoethane (3 eq). Yield 76\%. ${ }^{1} \mathrm{H}$ NMR (300 MHz, CHLOROFORM-d) $\delta 7.16-7.37$ (m, $3 \mathrm{H}), 7.08(\mathrm{~d}, J=7.54 \mathrm{~Hz}, 2 \mathrm{H}), 6.27-6.75(\mathrm{~m}, 5 \mathrm{H}), 4.50(\mathrm{dd}, J=8.38,14.98 \mathrm{~Hz}, 1 \mathrm{H}), 3.85$ $(\mathrm{d}, J=6.03 \mathrm{~Hz}, 6 \mathrm{H}), 3.71(\mathrm{~s}, 3 \mathrm{H}), 3.56-3.66(\mathrm{~m}, 2 \mathrm{H}), 3.38-3.56(\mathrm{~m}, 2 \mathrm{H}), 3.21-3.35(\mathrm{~m}$, 1H), $3.02-3.19(\mathrm{~m}, 3 \mathrm{H}), 2.77-3.00(\mathrm{~m}, 7 \mathrm{H}), 0.91-1.34(\mathrm{~m}, 6 \mathrm{H}) . \mathrm{m} / z 532(\mathrm{M}+\mathrm{H})$. HRMS (ESI, $\mathrm{CH}_{3} \mathrm{OH}$ ) $\mathrm{m} / \mathrm{z}$ calcd for $\mathrm{C}_{32} \mathrm{H}_{42} \mathrm{~N}_{3} \mathrm{O}_{4}[\mathrm{M}+\mathrm{H}]^{+} 532.3170, \mathrm{~m} / z$ found 532.3223 .

N-Benzyl-2-(6,7-dimethoxy-1-\{[4-methoxy-3-(propylamino)phenyl]methyl\}-1,2,3,4tetrahydroisoquinolin-2-yl)acetamide (31): This was prepared as per 29 using 1iodopropane (1 eq). Yield 15\%. ${ }^{1} \mathrm{H}$ NMR (300 MHz, CHLOROFORM-d) $\delta 7.16$ - 7.34 (m, $3 \mathrm{H}), 6.99$ - $7.12(\mathrm{~m}, 3 \mathrm{H}), 6.40-6.64(\mathrm{~m}, 5 \mathrm{H}), 4.51(\mathrm{dd}, J=8.29,15.07 \mathrm{~Hz}, 1 \mathrm{H}), 3.86(\mathrm{~s}$, $3 \mathrm{H}), 3.85(\mathrm{~s}, 3 \mathrm{H}), 3.70(\mathrm{~s}, 3 \mathrm{H}), 3.38$ - $3.67(\mathrm{~m}, 4 \mathrm{H}), 3.09$ - $3.32(\mathrm{~m}, 2 \mathrm{H}), 2.98-3.08(\mathrm{~m}, 1 \mathrm{H})$, $2.77-2.93(\mathrm{~m}, 4 \mathrm{H}), 2.42-2.57(\mathrm{~m}, 1 \mathrm{H}), 1.60-1.72(\mathrm{~m}, 2 \mathrm{H}), 1.01(\mathrm{t}, J=7.44 \mathrm{~Hz}, 3 \mathrm{H}) . \mathrm{m} / z$ $518(\mathrm{M}+\mathrm{H})$. HRMS (ESI, $\left.\mathrm{CH}_{3} \mathrm{OH}\right) \mathrm{m} / z$ calcd for $\mathrm{C}_{31} \mathrm{H}_{40} \mathrm{~N}_{3} \mathrm{O}_{4}[\mathrm{M}+\mathrm{H}]^{+} 518.3013, \mathrm{~m} / z$ found 518.3055 .

N-Benzyl-2-(1-\{[3-(dipropylamino)-4-methoxyphenyl]methyl\}-6,7-dimethoxy-1,2,3,4tetrahydroisoquinolin-2-yl)acetamide (32): This was prepared as per 29 using 1iodopropane. Yield 51\%. ${ }^{1} \mathrm{H}$ NMR (300 MHz, CHLOROFORM-d) $\delta 7.17$ - 7.40 (m, 2H), 6.91 - $7.15(\mathrm{~m}, 3 \mathrm{H}), 6.67$ - $6.78(\mathrm{~m}, 1 \mathrm{H}), 6.34$ - $6.65(\mathrm{~m}, 4 \mathrm{H}), 4.37$ - $4.58(\mathrm{~m}, 1 \mathrm{H}), 3.74$ $3.93(\mathrm{~m}, 6 \mathrm{H}), 3.70(\mathrm{~s}, 3 \mathrm{H}), 3.56-3.66(\mathrm{~m}, 1 \mathrm{H}), 3.36-3.55(\mathrm{~m}, 1 \mathrm{H}), 3.09-3.35(\mathrm{~m}, 2 \mathrm{H})$, $2.76-3.08(\mathrm{~m}, 9 \mathrm{H}), 2.50(\mathrm{dd}, J=4.05,15.92 \mathrm{~Hz}, 1 \mathrm{H}), 1.29-1.71(\mathrm{~m}, 4 \mathrm{H}), 0.67-1.15(\mathrm{~m}$, $6 \mathrm{H}) . \mathrm{m} / z 560(\mathrm{M}+\mathrm{H})$. HRMS (ESI, $\left.\mathrm{CH}_{3} \mathrm{OH}\right) \mathrm{m} / z$ calcd for $\mathrm{C}_{34} \mathrm{H}_{46} \mathrm{~N}_{3} \mathrm{O}_{4}[\mathrm{M}+\mathrm{H}]^{+} 560.3483$, $\mathrm{m} / \mathrm{z}$ found 560.3551 .

N-Benzyl-2-(1-\{[3-(benzylamino)-4-methoxyphenyl]methyl\}-6,7-dimethoxy-1,2,3,4tetrahydroisoquinolin-2-yl)acetamide (33): This was prepared as per 29 using benzyl bromide. Yield 82\%. ${ }^{1} \mathrm{H}$ NMR (300 MHz, CHLOROFORM-d) $\delta 7.06-7.34$ (m, 10H), 6.93 $(\mathrm{dd}, J=4.90,7.91 \mathrm{~Hz}, 1 \mathrm{H}), 6.53-6.64(\mathrm{~m}, 3 \mathrm{H}), 6.44-6.52(\mathrm{~m}, 2 \mathrm{H}), 6.41(\mathrm{~d}, J=1.70 \mathrm{~Hz}$, $1 \mathrm{H}), 4.51$ (dd, $J=8.29,15.07 \mathrm{~Hz}, 1 \mathrm{H}), 3.85$ (s, 3H), $3.83(\mathrm{~s}, 3 \mathrm{H}), 3.76$ (d, $J=0.75 \mathrm{~Hz}, 2 \mathrm{H}$ ), $3.73(\mathrm{~s}, 3 \mathrm{H}), 3.47$ - $3.62(\mathrm{~m}, 2 \mathrm{H}), 3.25$ - $3.40(\mathrm{~m}, 1 \mathrm{H}), 3.01-3.24(\mathrm{~m}, 2 \mathrm{H}), 2.58$ - $2.96(\mathrm{~m}$, $4 \mathrm{H}), 2.42(\mathrm{dd}, J=4.62,16.86 \mathrm{~Hz}, 1 \mathrm{H}) . \mathrm{m} / \mathrm{z} 566(\mathrm{M}+\mathrm{H})$. HRMS (ESI, $\left.\mathrm{CH}_{3} \mathrm{OH}\right) \mathrm{m} / z$ calcd for $\mathrm{C}_{35} \mathrm{H}_{40} \mathrm{~N}_{3} \mathrm{O}_{4}[\mathrm{M}+\mathrm{H}]^{+}$566.3013, $\mathrm{m} / z$ found 566.3068 .

N-Benzyl-2-\{1-[(3-acetamido-4-methoxyphenyl)methyl]-6,7-dimethoxy-1,2,3,4tetrahydroisoquinolin-2-yl \}acetamide (34): To a solution of amine $27(50 \mathrm{mg}, 0.10 \mathrm{mmol})$ and diisopropylethlamine (32 mg, $41 \mu \mathrm{L}, 0.25 \mathrm{mmol}$ ) in DCM (3 mL) under $\mathrm{N}_{2}$ cooled in an ice bath was added acetyl bromide ( $12 \mathrm{mg}, 8 \mu \mathrm{L}, 0.10 \mathrm{mmol})$. The reaction was stirred in ice for $10 \mathrm{~min}$, then at RT for $3 \mathrm{hr}$. The reaction was diluted with $\mathrm{NaHCO}_{3}$ solution and extracted 3 times with EtOAc. The combined extracts were washed with brine, dried over $\mathrm{MgSO}_{4}$ and the solvents were removed under reduced pressure. The crude was purified by 
chromatography on silica (0-75\% EtOAc in hexane) to give the desired amide as a yellow oil (32 mg, 62\%). ${ }^{1} \mathrm{H}$ NMR (300 MHz, CHLOROFORM-d) $\delta 8.34(\mathrm{~d}, J=1.51 \mathrm{~Hz}, 1 \mathrm{H})$, $7.52(\mathrm{~s}, 1 \mathrm{H}), 7.17-7.31(\mathrm{~m}, 3 \mathrm{H}), 6.97-7.05(\mathrm{~m}, 3 \mathrm{H}), 6.87(\mathrm{dd}, J=1.70,8.29 \mathrm{~Hz}, 1 \mathrm{H}), 6.66$ $(\mathrm{d}, J=8.29 \mathrm{~Hz}, 1 \mathrm{H}), 6.57(\mathrm{~d}, J=5.65 \mathrm{~Hz}, 2 \mathrm{H}), 4.42(\mathrm{dd}, J=8.01,15.35 \mathrm{~Hz}, 1 \mathrm{H}), 3.87(\mathrm{~s}$, $6 \mathrm{H}), 3.73(\mathrm{~s}, 3 \mathrm{H}), 3.44$ - $3.71(\mathrm{~m}, 3 \mathrm{H}), 3.05-3.34(\mathrm{~m}, 2 \mathrm{H}), 2.84-3.00(\mathrm{~m}, 4 \mathrm{H}), 2.44-2.56$ $(\mathrm{m}, 1 \mathrm{H}), 2.13(\mathrm{~s}, 3 \mathrm{H}) . \mathrm{m} / z 518(\mathrm{M}+\mathrm{H})$. HRMS (ESI, $\left.\mathrm{CH}_{3} \mathrm{OH}\right) \mathrm{m} / z$ calcd for $\mathrm{C}_{30} \mathrm{H}_{36} \mathrm{~N}_{3} \mathrm{O}_{5}[\mathrm{M}$ $+\mathrm{H}]^{+} 518.2650, \mathrm{~m} / \mathrm{z}$ found 518.271 .

N-[5-(\{2-[(Benzylcarbamoyl)methyl]-6,7-dimethoxy-1,2,3,4-tetrahydroisoquinolin-1yl\}methyl)-2-methoxyphenyl]butanamide (35): To amine $27(50 \mathrm{mg}, 0.1 \mathrm{mmol})$ and BOP (44 mg, $0.1 \mathrm{mmol})$ in DMF ( $3 \mathrm{~mL}$ ) was added butyric acid $(9 \mathrm{mg}, 9 \mu \mathrm{L}, 0.1 \mathrm{mmol})$ then diisopropylethylamine ( $32 \mathrm{mg}, 41 \mu \mathrm{L}, 0.25 \mathrm{mmol}$ ) and the reaction stirred at RT under $\mathrm{N}_{2}$ overnight. The reaction was diluted with EtOAc, washed with $1 \mathrm{~N} \mathrm{HCl}, 1 \mathrm{~N} \mathrm{NaOH}$ solution and brine, dried over $\mathrm{MgSO}_{4}$ and the solvent was removed under reduced pressure. The crude was purified by chromatography on silica (0-15\% methanol in DCM) to give the desired amide as a yellow oil (22 mg, 40\%). ${ }^{1} \mathrm{H}$ NMR (300 MHz, CHLOROFORM-d) $\delta$ $8.40(\mathrm{~d}, J=1.88 \mathrm{~Hz}, 1 \mathrm{H}), 7.58(\mathrm{~s}, 1 \mathrm{H}), 7.17-7.33(\mathrm{~m}, 3 \mathrm{H}), 7.01(\mathrm{~d}, J=6.40 \mathrm{~Hz}, 3 \mathrm{H}), 6.86$ $(\mathrm{dd}, J=2.07,8.29 \mathrm{~Hz}, 1 \mathrm{H}), 6.64(\mathrm{~d}, J=8.29 \mathrm{~Hz}, 1 \mathrm{H}), 6.55-6.60(\mathrm{~m}, 2 \mathrm{H}), 4.43(\mathrm{dd}, J=$ 8.10, $15.26 \mathrm{~Hz}, 1 \mathrm{H}), 3.86(\mathrm{~s}, 6 \mathrm{H}), 3.72(\mathrm{~s}, 4 \mathrm{H}), 3.41-3.69(\mathrm{~m}, 2 \mathrm{H}), 3.05-3.34(\mathrm{~m}, 2 \mathrm{H})$, $2.77-3.02(\mathrm{~m}, 4 \mathrm{H}), 2.42-2.55(\mathrm{~m}, 1 \mathrm{H}), 2.32(\mathrm{t}, J=7.44 \mathrm{~Hz}, 2 \mathrm{H}), 1.74(\mathrm{qd}, J=7.43,14.81$ $\mathrm{Hz}, 2 \mathrm{H}), 1.01(\mathrm{t}, J=7.35 \mathrm{~Hz}, 3 \mathrm{H}) . \mathrm{m} / \mathrm{z} 546(\mathrm{M}+\mathrm{H})$. HRMS (ESI, $\left.\mathrm{CH}_{3} \mathrm{OH}\right) \mathrm{m} / \mathrm{z}$ calcd for $\mathrm{C}_{32} \mathrm{H}_{40} \mathrm{~N}_{3} \mathrm{O}_{5}[\mathrm{M}+\mathrm{H}]^{+}$546.2963, $\mathrm{m} / z$ found 546.3021 .

\section{N-Benzyl-2-\{1-[(4-hydroxy-3-nitrophenyl)methyl]-6,7-dimethoxy-1,2,3,4-}

tetrahydroisoquinolin-2-yl lacetamide (36): This was made by the general procedure starting from 4-hydroxy-3-nitrophenylacetic acid in 4 steps in $15 \%$ overall yield. ${ }^{1} \mathrm{H}$ NMR (300 MHz, CHLOROFORM-d) $\delta 7.85$ (s, 1H), $7.21-7.40$ (m, 4H), 7.05 (d, $J=7.06 \mathrm{~Hz}$, $1 \mathrm{H}), 6.93(\mathrm{~d}, J=8.57 \mathrm{~Hz}, 1 \mathrm{H}), 6.85$ (br. s., $1 \mathrm{H}), 6.60(\mathrm{~s}, 1 \mathrm{H}), 6.44(\mathrm{~s}, 1 \mathrm{H}), 4.37$ (dd, $J=$ 7.06, $15.07 \mathrm{~Hz}, 1 \mathrm{H}), 3.97(\mathrm{dd}, J=5.18,14.98 \mathrm{~Hz}, 1 \mathrm{H}), 3.85(\mathrm{~d}, J=11.68 \mathrm{~Hz}, 6 \mathrm{H}), 3.57$ $3.71(\mathrm{~m}, 1 \mathrm{H}), 3.26-3.49(\mathrm{~m}, 3 \mathrm{H}), 3.10-3.24(\mathrm{~m}, 1 \mathrm{H}), 2.80-3.03(\mathrm{~m}, 4 \mathrm{H}), 2.52(\mathrm{~d}, J=$ $16.39 \mathrm{~Hz}, 1 \mathrm{H}$ ). $\mathrm{m} / \mathrm{z} 492\left(\mathrm{M}+\mathrm{H}\right.$ ). HRMS (ESI, $\left.\mathrm{CH}_{3} \mathrm{OH}\right) \mathrm{m} / \mathrm{z}$ calcd for $\mathrm{C}_{27} \mathrm{H}_{30} \mathrm{~N}_{3} \mathrm{O}_{6}[\mathrm{M}+\mathrm{H}]^{+}$ $492.2129, \mathrm{~m} / \mathrm{z}$ found 492.2182 .

\section{2-\{1-[(3-Amino-4-hydroxyphenyl)methyl]-6,7-dimethoxy-1,2,3,4-}

tetrahydroisoquinolin-2-yl\}-N-benzylacetamide (37): To the nitro derivative $\mathbf{3 6}$ (100 mg, $0.2 \mathrm{mmol})$ in ethanol $(10 \mathrm{~mL})$ was added hydrazine monohydrate $(100 \mathrm{mg}, 0.1 \mathrm{~mL}, 2 \mathrm{mmol})$ and the reaction warmed to $50{ }^{\circ} \mathrm{C}$. Raney nickel (2800 type as a slurry in water, $20 \mathrm{mg}$ ) was added and the reaction stirred at $50{ }^{\circ} \mathrm{C}$ for $1 \mathrm{hr}$. The reaction was cooled, filtered through Celite and washed with ethanol. The solvent was removed under reduced pressure and the crude purified by chromatography on silica (0-10\% methanol in DCM) to give the aminophenol (56 mg, 57\%). ${ }^{1} \mathrm{H}$ NMR (300 MHz, CHLOROFORM-d) $\delta 7.20-7.36$ (m, 3H), 7.11 - $7.18(\mathrm{~m}, 2 \mathrm{H}), 7.04-7.11(\mathrm{~m}, 1 \mathrm{H}), 6.55-6.60(\mathrm{~m}, 2 \mathrm{H}), 6.49-6.54(\mathrm{~m}, 1 \mathrm{H}), 6.42$ 6.49 (m, 2H), 5.49 (br. s., $1 \mathrm{H}), 4.48$ (dd, $J=8.01,14.98 \mathrm{~Hz}, 1 \mathrm{H}), 3.86$ (s, 3H), 3.83 (s, 3H), $3.72(\mathrm{dd}, J=4.80,14.98 \mathrm{~Hz}, 1 \mathrm{H}), 3.35-3.63(\mathrm{~m}, 4 \mathrm{H}), 3.07-3.33(\mathrm{~m}, 2 \mathrm{H}), 2.73-2.98(\mathrm{~m}$, 
$4 \mathrm{H}), 2.41-2.53(\mathrm{~m}, 1 \mathrm{H}) . \mathrm{m} / \mathrm{z} 462(\mathrm{M}+\mathrm{H})$. HRMS (ESI, $\left.\mathrm{CH}_{3} \mathrm{OH}\right) \mathrm{m} / z$ calcd for $\mathrm{C}_{27} \mathrm{H}_{32} \mathrm{~N}_{3} \mathrm{O}_{4}$ $[\mathrm{M}+\mathrm{H}]^{+} 462.2387, \mathrm{~m} / \mathrm{z}$ found 462.2384 .

N-Benzyl-2-\{6,7-dimethoxy-1-[(2-methyl-1,3-benzoxazol-5-yl)methyl]-1,2,3,4tetrahydroisoquinolin-2-yl\}acetamide (38): To aminophenol $37(56 \mathrm{mg}, 0.12 \mathrm{mmol})$ in chloroform $(10 \mathrm{~mL})$ was added ethyl acetimidate hydrochloride $(17 \mathrm{mg}, 0.13 \mathrm{mmol})$. The reaction was heated to reflux for $16 \mathrm{hr}$. The solvent was removed under reduced pressure and the crude purified by chromatography on silica (0-10\% $\mathrm{MeOH}$ in DCM) to give the desired benzoxazole (29 mg, 50\%). ${ }^{1} \mathrm{H}$ NMR (300 MHz, CHLOROFORM-d) $\delta 7.49$ (s, 1H), 7.19 - 7.29 (m, 4H), 7.11 (d, $J=8.29 \mathrm{~Hz}, 1 \mathrm{H}), 6.82-6.90$ (m, 2H), 6.71 (br. s., 1H), 6.60 (s, $1 \mathrm{H}), 6.49$ (s, 1H), $4.34(\mathrm{dd}, J=7.91,15.26 \mathrm{~Hz}, 1 \mathrm{H}), 3.87$ (s, 3H), $3.82(\mathrm{~s}, 3 \mathrm{H}), 3.62$ - 3.72 (m, 1H), 3.41 - $3.57(\mathrm{~m}, 2 \mathrm{H}), 3.09$ - $3.34(\mathrm{~m}, 2 \mathrm{H}), 2.83$ - $3.08(\mathrm{~m}, 4 \mathrm{H}), 2.57(\mathrm{~s}, 3 \mathrm{H}), 2.44$ $2.60(\mathrm{~m}, 1 \mathrm{H}) . \mathrm{m} / \mathrm{z} 486(\mathrm{M}+\mathrm{H})$. HRMS (ESI, $\left.\mathrm{CH}_{3} \mathrm{OH}\right) \mathrm{m} / \mathrm{z}$ calcd for $\mathrm{C}_{29} \mathrm{H}_{32} \mathrm{~N}_{3} \mathrm{O}_{4}[\mathrm{M}+\mathrm{H}]^{+}$ $486.2387, \mathrm{~m} / \mathrm{z}$ found 486.2435 .

\section{N-Benzyl-2-(6,7-dimethoxy-1-\{[3-(propan-2-yloxy)phenyl]methyl\}-1,2,3,4-} tetrahydroisoquinolin-2-yl)acetamide (41): This was made by the general procedure starting from 3-hydroxyphenylacetic acid to the phenol precursor in 4 steps in $6 \%$ overall yield. For the final step, the phenol (30 mg, $0.067 \mathrm{mmol})$, potassium carbonate $(23 \mathrm{mg}$, $0.168 \mathrm{mmol}$ ) and tetrabutylammonium iodide $(5 \mathrm{mg}, 0.013 \mathrm{mmol}$ ) were combined in DMF $(0.5 \mathrm{~mL})$ and 2-bromopropane $(12 \mathrm{mg}, 9 \mu \mathrm{L}, 0.101 \mathrm{mmol})$ was added and the reaction heated at $50{ }^{\circ} \mathrm{C}$ overnight. An additional $20 \mu \mathrm{L}$ of 2-bromopropane was added and the reaction was heated at $50{ }^{\circ} \mathrm{C}$ for a further $24 \mathrm{hr}$. It was cooled, diluted with EtOAc, washed with $\mathrm{NaHCO}_{3}$ solution, water and brine, dried over $\mathrm{MgSO}_{4}$ and the solvent was removed under reduced pressure. The crude was purified by chromatography on silica (0-70\% EtOAc in hexane) to give the desired isoproxy derivative as an off-white solid (20 mg, 61\%): $\mathrm{mp}$ 123-125 ${ }^{\circ} \mathrm{C} .{ }^{1} \mathrm{H}$ NMR (300 MHz, CHLOROFORM-d) $\delta 7.18$ - 7.35 (m, 3H), 7.04 - 7.17 (m, $3 \mathrm{H}), 6.92-7.04(\mathrm{~m}, 1 \mathrm{H}), 6.76(\mathrm{~d}, J=2.17 \mathrm{~Hz}, 2 \mathrm{H}), 6.60-6.73(\mathrm{~m}, 1 \mathrm{H}), 6.58(\mathrm{~s}, 1 \mathrm{H}), 6.43$ (s, 1H), 4.38 - $4.54(\mathrm{~m}, 2 \mathrm{H}), 3.83$ - $3.89(\mathrm{~m}, 3 \mathrm{H}), 3.76-3.82(\mathrm{~m}, 3 \mathrm{H}), 3.60$ - $3.71(\mathrm{~m}, 2 \mathrm{H})$, $3.34-3.52(\mathrm{~m}, 1 \mathrm{H}), 3.07-3.32(\mathrm{~m}, 2 \mathrm{H}), 2.79-3.03(\mathrm{~m}, 4 \mathrm{H}), 2.42-2.55(\mathrm{~m}, 1 \mathrm{H}), 1.26$ $1.32(\mathrm{~m}, 6 \mathrm{H}) . \mathrm{m} / z 489(\mathrm{M}+\mathrm{H})$. HRMS (ESI, $\left.\mathrm{CH}_{3} \mathrm{OH}\right) \mathrm{m} / z$ calcd for $\mathrm{C}_{30} \mathrm{H}_{37} \mathrm{~N}_{2} \mathrm{O}_{4}[\mathrm{M}+\mathrm{H}]^{+}$ $489.2748, \mathrm{~m} / \mathrm{z}$ found 489.2802 .

N-Benzyl-2-\{6,7-dimethoxy-1-[(3-nitrophenyl)methyl]-1,2,3,4-tetrahydroisoquinolin-2yl lacetamide (42): This was made by the general procedure starting from 3nitrophenylacetic acid in 4 steps in $4 \%$ overall yield. ${ }^{1} \mathrm{H}$ NMR (300 MHz, CHLOROFORMd) $\delta 8.03(\mathrm{~s}, 1 \mathrm{H}), 7.86(\mathrm{td}, J=0.99,8.19 \mathrm{~Hz}, 1 \mathrm{H}), 7.43(\mathrm{~d}, J=7.35 \mathrm{~Hz}, 1 \mathrm{H}), 7.17-7.36(\mathrm{~m}$, $4 \mathrm{H}), 6.98-7.08(\mathrm{~m}, 2 \mathrm{H}), 6.70(\mathrm{t}, J=5.65 \mathrm{~Hz}, 1 \mathrm{H}), 6.60(\mathrm{~s}, 1 \mathrm{H}), 6.43(\mathrm{~s}, 1 \mathrm{H}), 4.33(\mathrm{dd}, J=$ 6.97, $14.88 \mathrm{~Hz}, 1 \mathrm{H}), 3.87(\mathrm{~s}, 3 \mathrm{H}), 3.92(\mathrm{~d}, J=5.27 \mathrm{~Hz}, 0 \mathrm{H}), 3.81(\mathrm{~s}, 3 \mathrm{H}), 3.71(\mathrm{dd}, J=5.56$, $9.32 \mathrm{~Hz}, 1 \mathrm{H}), 2.84-3.48(\mathrm{~m}, 8 \mathrm{H}), 2.44-2.57(\mathrm{~m}, 1 \mathrm{H}) . \mathrm{m} / \mathrm{z} 476(\mathrm{M}+\mathrm{H})$. HRMS (ESI, $\left.\mathrm{CH}_{3} \mathrm{OH}\right) \mathrm{m} / \mathrm{z}$ calcd for $\mathrm{C}_{27} \mathrm{H}_{30} \mathrm{~N}_{3} \mathrm{O}_{5}[\mathrm{M}+\mathrm{H}]^{+} 476.2180, \mathrm{~m} / z$ found 476.2229 .

2-\{1-[(3-Aminophenyl)methyl]-6,7-dimethoxy-1,2,3,4-tetrahydroisoquinolin-2-yl\}-Nbenzylacetamide (43): To the nitro derivative $\mathbf{4 2}(100 \mathrm{mg}, 0.21 \mathrm{mmol})$ in ethanol (12 mL) was added hydrazine monohydrate $(100 \mathrm{mg}, 0.1 \mathrm{~mL}, 21 \mathrm{mmol})$ and the reaction warmed to 
$50{ }^{\circ} \mathrm{C}$. Raney nickel (2800 type as a slurry in water, $50 \mathrm{mg}$ ) was added and the reaction stirred at $50{ }^{\circ} \mathrm{C}$ for $1 \mathrm{hr}$. The reaction was cooled, filtered through Celite and washed with ethanol. The solvent was removed under reduced pressure to give the amine $(80 \mathrm{mg}$, 90\%). ${ }^{1} \mathrm{H}$ NMR (300 MHz, CHLOROFORM-d) $87.21-7.36(\mathrm{~m}, 3 \mathrm{H}), 7.15(\mathrm{~d}, J=7.54 \mathrm{~Hz}$, 2H), 6.94 - $7.10(\mathrm{~m}, 2 \mathrm{H}), 6.56-6.65(\mathrm{~m}, 2 \mathrm{H}), 6.43-6.54$ (m, 3H), 4.47 (dd, $J=7.86,14.93$ $\mathrm{Hz}, 1 \mathrm{H}), 3.85(\mathrm{~d}, J=13.00 \mathrm{~Hz}, 6 \mathrm{H}), 3.76(\mathrm{dd}, J=4.95,14.93 \mathrm{~Hz}, 1 \mathrm{H}), 3.64(\mathrm{dd}, J=5.89$, $8.90 \mathrm{~Hz}, 1 \mathrm{H}), 3.36$ - $3.54(\mathrm{~m}, 3 \mathrm{H}), 3.23$ - $3.35(\mathrm{~m}, 1 \mathrm{H}), 3.06-3.19(\mathrm{~m}, 1 \mathrm{H}), 2.76-3.00(\mathrm{~m}$, $4 \mathrm{H}), 2.43-2.55(\mathrm{~m}, 1 \mathrm{H}) . \mathrm{m} / z 446(\mathrm{M}+\mathrm{H})$. HRMS (ESI, $\left.\mathrm{CH}_{3} \mathrm{OH}\right) \mathrm{m} / z$ calcd for $\mathrm{C}_{27} \mathrm{H}_{32} \mathrm{~N}_{3} \mathrm{O}_{3}$ $[\mathrm{M}+\mathrm{H}]^{+} 446.2438, \mathrm{~m} / \mathrm{z}$ found 446.2487 .

N-Benzyl-2-(1-\{[3-(dimethylamino)phenyl]methyl\}-6,7-dimethoxy-1,2,3,4tetrahydroisoquinolin-2-yl)acetamide (44): To a solution of amine $\mathbf{4 3}(80 \mathrm{mg}, 0.18 \mathrm{mmol})$ in methanol $(1 \mathrm{~mL})$ was added formaldehyde $(37 \%$ solution in water, $1.5 \mathrm{~mL})$ and glacial acetic acid ( $39 \mathrm{mg}, 37 \mu \mathrm{L}, 0.65 \mathrm{mmol}$ ). To this was then added sodium cyanoborohydride $(56 \mathrm{mg}, 0.9 \mathrm{mmol})$ and the reaction stirred at RT for $2 \mathrm{hr} .1 \mathrm{~N} \mathrm{HCl}(0.1 \mathrm{~mL})$ was added then the reaction was diluted with EtOAc, washed with $\mathrm{NaHCO}_{3}$ solution and brine, dried over $\mathrm{MgSO}_{4}$ and the solvent was removed under reduced pressure. The crude was purified by chromatography on silica (0-50\% EtOAc in hexane) to give the desired dimethylamine as an off-white solid (30 mg, 35\%): mp 101-103 ${ }^{\circ} \mathrm{C} .{ }^{1} \mathrm{H}$ NMR (300 MHz, CHLOROFORM-d) $\delta$ 7.17 - $7.33(\mathrm{~m}, 4 \mathrm{H}), 7.06$ - $7.14(\mathrm{~m}, 3 \mathrm{H}), 6.98-7.06(\mathrm{~m}, 1 \mathrm{H}), 6.45$ - $6.62(\mathrm{~m}, 4 \mathrm{H}), 4.46(\mathrm{dd}$, $J=8.19,14.98 \mathrm{~Hz}, 1 \mathrm{H}), 3.86(\mathrm{~s}, 3 \mathrm{H}), 3.83(\mathrm{~s}, 3 \mathrm{H}), 3.55-3.71(\mathrm{~m}, 2 \mathrm{H}), 3.39-3.53(\mathrm{~m}, 1 \mathrm{H})$, 3.08 - $3.33(\mathrm{~m}, 2 \mathrm{H}), 2.86-2.88(\mathrm{~m}, 6 \mathrm{H}), 2.78-3.00(\mathrm{~m}, 4 \mathrm{H}), 2.42-2.55(\mathrm{~m}, 1 \mathrm{H}) . \mathrm{m} / z 496$ $(\mathrm{M}+\mathrm{Na}), 474(\mathrm{M}+\mathrm{H})$. HRMS (ESI, $\left.\mathrm{CH}_{3} \mathrm{OH}\right) \mathrm{m} / z$ calcd for $\mathrm{C}_{29} \mathrm{H}_{36} \mathrm{~N}_{3} \mathrm{O}_{3}[\mathrm{M}+\mathrm{H}]^{+} 474.2751$, $\mathrm{m} / \mathrm{z}$ found 474.2803 .

\section{N-Benzyl-2-\{6,7-dimethoxy-1-[(4-propoxyphenyl)methyl]-1,2,3,4-}

tetrahydroisoquinolin-2-yl lacetamide (45): This was prepared as per $\mathbf{4 1}$ except using 1bromopropane to give the desired product as a white solid. Yield of final step 39\%: $\mathrm{mp}$ 126-127 ${ }^{\circ} \mathrm{C} .{ }^{1} \mathrm{H}$ NMR (300 MHz, CHLOROFORM-d) $\delta 7.20$ - $7.34(\mathrm{~m}, 3 \mathrm{H}), 7.06$ - 7.15 (m, 4H), $6.84-6.94(\mathrm{~m}, 1 \mathrm{H}), 6.76(\mathrm{~d}, J=8.57 \mathrm{~Hz}, 2 \mathrm{H}), 6.58(\mathrm{~s}, 1 \mathrm{H}), 6.45(\mathrm{~s}, 1 \mathrm{H}), 4.47$ (dd, $J=$ $8.10,14.98 \mathrm{~Hz}, 1 \mathrm{H}), 3.86(\mathrm{~s}, 3 \mathrm{H}), 3.82(\mathrm{~s}, 3 \mathrm{H}), 3.77(\mathrm{dt}, J=2.35,6.59 \mathrm{~Hz}, 2 \mathrm{H}), 3.54-3.66$ $(\mathrm{m}, 2 \mathrm{H}), 3.37-3.52(\mathrm{~m}, 1 \mathrm{H}), 3.08-3.32(\mathrm{~m}, 2 \mathrm{H}), 2.80-2.99(\mathrm{~m}, 4 \mathrm{H}), 2.42-2.55(\mathrm{~m}, 1 \mathrm{H})$, $1.72-1.86(\mathrm{~m}, 2 \mathrm{H}), 1.03(\mathrm{t}, J=7.44 \mathrm{~Hz}, 3 \mathrm{H}) . \mathrm{m} / z, 489(\mathrm{M}+\mathrm{H})$. HRMS (ESI, $\left.\mathrm{CH}_{3} \mathrm{OH}\right) \mathrm{m} / \mathrm{z}$ calcd for $\mathrm{C}_{30} \mathrm{H}_{37} \mathrm{~N}_{2} \mathrm{O}_{4}[\mathrm{M}+\mathrm{H}]^{+} 489.2748, \mathrm{~m} / z$ found 489.2804 .

\section{N-Benzyl-2-(6,7-dimethoxy-1-\{[4-(propan-2-yloxy)phenyl]methyl\}-1,2,3,4-}

tetrahydroisoquinolin-2-yl)acetamide (46): This was prepared as 41 starting from 4hydroxyphenylacetic acid in 5 steps in $3 \%$ overall yield. ${ }^{1} \mathrm{H}$ NMR $(300 \mathrm{MHz}$, CHLOROFORM-d) $\delta 7.19-7.34(\mathrm{~m}, 3 \mathrm{H}), 7.14(\mathrm{~d}, J=7.63 \mathrm{~Hz}, 2 \mathrm{H}), 7.07$ (d, $J=8.19 \mathrm{~Hz}$, 2H), $6.94-7.03(\mathrm{~m}, 1 \mathrm{H}), 6.76(\mathrm{~d}, J=8.10 \mathrm{~Hz}, 2 \mathrm{H}), 6.58(\mathrm{~s}, 1 \mathrm{H}), 6.41(\mathrm{~s}, 1 \mathrm{H}), 4.35$ - 4.52 $(\mathrm{m}, 2 \mathrm{H}), 3.86(\mathrm{~s}, 3 \mathrm{H}), 3.80(\mathrm{~s}, 3 \mathrm{H}), 3.54-3.72(\mathrm{~m}, 2 \mathrm{H}), 3.33-3.52(\mathrm{~m}, 1 \mathrm{H}), 3.07$ - $3.32(\mathrm{~m}$, 2H), 2.78 - $2.99(\mathrm{~m}, 4 \mathrm{H}), 2.42-2.54(\mathrm{~m}, 1 \mathrm{H}), 1.31(\mathrm{~d}, \mathrm{~J}=6.03 \mathrm{~Hz}, 6 \mathrm{H}) . \mathrm{m} / \mathrm{z} 489(\mathrm{M}+\mathrm{H})$. HRMS (ESI, $\mathrm{CH}_{3} \mathrm{OH}$ ) $\mathrm{m} / z$ calcd for $\mathrm{C}_{30} \mathrm{H}_{37} \mathrm{~N}_{2} \mathrm{O}_{4}[\mathrm{M}+\mathrm{H}]^{+} 489.2748, \mathrm{~m} / z$ found 489.2807 . 
2-\{1-[(4-Aminophenyl)methyl]-6,7-dimethoxy-1,2,3,4-tetrahydroisoquinolin-2-yl\}-Nbenzylacetamide (47): This was made by the general procedure starting from 4nitrophenylacetic acid in 4 steps in $86 \%$ overall yield to give the 4-nitrophenyl derivative. The nitro compound $(0.89 \mathrm{~g}, 1.87 \mathrm{mmol})$ was dissolved in ethanol $(30 \mathrm{~mL})$ and to it was added hydrazine monohydrate $(1 \mathrm{~mL})$, the solution warmed to $50{ }^{\circ} \mathrm{C}$ and Raney nickel (2800 type as a slurry in water, $0.25 \mathrm{~g}$ ) was added. The reaction was stirred at $50{ }^{\circ} \mathrm{C}$ until gas evolution ceased $(\sim 1 \mathrm{hr})$ then it was filtered through Celite and the solvent was removed under reduced pressure to give the desired amine as an off-white solid $(0.79 \mathrm{~g}, 95 \%)$ : $\mathrm{mp}$ 145-147 ${ }^{\circ} \mathrm{C} .{ }^{1} \mathrm{H}$ NMR (300 MHz, CHLOROFORM-d) $\delta 7.21-7.37$ (m, 3H), 7.17 (d, $J=$ $6.78 \mathrm{~Hz}, 2 \mathrm{H}), 6.97(\mathrm{~d}, J=8.10 \mathrm{~Hz}, 3 \mathrm{H}), 6.58(\mathrm{~s}, 1 \mathrm{H}), 6.50(\mathrm{~d}, J=8.01 \mathrm{~Hz}, 2 \mathrm{H}), 6.46(\mathrm{~s}, 1 \mathrm{H})$, 4.47 (dd, $J=7.96,14.93 \mathrm{~Hz}, 1 \mathrm{H}), 3.86(\mathrm{~s}, 3 \mathrm{H}), 3.82(\mathrm{~s}, 3 \mathrm{H}), 3.72(\mathrm{dd}, J=4.99,14.79 \mathrm{~Hz}$, $1 \mathrm{H}), 3.36$ - $3.61(\mathrm{~m}, 4 \mathrm{H}), 3.05-3.33(\mathrm{~m}, 2 \mathrm{H}), 2.74-3.01(\mathrm{~m}, 4 \mathrm{H}), 2.40-2.55(\mathrm{~m}, 1 \mathrm{H}) . \mathrm{m} / \mathrm{z}$ $468(\mathrm{M}+\mathrm{Na}), 446(\mathrm{M}+\mathrm{H})$. HRMS (ESI, $\left.\mathrm{CH}_{3} \mathrm{OH}\right) \mathrm{m} / z$ calcd for $\mathrm{C}_{27} \mathrm{H}_{32} \mathrm{~N}_{3} \mathrm{O}_{3}[\mathrm{M}+\mathrm{H}]^{+}$ $446.2438, \mathrm{~m} / \mathrm{z}$ found 446.2476 .

N-Benzyl-2-(1-\{[4-(dimethylamino)phenyl]methyl\}-6,7-dimethoxy-1,2,3,4tetrahydroisoquinolin-2-yl)acetamide (48): This was made by the general procedure starting from 4-dimethylaminophenylacetic acid in 4 steps in $15 \%$ overall yield. ${ }^{1} \mathrm{H}$ NMR (300 MHz, CHLOROFORM-d) $\delta 7.18$ - 7.34 (m, 3H), 7.04 - 7.14 (m, 3H), 6.92 - 7.02 (m, $1 \mathrm{H}), 6.54-6.65(\mathrm{~m}, 3 \mathrm{H}), 6.48(\mathrm{~s}, 1 \mathrm{H}), 4.40-4.53(\mathrm{~m}, 1 \mathrm{H}), 3.80-3.90(\mathrm{~m}, 6 \mathrm{H}), 3.35$ - 3.64 (m, 3H), $3.06-3.33(\mathrm{~m}, 2 \mathrm{H}), 2.78-3.00(\mathrm{~m}, 10 \mathrm{H}), 2.42-2.55(\mathrm{~m}, 1 \mathrm{H}) . \mathrm{m} / \mathrm{z} 474(\mathrm{M}+\mathrm{H})$. HRMS (ESI, $\mathrm{CH}_{3} \mathrm{OH}$ ) $\mathrm{m} / z$ calcd for $\mathrm{C}_{29} \mathrm{H}_{36} \mathrm{~N}_{3} \mathrm{O}_{3}[\mathrm{M}+\mathrm{H}]^{+} 474.2751, \mathrm{~m} / z$ found 474.2746 .

\section{N-Benzyl-2-\{1-[(4-acetamidophenyl)methyl]-6,7-dimethoxy-1,2,3,4-}

tetrahydroisoquinolin-2-yl\}acetamide (49): To a solution of amine 47 (25 mg, 0.056 mmol) and diisopropylethlamine (18 mg, $24 \mu \mathrm{L}, 0.140 \mathrm{mmol})$ in DCM $(1 \mathrm{~mL})$ under $\mathrm{N}_{2}$ cooled in an ice bath was added acetyl chloride $(9 \mathrm{mg}, 8 \mu \mathrm{L}, 0.112 \mathrm{mmol})$. The reaction was stirred in ice for $10 \mathrm{~min}$, then at RT for $3 \mathrm{hr}$. The reaction was diluted with $\mathrm{NaHCO}_{3}$ solution and extracted 3 times with EtOAc. The combined extracts were washed with brine, dried over $\mathrm{MgSO}_{4}$ and the solvents were removed under reduced pressure. The crude was purified by chromatography on silica (0-75\% EtOAc in hexane) to give the desired amide as an off-white solid (13 mg, 48\%): mp 99-100 ${ }^{\circ} \mathrm{C} .{ }^{1} \mathrm{H}$ NMR (300 MHz, CHLOROFORM-d) $\delta$ $7.21-7.38(\mathrm{~m}, 5 \mathrm{H}), 7.03-7.16(\mathrm{~m}, 4 \mathrm{H}), 6.76-6.90(\mathrm{~m}, 2 \mathrm{H}), 6.59(\mathrm{~s}, 1 \mathrm{H}), 6.46(\mathrm{~s}, 1 \mathrm{H}), 4.42$ (dd, $J=7.77,15.31 \mathrm{~Hz}, 1 \mathrm{H}), 3.86(\mathrm{~s}, 3 \mathrm{H}), 3.82(\mathrm{~s}, 3 \mathrm{H}), 3.74-3.80(\mathrm{~m}, 1 \mathrm{H}), 3.56-3.66(\mathrm{~m}$, $1 \mathrm{H}), 3.36$ - $3.51(\mathrm{~m}, 1 \mathrm{H}), 3.07-3.35(\mathrm{~m}, 2 \mathrm{H}), 2.81-3.00(\mathrm{~m}, 4 \mathrm{H}), 2.43-2.55(\mathrm{~m}, 1 \mathrm{H}), 2.12$ (s, $3 \mathrm{H}) . \mathrm{m} / z 488(\mathrm{M}+\mathrm{H})$. HRMS (ESI, $\left.\mathrm{CH}_{3} \mathrm{OH}\right) \mathrm{m} / z$ calcd for $\mathrm{C}_{29} \mathrm{H}_{34} \mathrm{~N}_{3} \mathrm{O}_{4}[\mathrm{M}+\mathrm{H}]^{+}$ $488.2544, \mathrm{~m} / z$ found 488.2597 .

N-Benzyl-2-[1-(\{4-[(hexylcarbamoyl)amino]phenyl\}methyl)-6,7-dimethoxy-1,2,3,4tetrahydroisoquinolin-2-yl]acetamide (50): To the amine $47(27 \mathrm{mg}, 0.061 \mathrm{mmol})$ in toluene $(1 \mathrm{~mL})$ was added n-hexylisocyanate $(8.5 \mathrm{mg}, 10 \mu \mathrm{L}, 0.067 \mathrm{mmol})$ and the reaction heated to $75{ }^{\circ} \mathrm{C}$ for $3 \mathrm{hr}$. The reaction was cooled and the solvents were removed under reduced pressure. The crude was purified by chromatography on silica (0-100\% EtOAc in hexane) to give the desired urea as a white solid (33 mg, 94\%): mp 81-84 ${ }^{\circ} \mathrm{C} .{ }^{1} \mathrm{H}$ NMR (300 MHz, CHLOROFORM-d) $\delta 7.22$ - 7.35 (m, 4H), 7.05 - 7.13 (m, 5H), 6.82 - 6.93 (m, 1H), 
$6.59(\mathrm{~s}, 1 \mathrm{H}), 6.45(\mathrm{~s}, 1 \mathrm{H}), 5.97(\mathrm{~s}, 1 \mathrm{H}), 4.55(\mathrm{t}, J=5.56 \mathrm{~Hz}, 1 \mathrm{H}), 4.42(\mathrm{dd}, J=7.77,15.12$ $\mathrm{Hz}, 1 \mathrm{H}), 3.86$ (s, 3H), 3.81 (s, 3H), $3.73-3.80(\mathrm{~m}, 1 \mathrm{H}), 3.61(\mathrm{dd}, J=5.79,9.00 \mathrm{~Hz}, 1 \mathrm{H})$, $3.35-3.50(\mathrm{~m}, 1 \mathrm{H}), 3.08-3.34(\mathrm{~m}, 4 \mathrm{H}), 2.80-3.01(\mathrm{~m}, 4 \mathrm{H}), 2.42-2.56(\mathrm{~m}, 1 \mathrm{H}), 1.44$ $1.55(\mathrm{~m}, 2 \mathrm{H}), 1.22-1.39(\mathrm{~m}, 6 \mathrm{H}), 0.85-0.93(\mathrm{~m}, 3 \mathrm{H}) . \mathrm{m} / z 573(\mathrm{M}+\mathrm{H})$. HRMS (ESI, $\left.\mathrm{CH}_{3} \mathrm{OH}\right) \mathrm{m} / z$ calcd for $\mathrm{C}_{34} \mathrm{H}_{45} \mathrm{~N}_{4} \mathrm{O}_{4}[\mathrm{M}+\mathrm{H}]^{+} 573.3435, \mathrm{~m} / z$ found 573.3495 .

N-Benzyl-2-(6,7-dimethoxy-1-\{[4-(propan-2-yl)phenyl]methyl\}-1,2,3,4tetrahydroisoquinolin-2-yl)acetamide (51): This was made by the general procedure starting from 4-isopropylphenylacetic acid in 4 steps to give the desired product as a white solid in $65 \%$ overall yield: mp 97-99 ${ }^{\circ} \mathrm{C} .{ }^{1} \mathrm{H}$ NMR (300 MHz, CHLOROFORM-d) $\delta 7.20-$ $7.36(\mathrm{~m}, 3 \mathrm{H}), 7.03-7.15(\mathrm{~m}, 6 \mathrm{H}), 6.58(\mathrm{~s}, 1 \mathrm{H}), 6.35(\mathrm{~s}, 1 \mathrm{H}), 4.37$ (dd, $J=7.54,15.07 \mathrm{~Hz}$, $1 \mathrm{H}), 3.86(\mathrm{~s}, 3 \mathrm{H}), 3.76(\mathrm{~s}, 3 \mathrm{H}), 3.59-3.83(\mathrm{~m}, 2 \mathrm{H}), 3.39-3.54(\mathrm{~m}, 1 \mathrm{H}), 3.09-3.35(\mathrm{~m}, 2 \mathrm{H})$, $2.76-3.04(\mathrm{~m}, 5 \mathrm{H}), 2.43-2.57(\mathrm{~m}, 1 \mathrm{H}), 1.18(\mathrm{dd}, J=5.18,6.69 \mathrm{~Hz}, 6 \mathrm{H}) . \mathrm{m} / 2.473(\mathrm{M}+\mathrm{H})$. HRMS (ESI, $\mathrm{CH}_{3} \mathrm{OH}$ ) $\mathrm{m} / z$ calcd for $\mathrm{C}_{30} \mathrm{H}_{37} \mathrm{~N}_{2} \mathrm{O}_{3}[\mathrm{M}+\mathrm{H}]^{+} 473.2799, \mathrm{~m} / z$ found 473.2858 .

\section{N-Benzyl-2-\{6,7-dimethoxy-1-[(3,4,5-trimethoxyphenyl)methyl]-1,2,3,4-} tetrahydroisoquinolin-2-yl \}acetamide (52): This was made by the general procedure starting from 3,4,5-trimethoxyphenylacetic acid in 4 steps to give the desired product as an orange solid in 7\% overall yield: mp 127-128 ${ }^{\circ} \mathrm{C} .{ }^{1} \mathrm{H}$ NMR (300 MHz, CHLOROFORM-d) $\delta 7.10-7.39(\mathrm{~m}, 6 \mathrm{H}), 6.59(\mathrm{~s}, 1 \mathrm{H}), 6.32-6.41(\mathrm{~m}, 3 \mathrm{H}), 4.46-4.57(\mathrm{~m}, 1 \mathrm{H}), 3.86(\mathrm{~s}, 3 \mathrm{H})$, $3.78(\mathrm{~s}, 3 \mathrm{H}), 3.78(\mathrm{~s}, 3 \mathrm{H}), 3.77(\mathrm{~s}, 6 \mathrm{H}), 3.81(\mathrm{~d}, J=2.26 \mathrm{~Hz}, 1 \mathrm{H}), 3.70(\mathrm{dd}, J=5.84,8.48$ $\mathrm{Hz}, 1 \mathrm{H}), 3.12-3.45(\mathrm{~m}, 3 \mathrm{H}), 2.78-3.04(\mathrm{~m}, 4 \mathrm{H}), 2.45-2.59(\mathrm{~m}, 1 \mathrm{H}) . \mathrm{m} / \mathrm{z} 521(\mathrm{M}+\mathrm{H})$. HRMS (ESI, $\mathrm{CH}_{3} \mathrm{OH}$ ) $\mathrm{m} / z$ calcd for $\mathrm{C}_{30} \mathrm{H}_{37} \mathrm{~N}_{2} \mathrm{O}_{6}[\mathrm{M}+\mathrm{H}]^{+} 521.2646, \mathrm{~m} / z$ found 521.2683.

\section{N-Benzyl-2-\{1-[(3,4-dimethylphenyl)methyl]-6,7-dimethoxy-1,2,3,4-}

tetrahydroisoquinolin-2-yl\}acetamide (53): This was made by the general procedure starting from 3,4-dimethylphenylacetic acid in 4 steps to give the desired product as an offwhite solid in $37 \%$ overall yield: $\mathrm{mp} 112-114{ }^{\circ} \mathrm{C} .{ }^{1} \mathrm{H}$ NMR (300 MHz, CHLOROFORM-d) $\delta 7.18$ - $7.34(\mathrm{~m}, 3 \mathrm{H}), 6.95$ - $7.08(\mathrm{~m}, 4 \mathrm{H}), 6.83$ - $6.95(\mathrm{~m}, 2 \mathrm{H}), 6.59(\mathrm{~s}, 1 \mathrm{H}), 6.48(\mathrm{~s}, 1 \mathrm{H})$, $4.44(\mathrm{dd}, J=8.15,15.12 \mathrm{~Hz}, 1 \mathrm{H}), 3.87$ (s, $3 \mathrm{H}), 3.83(\mathrm{~s}, 3 \mathrm{H}), 3.40-3.67(\mathrm{~m}, 3 \mathrm{H}), 3.06-3.32$ (m, 2H), 2.80 - $3.01(\mathrm{~m}, 4 \mathrm{H}), 2.43-2.55(\mathrm{~m}, 1 \mathrm{H}), 2.13(\mathrm{~s}, 6 \mathrm{H}) . \mathrm{m} / z .459(\mathrm{M}+\mathrm{H})$. HRMS (ESI, $\mathrm{CH}_{3} \mathrm{OH}$ ) $\mathrm{m} / z$ calcd for $\mathrm{C}_{29} \mathrm{H}_{35} \mathrm{~N}_{2} \mathrm{O}_{3}[\mathrm{M}+\mathrm{H}]^{+} 459.2642, \mathrm{~m} / z$ found 459.2695 .

N-Benzyl-2-[6,7-dimethoxy-1-(naphthalen-2-ylmethyl)-1,2,3,4-tetrahydroisoquinolin-2yllacetamide (54): This was made by the general procedure starting from 2naphthaleneacetic acid in 4 steps in $50 \%$ overall yield as an off-white: mp $69-72{ }^{\circ} \mathrm{C} .{ }^{1} \mathrm{H}$ NMR (300 MHz, CHLOROFORM-d) $\delta 7.68$ - $7.84(\mathrm{~m}, 3 \mathrm{H}), 7.66(\mathrm{~s}, 1 \mathrm{H}), 7.41-7.53$ (m, 2H), $7.35(\mathrm{dd}, J=1.55,8.34 \mathrm{~Hz}, 1 \mathrm{H}), 7.15(\mathrm{dd}, J=1.79,4.90 \mathrm{~Hz}, 2 \mathrm{H}), 6.64-6.76(\mathrm{~m}, 3 \mathrm{H})$, $6.61(\mathrm{~s}, 1 \mathrm{H}), 6.49(\mathrm{~s}, 1 \mathrm{H}), 4.13-4.25(\mathrm{~m}, 1 \mathrm{H}), 3.87(\mathrm{~s}, 3 \mathrm{H}), 3.70-3.81(\mathrm{~m}, 4 \mathrm{H}), 3.45-3.60$ (m, 1H), $3.05-3.32(\mathrm{~m}, 4 \mathrm{H}), 2.83-3.03(\mathrm{~m}, 3 \mathrm{H}), 2.45-2.58(\mathrm{~m}, 1 \mathrm{H}) . \mathrm{m} / z 481(\mathrm{M}+\mathrm{H})$. HRMS (ESI, $\mathrm{CH}_{3} \mathrm{OH}$ ) $\mathrm{m} / z$ calcd for $\mathrm{C}_{31} \mathrm{H}_{33} \mathrm{~N}_{2} \mathrm{O}_{3}[\mathrm{M}+\mathrm{H}]^{+} 481.2486, \mathrm{~m} / z$ found 481.2493 .

N-Benzyl-2-[6,7-dimethoxy-1-(quinolin-6-ylmethyl)-1,2,3,4-tetrahydroisoquinolin-2yllacetamide (55): This was made by the general procedure starting from 2-(quinolin-6yl)acetic acid in 4 steps in $48 \%$ overall yield as a yellow glassy solid. ${ }^{1} \mathrm{H}$ NMR (300 MHz, 
CHLOROFORM-d) $\delta 8.90(\mathrm{dd}, J=1.60,4.24 \mathrm{~Hz}, 1 \mathrm{H}), 8.01(\mathrm{dd}, J=9.09,12.76 \mathrm{~Hz}, 2 \mathrm{H})$, $7.54-7.62(\mathrm{~m}, 2 \mathrm{H}), 7.36(\mathrm{dd}, J=4.24,8.29 \mathrm{~Hz}, 1 \mathrm{H}), 7.13-7.20(\mathrm{~m}, 2 \mathrm{H}), 6.69-6.81(\mathrm{~m}$, $3 \mathrm{H}), 6.61(\mathrm{~s}, 1 \mathrm{H}), 6.43(\mathrm{~s}, 1 \mathrm{H}), 4.23(\mathrm{dd}, J=8.01,14.79 \mathrm{~Hz}, 1 \mathrm{H}), 3.87(\mathrm{~s}, 3 \mathrm{H}), 3.74(\mathrm{~s}, 3 \mathrm{H})$, 3.69 - $3.84(\mathrm{~m}, 1 \mathrm{H}), 3.42-3.58(\mathrm{~m}, 1 \mathrm{H}), 3.06-3.35(\mathrm{~m}, 4 \mathrm{H}), 2.84-3.02(\mathrm{~m}, 3 \mathrm{H}), 2.46$ $2.60(\mathrm{~m}, 1 \mathrm{H}) . \mathrm{m} / \mathrm{z} 482(\mathrm{M}+\mathrm{H})$. HRMS (ESI, $\left.\mathrm{CH}_{3} \mathrm{OH}\right) \mathrm{m} / z$ calcd for $\mathrm{C}_{30} \mathrm{H}_{32} \mathrm{~N}_{3} \mathrm{O}_{3}[\mathrm{M}+\mathrm{H}]^{+}$ $482.2438, \mathrm{~m} / \mathrm{z}$ found 482.2483 .

N-Benzyl-2-[6,7-dimethoxy-1-(1-phenylethyl)-1,2,3,4-tetrahydroisoquinolin-2yl]acetamide (56): This was made by the general procedure starting from 2-phenylpropionic acid in 4 steps in $29 \%$ overall yield as a yellow glassy solid. ${ }^{1} \mathrm{H}$ NMR $(300 \mathrm{MHz}$, CHLOROFORM-d) $\delta 7.04-7.35(\mathrm{~m}, 10 \mathrm{H}), 6.63-6.74(\mathrm{~m}, 1 \mathrm{H}), 6.54(\mathrm{~s}, 1 \mathrm{H}), 4.38$ (dd, $J=$ 7.63, $14.98 \mathrm{~Hz}, 1 \mathrm{H}), 3.87(\mathrm{~s}, 3 \mathrm{H}), 3.84(\mathrm{~s}, 3 \mathrm{H}), 3.74-3.89(\mathrm{~m}, 1 \mathrm{H}), 3.45-3.52(\mathrm{~m}, 1 \mathrm{H})$, $3.34-3.45(\mathrm{~m}, 1 \mathrm{H}), 3.13-3.22(\mathrm{~m}, 1 \mathrm{H}), 2.79-3.08(\mathrm{~m}, 3 \mathrm{H}), 2.48-2.71(\mathrm{~m}, 2 \mathrm{H}), 1.25(\mathrm{~d}, J$ $=7.25 \mathrm{~Hz}, 1 \mathrm{H}) . \mathrm{m} / \mathrm{z} 445(\mathrm{M}+\mathrm{H})$. HRMS $\left(\mathrm{ESI}, \mathrm{CH}_{3} \mathrm{OH}\right) \mathrm{m} / \mathrm{z}$ calcd for $\mathrm{C}_{28} \mathrm{H}_{33} \mathrm{~N}_{2} \mathrm{O}_{3}[\mathrm{M}+\mathrm{H}]^{+}$ $445.2486, \mathrm{~m} / \mathrm{z}$ found 445.2496 .

\section{Pictet-Spengler route to 1-alkyl-tetrahydroisoquinolines. General procedure}

N-Benzyl-2-[1-(3,4-dimethoxyphenyl)-6,7-dimethoxy-1,2,3,4-tetrahydroisoquinolin-2yllacetamide (59): 3,4-Dimethoxyphenethylamine $(0.10 \mathrm{~g}, 93 \mu \mathrm{L}, 0.55 \mathrm{mmol})$ and 3,4dimethoxybenzaldehyde $(0.11 \mathrm{~g}, 0.66 \mathrm{mmol})$ were combined in dry toluene $(0.55 \mathrm{~mL})$. Trifluoroacetic acid $(0.50 \mathrm{~g}, 0.33 \mathrm{~mL}, 4.41 \mathrm{mmol})$ was added and the reaction heated in the microwave at $140{ }^{\circ} \mathrm{C}$ for $30 \mathrm{~min}$. The reaction was cooled, the solvent was removed under reduced pressure and water was added. The $\mathrm{pH}$ was adjusted to 8-9 with $2 \mathrm{~N} \mathrm{NaOH}$ solution then extracted three times with $\mathrm{CH}_{2} \mathrm{Cl}_{2}$. The combined extracts were dried over $\mathrm{MgSO}_{4}$ and the solvent was removed under reduced pressure to yield the tetrahydroisoquinoline which was used in the next step without further purification.

The crude tetrahydroisoquinoline was combined with $\mathrm{N}$-benzyl bromoacetamide $(0.19 \mathrm{~g}$, $0.82 \mathrm{mmol}$ ) and tetrabutylammonium iodide $(41 \mathrm{mg}, 0.11 \mathrm{mmol})$ in DMF $(6 \mathrm{~mL})$, diisopropylethylamine $(0.18 \mathrm{~g}, 0.24 \mathrm{~mL}, 1.37 \mathrm{mmol})$ was added then the reaction stirred at RT under $\mathrm{N}_{2}$ overnight. The reaction was diluted with EtOAc, washed with $\mathrm{NaHCO}_{3}$ solution and brine, dried over $\mathrm{MgSO}_{4}$ and the solvent removed under reduced pressure. The crude was purified by chromatography on silica (0-75\% EtOAc in hexane) to give the desired 1-phenyl derivative as an off-white solid $(0.11 \mathrm{~g}, 41 \%)$ : mp 140-141 ${ }^{\circ} \mathrm{C} .{ }^{1} \mathrm{H}$ NMR (300 MHz, CHLOROFORM-d) $\delta 7.47-7.58(\mathrm{~m}, 1 \mathrm{H}), 7.25-7.38(\mathrm{~m}, 3 \mathrm{H}), 7.21(\mathrm{~d}, J=7.44$ $\mathrm{Hz}, 2 \mathrm{H}), 6.77$ (s, 2H), $6.60(\mathrm{~d}, J=4.05 \mathrm{~Hz}, 2 \mathrm{H}), 6.14(\mathrm{~s}, 1 \mathrm{H}), 4.35-4.55(\mathrm{~m}, 3 \mathrm{H}), 3.89$ (s, $3 \mathrm{H}), 3.86(\mathrm{~s}, 3 \mathrm{H}), 3.60(\mathrm{~s}, 6 \mathrm{H}), 3.33(\mathrm{~d}, J=16.48 \mathrm{~Hz}, 1 \mathrm{H}), 3.12(\mathrm{dd}, J=4.05,11.11 \mathrm{~Hz}$, 1H), $2.93-3.06(\mathrm{~m}, 2 \mathrm{H}), 2.65-2.83(\mathrm{~m}, 2 \mathrm{H}) . \mathrm{m} / \mathrm{z} 477(\mathrm{M}+\mathrm{H})$. HRMS (ESI, $\left.\mathrm{CH}_{3} \mathrm{OH}\right) \mathrm{m} / \mathrm{z}$ calcd for $\mathrm{C}_{28} \mathrm{H}_{33} \mathrm{~N}_{2} \mathrm{O}_{5}[\mathrm{M}+\mathrm{H}]^{+} 477.2384, \mathrm{~m} / z$ found 477.2438 .

\section{N-Benzyl-2-\{1-[2-(3,4-dimethoxyphenyl)ethyl]-6,7-dimethoxy-1,2,3,4-}

tetrahydroisoquinolin-2-yl\}acetamide (60): This was prepared via Bischler-Napieralski cyclization using the general procedures outlined for $\mathbf{1 2}$. The compound was obtained in $45 \%$ yield over 4 steps as a yellow glassy solid. ${ }^{1} \mathrm{H}$ NMR (300 MHz, CHLOROFORM-d) $\delta$ 7.70 (br. t, $J=5.70 \mathrm{~Hz}, 1 \mathrm{H}), 7.22-7.40(\mathrm{~m}, 5 \mathrm{H}), 6.74(\mathrm{~d}, J=8.01 \mathrm{~Hz}, 1 \mathrm{H}), 6.52-6.61$ (m, 
$3 \mathrm{H}), 6.45(\mathrm{~s}, 1 \mathrm{H}), 4.48-4.55(\mathrm{~m}, 2 \mathrm{H}), 3.85(\mathrm{~s}, 3 \mathrm{H}), 3.84(\mathrm{~s}, 3 \mathrm{H}), 3.82(\mathrm{~s}, 6 \mathrm{H}), 3.54(\mathrm{dd}, J=$ 4.90, $7.82 \mathrm{~Hz}, 1 \mathrm{H}), 3.15$ - $3.40(\mathrm{~m}, 3 \mathrm{H}), 2.74-2.95(\mathrm{~m}, 2 \mathrm{H}), 2.41$ - $2.72(\mathrm{~m}, 3 \mathrm{H}), 1.84-2.12$ (m, $2 \mathrm{H}) . m / z, 505(\mathrm{M}+\mathrm{H})$. HRMS (ESI, $\left.\mathrm{CH}_{3} \mathrm{OH}\right) \mathrm{m} / z$ calcd for $\mathrm{C}_{30} \mathrm{H}_{37} \mathrm{~N}_{2} \mathrm{O}_{5}[\mathrm{M}+\mathrm{H}]^{+}$ $505.2697, \mathrm{~m} / \mathrm{z}$ found 505.2685 .

N-Benzyl-2-\{1-[(E)-2-[4-(dimethylamino)phenyl]ethenyl]-6,7-dimethoxy-1,2,3,4tetrahydroisoquinolin-2-yl\}acetamide (61): Synthesized via Pictet-Spengler general method from 4-dimethylaminocinnamaldehyde. Yield $9 \%$. ${ }^{1} \mathrm{H}$ NMR $(300 \mathrm{MHz}$, CHLOROFORM-d) $\delta 7.17-7.36(\mathrm{~m}, 7 \mathrm{H}), 6.72-6.79(\mathrm{~m}, 1 \mathrm{H}), 6.63-6.71(\mathrm{~m}, 4 \mathrm{H}), 6.41(\mathrm{~d}$, $J=15.73 \mathrm{~Hz}, 1 \mathrm{H}), 5.66(\mathrm{dd}, J=8.57,15.73 \mathrm{~Hz}, 1 \mathrm{H}), 4.83(\mathrm{~d}, J=14.88 \mathrm{~Hz}, 1 \mathrm{H}), 4.31(\mathrm{~d}, J=$ $8.67 \mathrm{~Hz}, 1 \mathrm{H}), 4.07$ (d, $J=14.79 \mathrm{~Hz}, 1 \mathrm{H}), 3.84(\mathrm{~s}, 3 \mathrm{H}), 3.79$ (s, 3H), $3.73(\mathrm{~d}, J=15.07 \mathrm{~Hz}$, $1 \mathrm{H}), 3.19(\mathrm{dd}, J=1.46,14.27 \mathrm{~Hz}, 1 \mathrm{H}), 3.00(\mathrm{~s}, 6 \mathrm{H}), 2.49-2.75(\mathrm{~m}, 4 \mathrm{H}) . \mathrm{m} / z .486(\mathrm{M}+\mathrm{H})$. HRMS (ESI, $\mathrm{CH}_{3} \mathrm{OH}$ ) $\mathrm{m} / z$ calcd for $\mathrm{C}_{30} \mathrm{H}_{36} \mathrm{~N}_{3} \mathrm{O}_{3}[\mathrm{M}+\mathrm{H}]^{+} 486.2751, \mathrm{~m} / z$ found 486.2817 .

\section{N-Benzyl-2-(1-\{2-[4-(dimethylamino)phenyl]ethyl\}-6,7-dimethoxy-1,2,3,4-}

tetrahydroisoquinolin-2-yl)acetamide (62): The olefin $61(20 \mathrm{mg}, 0.041 \mathrm{mmol})$ and palladium on carbon $(10 \%, 20 \mathrm{mg})$ in ethanol $(5 \mathrm{~mL})$ were stirred under an atmosphere of hydrogen ( $35 \mathrm{psi}$ ) on a Parr shaker for $1.5 \mathrm{hr}$. The reaction was filtered through Celite, rinsed with ethanol and the solvent was removed under reduced pressure. The crude was purified by chromatography on silica (0-75\% EtOAc in hexane) to give the saturated analog as a yellow oil (7 mg, 35\%). ${ }^{1} \mathrm{H}$ NMR (300 MHz, CHLOROFORM-d) $\delta 7.18-7.38(\mathrm{~m}, 5 \mathrm{H})$, $6.87(\mathrm{~d}, J=8.48 \mathrm{~Hz}, 2 \mathrm{H}), 6.76-6.82(\mathrm{~m}, 1 \mathrm{H}), 6.64-6.75(\mathrm{~m}, 5 \mathrm{H}), 5.00(\mathrm{~d}, J=14.98 \mathrm{~Hz}$, 1H), 4.01 (br. s., 1H), 3.86 (s, 3H), 3.85 (s, 3H), $3.77-3.95$ (m, 2H), 3.21 (d, J = $15.26 \mathrm{~Hz}$, $1 \mathrm{H}), 2.92(\mathrm{~s}, 6 \mathrm{H}), 2.81-2.88(\mathrm{~m}, 1 \mathrm{H}), 2.59-2.72(\mathrm{~m}, 2 \mathrm{H}), 2.24-2.56(\mathrm{~m}, 2 \mathrm{H}), 1.79(\mathrm{dt}, J=$ $3.53,8.08 \mathrm{~Hz}, 2 \mathrm{H}) . \mathrm{m} / z 488(\mathrm{M}+\mathrm{H})$. HRMS (ESI, $\left.\mathrm{CH}_{3} \mathrm{OH}\right) \mathrm{m} / z$ calcd for $\mathrm{C}_{30} \mathrm{H}_{38} \mathrm{~N}_{3} \mathrm{O}_{3}[\mathrm{M}$ $+\mathrm{H}]^{+} 488.2908, \mathrm{~m} / \mathrm{z}$ found 488.2956 .

N-Benzyl-2-[6,7-dimethoxy-1-(3-phenylpropyl)-1,2,3,4-tetrahydroisoquinolin-2yl]acetamide (63): Synthesized via Pictet-Spengler general method from 4phenylbutyraldehyde. Yield 69\%. ${ }^{1} \mathrm{H}$ NMR (300 MHz, CHLOROFORM-d) $\delta 7.70$ (br. s., 1H), $7.15-7.38(\mathrm{~m}, 8 \mathrm{H}), 7.05(\mathrm{~d}, J=7.72 \mathrm{~Hz}, 2 \mathrm{H}), 6.53(\mathrm{~s}, 1 \mathrm{H}), 6.41(\mathrm{~s}, 1 \mathrm{H}), 4.48$ (d, $J=$ $5.93 \mathrm{~Hz}, 2 \mathrm{H}), 3.82(\mathrm{~s}, 3 \mathrm{H}), 3.79(\mathrm{~s}, 3 \mathrm{H}), 3.47$ (d, J = 4.14 Hz, 1H), $3.17-3.34(\mathrm{~m}, 2 \mathrm{H}), 3.07$ - $3.17(\mathrm{~m}, 1 \mathrm{H}), 2.69-2.89(\mathrm{~m}, 2 \mathrm{H}), 2.43-2.64(\mathrm{~m}, 3 \mathrm{H}), 1.53-1.80(\mathrm{~m}, 4 \mathrm{H}) . \mathrm{m} / z .459(\mathrm{M}$ $+\mathrm{H})$. HRMS (ESI, $\left.\mathrm{CH}_{3} \mathrm{OH}\right) \mathrm{m} / z$ calcd for $\mathrm{C}_{29} \mathrm{H}_{35} \mathrm{~N}_{2} \mathrm{O}_{3}[\mathrm{M}+\mathrm{H}]^{+} 459.2642, \mathrm{~m} / z$ found 459.269 .

N-Benzyl-2-(1-butyl-6,7-dimethoxy-1,2,3,4-tetrahydroisoquinolin-2-yl)acetamide (64): Synthesized via Pictet-Spengler general method from valeraldehyde. Yield 68\%. ${ }^{1} \mathrm{H}$ NMR (300 MHz, CHLOROFORM-d) $\delta 7.76$ (br. s., 1H), $7.28-7.41$ (m, 5H), 6.55 (s, 1H), 6.48 (s, $1 \mathrm{H}), 4.51(\mathrm{t}, J=5.70 \mathrm{~Hz}, 2 \mathrm{H}), 3.84(\mathrm{~s}, 6 \mathrm{H}), 3.44(\mathrm{dd}, J=4.85,8.05 \mathrm{~Hz}, 1 \mathrm{H}), 3.12-3.36(\mathrm{~m}$, $3 \mathrm{H}), 2.71-2.92(\mathrm{~m}, 2 \mathrm{H}), 2.44-2.57(\mathrm{~m}, 1 \mathrm{H}), 1.51-1.75(\mathrm{~m}, 2 \mathrm{H}), 1.14-1.34(\mathrm{~m}, 4 \mathrm{H}), 0.80$ (t, $J=6.78 \mathrm{~Hz}, 3 \mathrm{H}$ ). $\mathrm{m} / z 397\left(\mathrm{M}+\mathrm{H}\right.$ ). HRMS (ESI, $\left.\mathrm{CH}_{3} \mathrm{OH}\right) \mathrm{m} / z$ calcd for $\mathrm{C}_{24} \mathrm{H}_{33} \mathrm{~N}_{2} \mathrm{O}_{3}[\mathrm{M}$ $+\mathrm{H}]^{+}$397.2486, $\mathrm{m} / \mathrm{z}$ found 397.253 . 
N-Benzyl-2-[6,7-dimethoxy-1-(2-methylpropyl)-1,2,3,4-tetrahydroisoquinolin-2yllacetamide (65): Synthesized via Pictet-Spengler general method from isovaleraldehyde. Yield $100 \%$ as an off-white solid: mp $92-94{ }^{\circ} \mathrm{C} .{ }^{1} \mathrm{H}$ NMR (300 MHz, CHLOROFORM-d) $\delta$ 7.75 (br. s., 1H), $7.24-7.41$ (m, 5H), $6.55(\mathrm{~s}, 1 \mathrm{H}), 6.43(\mathrm{~s}, 1 \mathrm{H}), 4.40-4.60(\mathrm{~m}, 2 \mathrm{H}), 3.84(\mathrm{~s}$, $6 \mathrm{H}), 3.49(\mathrm{dd}, J=4.57,9.00 \mathrm{~Hz}, 1 \mathrm{H}), 3.09-3.41(\mathrm{~m}, 3 \mathrm{H}), 2.73-2.99(\mathrm{~m}, 2 \mathrm{H}), 2.45(\mathrm{dd}, J=$ $4.85,16.44 \mathrm{~Hz}, 1 \mathrm{H}), 1.64-1.79(\mathrm{~m}, 2 \mathrm{H}), 1.21-1.41(\mathrm{~m}, 1 \mathrm{H}), 0.88(\mathrm{dd}, J=2.07,6.31 \mathrm{~Hz}$, $6 \mathrm{H}) . \mathrm{m} / z 397(\mathrm{M}+\mathrm{H})$. HRMS (ESI, $\left.\mathrm{CH}_{3} \mathrm{OH}\right) \mathrm{m} / z$ calcd for $\mathrm{C}_{24} \mathrm{H}_{33} \mathrm{~N}_{2} \mathrm{O}_{3}[\mathrm{M}+\mathrm{H}]^{+}$397.2486, $\mathrm{m} / \mathrm{z}$ found 397.2544 .

N-Benzyl-2-(1-heptyl-6,7-dimethoxy-1,2,3,4-tetrahydroisoquinolin-2-yl)acetamide (66): Synthesized via Pictet-Spengler general method from octyl aldehyde. Yield 89\%. ${ }^{1} \mathrm{H}$ NMR (300 MHz, CHLOROFORM-d) $\delta 7.76$ (br. s., 1H), 7.21 - 7.42 (m, 5H), 6.55 (s, 1H), 6.47 (s, $1 \mathrm{H}), 4.51(\mathrm{~d}, J=5.84 \mathrm{~Hz}, 2 \mathrm{H}), 3.85(\mathrm{~s}, 3 \mathrm{H}), 3.84(\mathrm{~s}, 3 \mathrm{H}), 3.44(\mathrm{dd}, J=4.99,8.10 \mathrm{~Hz}, 1 \mathrm{H})$, 3.10 - $3.36(\mathrm{~m}, 3 \mathrm{H}), 2.70-2.90(\mathrm{~m}, 2 \mathrm{H}), 2.44-2.58(\mathrm{~m}, 1 \mathrm{H}), 1.52$ - $1.76(\mathrm{~m}, 2 \mathrm{H}), 1.10$ $1.39(\mathrm{~m}, 10 \mathrm{H}), 0.88(\mathrm{t}, J=6.88 \mathrm{~Hz}, 3 \mathrm{H}) . \mathrm{m} / \mathrm{z} 439(\mathrm{M}+\mathrm{H})$. HRMS (ESI, $\left.\mathrm{CH}_{3} \mathrm{OH}\right) \mathrm{m} / \mathrm{z}$ calcd for $\mathrm{C}_{27} \mathrm{H}_{39} \mathrm{~N}_{2} \mathrm{O}_{3}[\mathrm{M}+\mathrm{H}]^{+} 439.2955, \mathrm{~m} / z$ found 439.3016 .

N-Benzyl-2-[1-(cyclohexylmethyl)-6,7-dimethoxy-1,2,3,4-tetrahydroisoquinolin-2yllacetamide (67): Synthesized via Pictet-Spengler general method from 2cyclohexylacetaldehyde. Yield 69\%. ${ }^{1} \mathrm{H}$ NMR $(300 \mathrm{MHz}$, CHLOROFORM-d) $\delta 7.77$ (br. s., $1 \mathrm{H}), 7.27$ - $7.42(\mathrm{~m}, 5 \mathrm{H}), 6.55(\mathrm{~s}, 1 \mathrm{H}), 6.43(\mathrm{~s}, 1 \mathrm{H}), 4.54$ - $4.65(\mathrm{~m}, 1 \mathrm{H}), 4.37$ - $4.49(\mathrm{~m}, 1 \mathrm{H})$, $3.84(\mathrm{~s}, 6 \mathrm{H}), 3.50-3.60(\mathrm{~m}, 1 \mathrm{H}), 3.09-3.42(\mathrm{~m}, 3 \mathrm{H}), 2.72-2.99(\mathrm{~m}, 2 \mathrm{H}), 2.46(\mathrm{dd}, J=$ $4.99,16.48 \mathrm{~Hz}, 1 \mathrm{H}), 1.55-1.85(\mathrm{~m}, 5 \mathrm{H}), 1.32-1.52(\mathrm{~m}, 2 \mathrm{H}), 0.82-1.20(\mathrm{~m}, 6 \mathrm{H}) . \mathrm{m} / \mathrm{z} 437$ $\left(\mathrm{M}+\mathrm{H}\right.$ ). HRMS (ESI, $\left.\mathrm{CH}_{3} \mathrm{OH}\right) \mathrm{m} / z$ calcd for $\mathrm{C}_{27} \mathrm{H}_{37} \mathrm{~N}_{2} \mathrm{O}_{3}[\mathrm{M}+\mathrm{H}]^{+} 437.2799, \mathrm{~m} / z$ found 437.2855 .

N-Benzyl-2-[1-(2-cyclohexylethyl)-6,7-dimethoxy-1,2,3,4-tetrahydroisoquinolin-2yl]acetamide (68): Synthesized via Pictet-Spengler general method from 3cyclohexylpropionaldehyde. Yield 65\%. ${ }^{1} \mathrm{H}$ NMR (300 MHz, CHLOROFORM-d) 87.75 (t, $J=4.99 \mathrm{~Hz}, 1 \mathrm{H}), 7.28-7.41(\mathrm{~m}, 5 \mathrm{H}), 6.54(\mathrm{~s}, 1 \mathrm{H}), 6.47(\mathrm{~s}, 1 \mathrm{H}), 4.41-4.58(\mathrm{~m}, 2 \mathrm{H}), 3.84$ (s, 3H), $3.83(\mathrm{~s}, 3 \mathrm{H}), 3.41(\mathrm{dd}, J=4.99,7.91 \mathrm{~Hz}, 1 \mathrm{H}), 3.21-3.28(\mathrm{~m}, 2 \mathrm{H}), 3.09-3.20(\mathrm{~m}$, $1 \mathrm{H}), 2.68-2.90(\mathrm{~m}, 2 \mathrm{H}), 2.44-2.58(\mathrm{~m}, 1 \mathrm{H}), 1.48-1.75(\mathrm{~m}, 7 \mathrm{H}), 1.03-1.23(\mathrm{~m}, 6 \mathrm{H}), 0.64$ - $0.82(\mathrm{~m}, 2 \mathrm{H}) . \mathrm{m} / z 451(\mathrm{M}+\mathrm{H})$. HRMS $\left(\mathrm{ESI}, \mathrm{CH}_{3} \mathrm{OH}\right) \mathrm{m} / z$ calcd for $\mathrm{C}_{28} \mathrm{H}_{39} \mathrm{~N}_{2} \mathrm{O}_{3}[\mathrm{M}+\mathrm{H}]^{+}$ $451.2955, \mathrm{~m} / \mathrm{z}$ found 451.301 .

N-Benzyl-2-[1-(3-cyclohexylpropyl)-6,7-dimethoxy-1,2,3,4-tetrahydroisoquinolin-2yl]acetamide (69): Synthesized via Pictet-Spengler general method from 4cyclohexylbutyraldehyde. Yield 43\%. ${ }^{1} \mathrm{H}$ NMR (300 MHz, CHLOROFORM-d) $\delta 7.76$ (t, $J$ $=5.60 \mathrm{~Hz}, 1 \mathrm{H}), 7.23-7.41(\mathrm{~m}, 5 \mathrm{H}), 6.54(\mathrm{~s}, 1 \mathrm{H}), 6.47(\mathrm{~s}, 1 \mathrm{H}), 4.50(\mathrm{~d}, J=5.93 \mathrm{~Hz}, 2 \mathrm{H})$, $3.84(\mathrm{~s}, 3 \mathrm{H}), 3.84$ (s, 3H), $3.44(\mathrm{dd}, J=4.85,8.24 \mathrm{~Hz}, 1 \mathrm{H}), 3.11-3.35(\mathrm{~m}, 3 \mathrm{H}), 2.70-2.91$ (m, 2H), $2.43-2.57(\mathrm{~m}, 1 \mathrm{H}), 1.48-1.75(\mathrm{~m}, 9 \mathrm{H}), 1.02-1.20(\mathrm{~m}, 6 \mathrm{H}), 0.68-0.86(\mathrm{~m}, 2 \mathrm{H})$. $\mathrm{m} / z 465(\mathrm{M}+\mathrm{H})$. HRMS (ESI, $\left.\mathrm{CH}_{3} \mathrm{OH}\right) \mathrm{m} / z$ calcd for $\mathrm{C}_{29} \mathrm{H}_{41} \mathrm{~N}_{2} \mathrm{O}_{3}[\mathrm{M}+\mathrm{H}] 465.3112, \mathrm{~m} / z$ found 465.3171 . 
2-(3-Methoxy-4-propoxyphenyl)-N-[2-(3-methoxy-4-propoxyphenyl)ethyl]acetamide (71): To a solution of 4-hydroxy-3-methoxyphenethylamine hydrochloride 7 (2.24 g, 10.98 mmol), 4-hydroxy-3-methoxyphenylacetic acid ( $2.0 \mathrm{~g}, 10.98 \mathrm{mmol})$ and HBTU (4.58 g, $12.08 \mathrm{mmol})$ in dry DMF $(60 \mathrm{~mL})$ was added diisopropylethylamine $(5.68 \mathrm{~g}, 7.7 . \mathrm{mL}, 43.92$ mmol) and the reaction stirred under $\mathrm{N}_{2}$ at RT overnight. The reaction was diluted with EtOAc, washed with $1 \mathrm{~N}$

$\mathrm{HCl}, \mathrm{NaHCO}_{3}$ solution and saturated brine, then dried over $\mathrm{MgSO}_{4}$ and the solvent removed under reduced pressure to give the amide.

To a solution of the amide in DMF $(60 \mathrm{~mL})$ was added potassium carbonate $(9.08 \mathrm{~g}, 65.73$ $\mathrm{mmol})$ and 1-iodopropane $(7.45 \mathrm{~g}, 4.3 \mathrm{~mL}, 43.82 \mathrm{mmol})$ and the reaction stirred at RT under $\mathrm{N}_{2}$ overnight. The reaction was diluted with EtOAc, washed with $\mathrm{NaHCO}_{3}$ solution and brine, dried over $\mathrm{MgSO}_{4}$ and the solvent was removed under reduced pressure to give the dipropoxy amide as a yellow oil which solidified on standing (3.69 g, 81\%). ${ }^{1} \mathrm{H}$ NMR (300 MHz, CHLOROFORM-d) $\delta 6.80(\mathrm{~d}, J=8.67 \mathrm{~Hz}, 1 \mathrm{H}), 6.72(\mathrm{~d}, J=8.10 \mathrm{~Hz}, 1 \mathrm{H}), 6.61-6.69$ $(\mathrm{m}, 3 \mathrm{H}), 6.49$ (dd, $J=2.07,8.10 \mathrm{~Hz}, 1 \mathrm{H}), 5.43$ (br. t, $J=5.10 \mathrm{~Hz}, 1 \mathrm{H}), 3.96$ (q, $J=6.78 \mathrm{~Hz}$, 4H), $3.81(\mathrm{~s}, 3 \mathrm{H}), 3.81(\mathrm{~s}, 3 \mathrm{H}), 3.39-3.50(\mathrm{~m}, 4 \mathrm{H}), 2.66(\mathrm{t}, J=6.88 \mathrm{~Hz}, 2 \mathrm{H}), 1.79-1.92(\mathrm{~m}$, $4 \mathrm{H}), 1.01-1.08(\mathrm{~m}, 6 \mathrm{H})$.

6-Methoxy-1-[(3-methoxy-4-propoxyphenyl)methyl]-7-propoxy-1,2,3,4tetrahydroisoquinoline (72): This was prepared by the method used for 10, from amide $\mathbf{7 1}$. Yield 28\%. ${ }^{1} \mathrm{H}$ NMR (300 MHz, METHANOL-d 4$) \delta 6.83-6.89(\mathrm{~m}, 1 \mathrm{H}), 6.71-6.82(\mathrm{~m}$, $2 \mathrm{H}), 6.66(\mathrm{~s}, 1 \mathrm{H}), 6.56(\mathrm{~s}, 1 \mathrm{H}), 4.09(\mathrm{t}, J=6.78 \mathrm{~Hz}, 1 \mathrm{H}), 3.91(\mathrm{t}, J=6.59 \mathrm{~Hz}, 2 \mathrm{H}), 3.71$ $3.81(\mathrm{~m}, 8 \mathrm{H}), 3.04-3.22(\mathrm{~m}, 2 \mathrm{H}), 2.80-2.92(\mathrm{~m}, 2 \mathrm{H}), 2.71(\mathrm{t}, J=5.75 \mathrm{~Hz}, 2 \mathrm{H}), 1.66-1.85$ (m, 4H), 1.03 (t, $J=7.44 \mathrm{~Hz}, 3 \mathrm{H}), 0.99(\mathrm{t}, J=7.54 \mathrm{~Hz}, 3 \mathrm{H}) . \mathrm{m} / z .400(\mathrm{M}+\mathrm{H})$.

N-Benzyl-2-\{6-methoxy-1-[(3-methoxy-4-propoxyphenyl)methyl]-7-propoxy-1,2,3,4tetrahydroisoquinolin-2-yl \}acetamide (73): Amine 72 (0.85 g, $2.13 \mathrm{mmol})$, N-benzyl-2bromoacetamide $(0.58 \mathrm{~g}, 2.55 \mathrm{mmol})$ and potassium carbonate $(0.59 \mathrm{~g}, 4.20 \mathrm{mmol})$ were combined in DMF (50 mL) and heated to $65^{\circ} \mathrm{C}$ overnight. The reaction was cooled, diluted with water then extracted 3 times with EtOAc. The combined extracts were washed with brine, dried over $\mathrm{MgSO}_{4}$ and the solvent removed under reduced pressure. The crude material was purified by chromatography on silica (0-80\% EtOAc in hexane) to give the desired product as a pale brown solid $(0.67 \mathrm{~g}, 58 \%)$ : mp $98-101{ }^{\circ} \mathrm{C} .{ }^{1} \mathrm{H}$ NMR $(300 \mathrm{MHz}$, CHLOROFORM-d) $\delta 7.19-7.34(\mathrm{~m}, 3 \mathrm{H}), 7.11(\mathrm{~d}, J=6.78 \mathrm{~Hz}, 2 \mathrm{H}), 6.96-7.06(\mathrm{~m}, 1 \mathrm{H})$, $6.62-6.73(\mathrm{~m}, 3 \mathrm{H}), 6.58(\mathrm{~s}, 1 \mathrm{H}), 6.47(\mathrm{~s}, 1 \mathrm{H}), 4.49(\mathrm{dd}, J=8.05,14.93 \mathrm{~Hz}, 1 \mathrm{H}), 3.89(\mathrm{t}, J=$ $6.83 \mathrm{~Hz}, 2 \mathrm{H}), 3.84(\mathrm{~s}, 3 \mathrm{H}), 3.76-3.83(\mathrm{~m}, 5 \mathrm{H}), 3.57-3.70(\mathrm{~m}, 2 \mathrm{H}), 3.34-3.48(\mathrm{~m}, 1 \mathrm{H})$, $3.11-3.33(\mathrm{~m}, 2 \mathrm{H}), 2.79-2.98(\mathrm{~m}, 4 \mathrm{H}), 2.42-2.54(\mathrm{~m}, 1 \mathrm{H}), 1.76-1.92(\mathrm{~m}, 4 \mathrm{H}), 1.04(\mathrm{t}, J$ $=7.39 \mathrm{~Hz}, 3 \mathrm{H}), 1.02(\mathrm{t}, J=7.39 \mathrm{~Hz}, 3 \mathrm{H}) . \mathrm{m} / 2547(\mathrm{M}+\mathrm{H})$. HRMS $\left(\mathrm{ESI}, \mathrm{CH}_{3} \mathrm{OH}\right) \mathrm{m} / \mathrm{z}$ calcd for $\mathrm{C}_{33} \mathrm{H}_{43} \mathrm{~N}_{2} \mathrm{O}_{5}[\mathrm{M}+\mathrm{H}]^{+}$547.3167, $\mathrm{m} / \mathrm{z}$ found 547.3231 .

Calcium Mobilization Ke Assay for $\mathrm{OX}_{\mathbf{1}}$ and $\mathrm{OX}_{\mathbf{2}}$-Two individual stable cell lines were created by over-expressing human $\mathrm{OX}_{1}$ and $\mathrm{OX}_{2}$ receptors in CHO-RD-HGA16 (Molecular Devices) cells. The day before the assay, cells were plated into 96-well blackwalled assay plates at 25,000 cells/well in Ham's F12 supplemented with 10\% fetal bovine 
serum, 100 units of penicillin and streptomycin, and $100 \mu \mathrm{g} / \mathrm{mL}$ normocin ${ }^{\mathrm{TM}}$. The cells were incubated overnight at $37^{\circ} \mathrm{C}, 5 \% \mathrm{CO}_{2}$. Prior to the assay, Calcium 5 dye (Molecular Devices) was reconstituted according to the manufacturer instructions. The reconstituted dye was diluted 1:40 in pre-warmed $\left(37^{\circ} \mathrm{C}\right.$ ) assay buffer (1X HBSS, $20 \mathrm{mM}$ HEPES, $2.5 \mathrm{mM}$ probenecid, pH 7.4 at $37^{\circ} \mathrm{C}$ ). Growth medium was removed and the cells were gently washed with $100 \mu \mathrm{L}$ of pre-warmed $\left(37^{\circ} \mathrm{C}\right)$ assay buffer. The cells were incubated for 45 minutes at $37^{\circ} \mathrm{C}, 5 \% \mathrm{CO}_{2}$ in $200 \mu \mathrm{L}$ of the diluted Calcium 5 dye. A single concentration of each test compound was prepared at 10x the desired final concentration in 2.5\% BSA/8\% DMSO/assay buffer. Serial dilutions of orexin A were prepared at 10x the desired final concentration in $0.25 \% \mathrm{BSA} / 1 \%$ DMSO/assay buffer, aliquoted into 96-well polypropylene plates, and warmed to $37^{\circ} \mathrm{C}$. After the dye-loading incubation period, the cells were pretreated with $25 \mu \mathrm{L}$ of the test compounds and incubated for $15 \mathrm{~min}$ at $37^{\circ} \mathrm{C}$. After the pretreatment incubation period, the plate was read with a FlexStation II (Molecular Devices). Calcium-mediated changes in fluorescence were monitored every 1.52 seconds over a 60 second time period, with the FlexStation II adding $25 \mu \mathrm{L}$ of the orexin A serial dilutions at the 19 second time point (excitation at $485 \mathrm{~nm}$, detection at $525 \mathrm{~nm}$ ). Peak kinetic reduction (SoftMax, Molecular Devices) relative fluorescent units (RFU) were plotted against the log of compound concentration. Data were fit to a three-parameter logistic curve to generate $\mathrm{EC}_{50}$ values (Prism, version 6.0, GraphPad Software, Inc., San Diego, CA). Ke values were calculated using the equation $\mathrm{Ke}=[\mathrm{L}] /\left(\left(\mathrm{EC}_{50}{ }^{+} / \mathrm{EC}_{50^{-}}{ }^{-}\right)-1\right)$ where $[\mathrm{L}]$ is the concentration of test compound, $\mathrm{EC}_{50}{ }^{+}$is the $\mathrm{EC}_{50}$ of orexin $\mathrm{A}$ with test compound, and $\mathrm{EC}_{50}{ }^{-}$is the $\mathrm{EC}_{50}$ of orexin A alone.

\section{Behavioral studies}

Animals: Sixteen adult male Sprague-Dawley rats (Harlan, Indianapolis, IN) $(\mathrm{n}=8$ per group) were housed individually on a 12/12-h light/dark cycle (behavioral experiments were conducted during the light period) with free access to water and food except during testing. Animals were maintained and experiments were approved by the Institutional Animal Care and Use Committee, University at Buffalo, the State University of New York, and with the 2011 Guide for the Care and Use of Laboratory Animals (Institute of Laboratory Animal Resources on Life Sciences, National Research Council, National Academy of Sciences, Washington DC).

Drugs: Drugs used in this study included cocaine hydrochloride (Research Technology Branch, National Institute of Drug Abuse, Rockville, MD, USA) and compound 73. Cocaine hydrochloride was dissolved in $0.9 \%$ physiological saline. Compound $\mathbf{7 3}$ was dissolved in a mixture of 1 part absolute ethanol, 1 part Emulphor-620 (Rhodia Inc.), and 18 parts physiologic saline. Doses were expressed as the weight of the forms listed above in milligrams per kilogram of body weight and drugs were administered intraperitoneally.

Experimental protocols: Locomotor activity was monitored by an infrared motor-sensor system (AccuScan Instruments, Columbus, $\mathrm{OH})$ fitted outside clear acrylic chambers $(40 \times$ $40 \times 30 \mathrm{~cm}$ ) that were cleaned between test sessions. Locomotor activity (distance travelled) was analyzed with the Versa Max animal activity monitoring software (AccuScan Instruments, Columbus, OH). ${ }^{41}$ The dose-effect curve of cocaine was determined by using a 
cumulative dosing procedure as previously described ${ }^{41,42}$ For this experiment, vehicle or $10 \mathrm{mg} / \mathrm{kg}$ compound $\mathbf{7 3}$ was administered immediately prior to the start of the test session and different doses of cocaine (cumulative doses of $3.2,10,32 \mathrm{mg} / \mathrm{kg}$ ) were given at times $20 \mathrm{~min}, 40 \mathrm{~min}$ and $60 \mathrm{~min}$. The locomotor effects of each dose of cocaine were recorded for $20 \mathrm{~min}$ but for each dose the data from the first $5 \mathrm{~min}$ immediately after the drug injection were discarded due to the brief hyperactivity associated with handling and injection. For behavioral sensitization study, a similar protocol was used as described in our previous reports. ${ }^{41,42}$ Briefly, an acute cocaine dose-effect curve with vehicle or $10 \mathrm{mg} / \mathrm{kg}$ compound 73 pretreatment was determined on day 1 , which was followed by 7 days of daily $15 \mathrm{mg} / \mathrm{kg}$ cocaine in combination with vehicle or $10 \mathrm{mg} / \mathrm{kg}$ compound $\mathbf{7 3}$ and stayed in the test chambers for 1 hour. Thereafter, six days of drug-free period was implemented, which was followed by another cocaine dose-effect curve determination on day 15 during which no compound $\mathbf{7 3}$ was given.

Statistical analyses: The locomotion data were analyzed by two-way ANOVA (cocaine dose $\times$ compound 73 treatment) followed by post hoc Bonferroni's test. $\mathrm{P}<0.05$ was considered statistically significant.

\section{Supplementary Material}

Refer to Web version on PubMed Central for supplementary material.

\section{ACKNOWLEDGMENT}

We are grateful to National Institute on Drug Abuse, National Institutes of Health, U.S. (Grants DA032837 and DA026582 to Y.Z. and Grant DA034806 to JXL) for the financial support of this research. We thank Tiffany Langston, Keith Warner and Dr. Angela Giddings for their valuable technical assistance.

\section{ABBREVIATIONS}

$\begin{array}{ll}\text { BOP } & \text { (Benzotriazol-1-yloxy)tris(dimethylamino)phosphonium hexafluorophosphate } \\ \text { HBTU } & \text { O-Benzotriazole-N,N,N',N'-tetramethyl-uronium-hexafluoro-phosphate } \\ \text { HPLC } & \text { performance liquid chromatography } \\ \text { OX }_{1} & \text { orexin 1 receptor } \\ \text { OX }_{2} & \text { orexin 2 receptor } \\ \text { SAR } & \text { structure-activity relationship } \\ \text { TLC } & \text { thin layer chromatography }\end{array}$

\section{REFERENCES}

1. Sakurai T, Amemiya A, Ishii M, Matsuzaki I, Chemelli RM, Tanaka H, Williams SC, Richardson JA, Kozlowski GP, Wilson S, Arch JR, Buckingham RE, Haynes AC, Carr SA, Annan RS, McNulty DE, Liu WS, Terrett JA, Elshourbagy NA, Bergsma DJ, Yanagisawa M. Orexins and orexin receptors: a family of hypothalamic neuropeptides and $\mathrm{G}$ protein-coupled receptors that regulate feeding behavior. Cell. 1998; 92:573-585. [PubMed: 9491897] 
2. de Lecea L, Kilduff TS, Peyron C, Gao X, Foye PE, Danielson PE, Fukuhara C, Battenberg EL, Gautvik VT, Bartlett FS 2nd, Frankel WN, van den Pol AN, Bloom FE, Gautvik KM, Sutcliffe JG. The hypocretins: hypothalamus-specific peptides with neuroexcitatory activity. Proceedings of the National Academy of Sciences of the United States of America. 1998; 95:322-327. [PubMed: 9419374]

3. Peyron C, Tighe DK, van den Pol AN, de Lecea L, Heller HC, Sutcliffe JG, Kilduff TS. Neurons containing hypocretin (orexin) project to multiple neuronal systems. Journal of Neuroscience. 1998; 18:9996-10015. [PubMed: 9822755]

4. Nambu T, Sakurai T, Mizukami K, Hosoya Y, Yanagisawa M, Goto K. Distribution of orexin neurons in the adult rat brain. Brain Research. 1999; 827:243-260. [PubMed: 10320718]

5. Li J, Hu Z, de Lecea L. The hypocretins/orexins: integrators of multiple physiological functions. Br. J. Pharmacol. 2014; 171:332-350. [PubMed: 24102345]

6. Kukkonen JP, Leonard CS. Orexin/hypocretin receptor signalling cascades. Br. J. Pharmacol. 2014; 171:314-331. [PubMed: 23902572]

7. Leonard CS, Kukkonen JP. Orexin/hypocretin receptor signalling: a functional perspective. Br. J. Pharmacol. 2014; 171:294-313. [PubMed: 23848055]

8. Marcus JN, Aschkenasi CJ, Lee CE, Chemelli RM, Saper CB, Yanagisawa M, Elmquist JK. Differential expression of orexin receptors 1 and 2 in the rat brain. Journal of Comparative Neurology. 2001; 435:6-25. [PubMed: 11370008]

9. Trivedi P, Yu H, MacNeil DJ, Van der Ploeg LH, Guan XM. Distribution of orexin receptor mRNA in the rat brain. FEBS Letters. 1998; 438:71-75. [PubMed: 9821961]

10. Kukkonen JP, Holmqvist T, Ammoun S, Akerman KE. Functions of the orexinergic/ hypocretinergic system, American journal of physiology. Cell physiology. 2002; 283:C15671591. [PubMed: 12419707]

11. Mahler SV, Moorman DE, Smith RJ, James MH, Aston-Jones G. Motivational activation: a unifying hypothesis of orexin/hypocretin function. Nat. Neurosci. 2014; 17:1298-1303. [PubMed: 25254979]

12. Kukkonen JP. Physiology of the orexinergic/hypocretinergic system: a revisit in 2012, American journal of physiology. Cell physiology. 2013; 304:C2-32. [PubMed: 23034387]

13. Tsujino N, Sakurai T. Orexin/hypocretin: a neuropeptide at the interface of sleep, energy homeostasis, and reward system. Pharmacol. Rev. 2009; 61:162-176. [PubMed: 19549926]

14. Mahler SV, Smith RJ, Moorman DE, Sartor GC, Aston-Jones G. Multiple roles for orexin/ hypocretin in addiction. Prog. Brain Res. 2012; 198:79-121. [PubMed: 22813971]

15. Harris GC, Wimmer M, Aston-Jones G. A role for lateral hypothalamic orexin neurons in reward seeking. Nature. 2005; 437:556-559. [PubMed: 16100511]

16. Boutrel B, Kenny PJ, Specio SE, Martin-Fardon R, Markou A, Koob GF, de Lecea L. Role for hypocretin in mediating stress-induced reinstatement of cocaine-seeking behavior. Proceedings of the National Academy of Sciences of the United States of America. 2005; 102:19168-19173. [PubMed: 16357203]

17. Lawrence AJ, Cowen MS, Yang HJ, Chen F, Oldfield B. The orexin system regulates alcoholseeking in rats. British journal of pharmacology. 2006; 148:752-759. [PubMed: 16751790]

18. Richards JK, Simms JA, Steensland P, Taha SA, Borgland SL, Bonci A, Bartlett SE. Inhibition of orexin-1/hypocretin-1 receptors inhibits yohimbine-induced reinstatement of ethanol and sucrose seeking in Long-Evans rats. Psychopharmacology. 2008; 199:109-117. [PubMed: 18470506]

19. Roecker AJ, Coleman PJ. Orexin receptor antagonists: medicinal chemistry and therapeutic potential. Curr Top Med Chem. 2008; 8:977-987. [PubMed: 18673167]

20. Boss C, Brisbare-Roch C, Jenck F. Biomedical application of orexin/hypocretin receptor ligands in neuroscience. Journal of Medicinal Chemistry. 2009; 52:891-903. [PubMed: 19199652]

21. Gatfield J, Brisbare-Roch C, Jenck F, Boss C. Orexin receptor antagonists: a new concept in CNS disorders? ChemMedChem. 2010; 5:1197-1214. [PubMed: 20544785]

22. Kodadek T, Cai D. Chemistry and biology of orexin signaling. Molecular bioSystems. 2010; 6:1366-1375. [PubMed: 20532299]

23. Scammell TE, Winrow CJ. Orexin receptors: pharmacology and therapeutic opportunities. Annual Review of Pharmacology and Toxicology. 2011; 51:243-266. 
24. Mieda M, Sakurai T. Orexin (hypocretin) receptor agonists and antagonists for treatment of sleep disorders. Rationale for development and current status. CNS Drugs. 2013; 27:83-90. [PubMed: 23359095]

25. Winrow CJ, Renger JJ. Discovery and development of orexin receptor antagonists as therapeutics for insomnia. Br. J. Pharmacol. 2014; 171:283-293. [PubMed: 23731216]

26. Yang LP. Suvorexant: First Global Approval, Drugs. 2014

27. Lebold TP, Bonaventure P, Shireman BT. Selective orexin receptor antagonists. Bioorg. Med. Chem. Lett. 2013; 23:4761-4769. [PubMed: 23891187]

28. Smart D, Sabido-David C, Brough SJ, Jewitt F, Johns A, Porter RA, Jerman JC. SB-334867-A: the first selective orexin-1 receptor antagonist. Br. J. Pharmacol. 2001; 132:1179-1182. [PubMed: 11250867]

29. Stasi, PL.; Rovati, L. Spiro amino compounds suitable for the treatment of inter alia sleep disorders and drug addiction. 2011. WO2011006960, Rottapharm S.P.A.

30. Stasi LP, Artusi R, Bovino C, Buzzi B, Canciani L, Caselli G, Colace F, Garofalo P, Giambuzzi S, Larger P, Letari O, Mandelli S, Perugini L, Pucci S, Salvi M, Toro P. Discovery, synthesis, selectivity modulation and DMPK characterization of 5-azaspiro[2.4] heptanes as potent orexin receptor antagonists. Bioorg. Med. Chem. Lett. 2013; 23:2653-2658. [PubMed: 23535328]

31. Gozzi A, Turrini G, Piccoli L, Massagrande M, Amantini D, Antolini M, Martinelli P, Cesari N, Montanari D, Tessari M, Corsi M, Bifone A. Functional magnetic resonance imaging reveals different neural substrates for the effects of orexin-1 and orexin-2 receptor antagonists. PloS one. 2011; 6:e16406. [PubMed: 21307957]

32. Steiner MA, Gatfield J, Brisbare-Roch C, Dietrich H, Treiber A, Jenck F, Boss C. Discovery and Characterization of ACT-335827, an Orally Available, Brain Penetrant Orexin Receptor Type 1 Selective Antagonist. ChemMedChem. 2013; 8:898-903. [PubMed: 23589487]

33. Jiang R, Song X, Bali P, Smith A, Bayona CR, Lin L, Cameron MD, McDonald PH, Kenny PJ, Kamenecka TM. Disubstituted piperidines as potent orexin (hypocretin) receptor antagonists. Bioorganic \& medicinal chemistry letters. 2012; 22:3890-3894. [PubMed: 22617492]

34. Perrey DA, German NA, Gilmour BP, Li JX, Harris DL, Thomas BF, Zhang Y. Substituted tetrahydroisoquinolines as selective antagonists for the orexin 1 receptor. Journal of Medicinal Chemistry. 2013; 56:6901-6916. [PubMed: 23941044]

35. Perrey DA, Gilmour BP, Runyon SP, Thomas BF, Zhang Y. Diaryl urea analogues of SB-334867 as orexin-1 receptor antagonists. Bioorganic \& medicinal chemistry letters. 2011; 21:2980-2985. [PubMed: 21478014]

36. Perrey DA, Gilmour BP, Thomas BF, Zhang Y. Toward the Development of Bivalent Ligand Probes of Cannabinoid CB1 and Orexin OX1 Receptor Heterodimers. ACS medicinal chemistry letters. 2014; 5:634-638. [PubMed: 24944734]

37. Hirose M, Egashira S, Goto Y, Hashihayata T, Ohtake N, Iwaasa H, Hata M, Fukami T, Kanatani A, Yamada K. N-acyl 6,7-dimethoxy-1,2,3,4-tetrahydroisoquinoline: the first orexin-2 receptor selective non-peptidic antagonist. Bioorganic \& medicinal chemistry letters. 2003; 13:4497-4499. [PubMed: 14643355]

38. Koberstein R, Aissaoui H, Bur D, Clozel M, Fischli W, Jenck F, Mueller C, Nayler O, Sifferlen T, Treiber A, Weller T. Tetrahydroisoquinolines as Orexin Receptor Antagonists: Strategies for Lead Optimization by Solution-Phase Chemistry. Chimia. 2003; 57:270-275.

39. Neubauer DN. Almorexant, a dual orexin receptor antagonist for the treatment of insomnia. Curr Opin Investig Drugs. 2010; 11:101-110.

40. Borgland SL, Taha SA, Sarti F, Fields HL, Bonci A. Orexin A in the VTA is critical for the induction of synaptic plasticity and behavioral sensitization to cocaine. Neuron. 2006; 49:589-601. [PubMed: 16476667]

41. Thorn DA, Zhang C, Zhang Y, Li JX. The trace amine associated receptor 1 agonist RO5263397 attenuates the induction of cocaine behavioral sensitization in rats. Neurosci. Lett. 2014; 566:6771. [PubMed: 24561093]

42. Thorn DA, Jing L, Qiu Y, Gancarz-Kausch AM, Galuska CM, Dietz DM, Zhang Y, Li JX. Effects of the trace amine-associated receptor 1 agonist RO5263397 on abuse-related effects of cocaine in rats. Neuropsychopharmacology. 2014; 39:2309-2316. [PubMed: 24743376] 


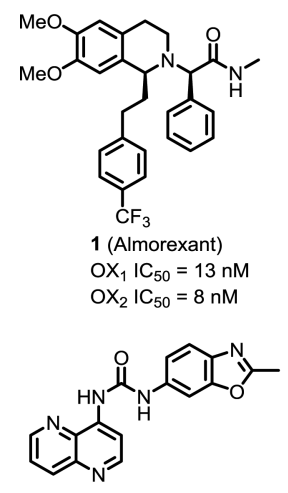

4 (SB-334867)

$\mathrm{OX}_{1} \mathrm{Ki}=28 \mathrm{nM}$ $\mathrm{OX}_{2} \mathrm{Ki}=1704 \mathrm{nM}$

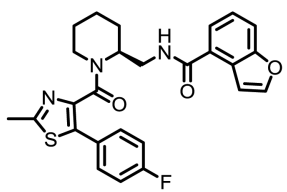

2 (SB-649868)

$\mathrm{OX}_{1} \mathrm{Ki}=0.3 \mathrm{nM}$

$\mathrm{OX}_{2} \mathrm{Ki}=0.4 \mathrm{nM}$

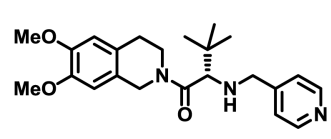

5 (TCS-OX2-29)

$\mathrm{OX}_{1} \mathrm{IC}_{50}>10,000 \mathrm{nM}$

$\mathrm{OX}_{2} \mathrm{IC}_{50}=40 \mathrm{nM}$

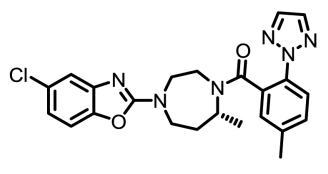

3 (Suvorexant)

$\mathrm{OX}_{1} \mathrm{Ki}=0.6 \mathrm{nM}$

$\mathrm{OX}_{2} \mathrm{Ki}=0.4 \mathrm{nM}$

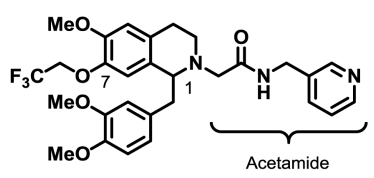

6 (RTIOX-276)

$\mathrm{OX} 1 \mathrm{Ke}=8.5 \mathrm{nM}$

OX2 Ke>10,000 nM

Figure 1.

Orexin Antagonists 

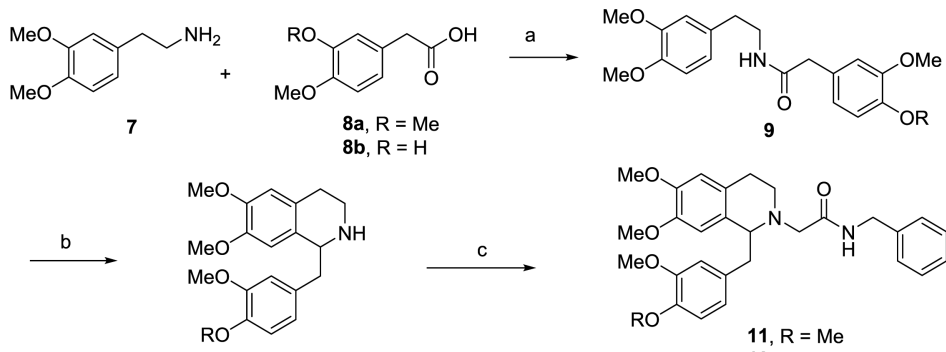

10

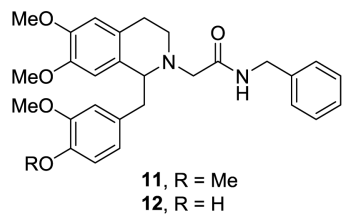

$13, \mathrm{R}=\mathrm{n}-\mathrm{Bu}$

$14, \mathrm{R}=\mathrm{n}$-hexyl

$15, \mathrm{R}=\left(\mathrm{CH}_{2}\right)_{2}$-piperidinyl

16, $\mathrm{R}=\mathrm{CO}\left(\mathrm{CH}_{2}\right)_{2} \mathrm{CH}_{3}$

12
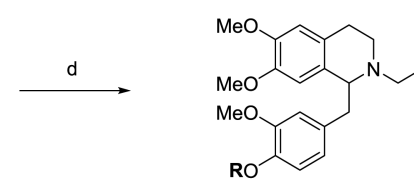

17, $\mathrm{R}=\mathrm{SO}_{2} \mathrm{Me}$

18, $\mathrm{R}=\mathrm{Bn}$

19, $\mathrm{R}=\left(\mathrm{CH}_{2}\right)_{4} \mathrm{OPh}$

20, $\mathrm{R}=\mathrm{SO}_{2}(4-\mathrm{Me}) \mathrm{Ph}$

21, $\mathrm{R}=\mathrm{CH}_{2}$-2-pyridyl

22, $\mathrm{R}=\mathrm{CH}_{2}$-3-pyridyl

23, $\mathrm{R}=\mathrm{SO}_{2} \mathrm{Ph}$

${ }^{a}$ Reagents and Conditions: (a) HBTU or BOP, $\mathrm{iPr}_{2} \mathrm{EtN}$, DMF; (b) (i) $\mathrm{POCl}_{3}$, toluene; (ii) $\mathrm{NaBH}_{4}, \mathrm{MeOH}$; (c) $\mathrm{BrCH}_{2} \mathrm{CONHCH}_{2} \mathrm{Ph}, \mathrm{iPr}_{2} \mathrm{EtN}, \mathrm{Bu}_{4} \mathrm{NI}, \mathrm{DMF}$; (d) R'- $\mathrm{Br}, \mathrm{K}_{2} \mathrm{CO}_{3}, \mathrm{DMF}$ or $\mathrm{CH}_{3}\left(\mathrm{CH}_{2}\right)_{2} \mathrm{COOH}, \mathrm{BOP}, \mathrm{Pr}_{2} \mathrm{EtN}, \mathrm{CH}_{2} \mathrm{Cl}_{2}$ or R'SO $\mathrm{SO}_{2} \mathrm{Cl} \mathrm{Et}_{3} \mathrm{~N}, \mathrm{CH}_{2} \mathrm{Cl}_{2}$.

Scheme 1.

Synthesis of 1-substituted tetrahydroisoquinolines $\mathbf{1 1 - 2 3 ^ { a }}$ 

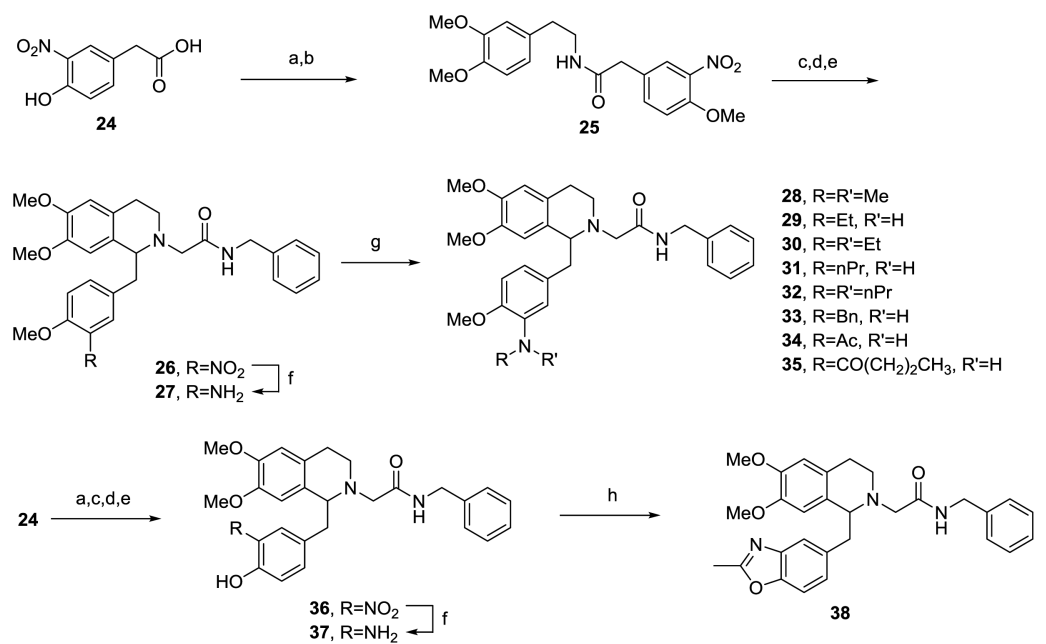

${ }^{a}$ Reagents and Conditions: (a) 3,4-dimethoxyphenethylamine (7), HBTU, iPr 2 EtN, DMF; (b) MeI, $\mathrm{K}_{2} \mathrm{CO}_{3}$, DMF; (c) $\mathrm{POCl}_{3}$, toluene; (d) $\mathrm{NaBH}_{4}, \mathrm{MeOH}$; (e) $\mathrm{BrCH}_{2} \mathrm{CONHCH}_{2} \mathrm{Ph}$, $\mathrm{iPr}_{2} \mathrm{EtN}$,

$\mathrm{Bu}_{4} \mathrm{NI}$, DMF; (f) Raney Ni, $\mathrm{NH}_{2} \mathrm{NH}_{2} \cdot \mathrm{H}_{2} \mathrm{O}$, EtOH; (g) R-CHO, Na(AcO) 3 BH, 1,2-DCE or R$\mathrm{CHO}, \mathrm{NaBH}_{3} \mathrm{CN}, \mathrm{AcOH}, \mathrm{MeOH}$ or R-Br, $\mathrm{PPr}_{2} \mathrm{EtN}, \mathrm{Bu}_{4} \mathrm{NI}$, DMF or butyric acid, BOP, $\mathrm{iPr}_{2} \mathrm{EtN}$, DMF; (h) ethyl acetimidate $\mathrm{HCl}, \mathrm{CHCl}_{3}$.

Scheme 2.

Synthesis of 1-aminobenzyl substituted tetrahydroisoquinolines $\mathbf{2 8 - 3 8}{ }^{\text {a }}$ 


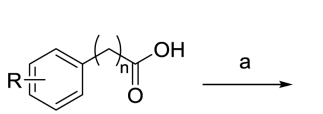

39

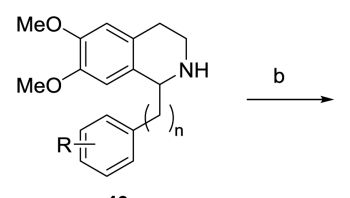

40

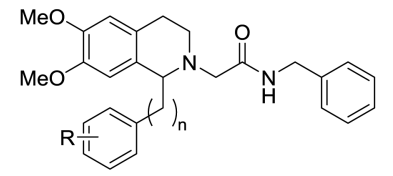

54, $\mathrm{CH}_{2}$-2-naphthyl

$\begin{array}{ll}\mathbf{4 8}, \mathrm{CH}_{2}-4-\mathrm{NMe}_{2} \mathrm{Ph} & \mathbf{5 5}, \mathrm{CH}_{2}-6 \text {-quinolinyl } \\ \mathbf{5 1}, \mathrm{CH}_{2}-4 \text {-iPrPh } & \mathbf{5 6}, \mathrm{CHMe}^{-\mathrm{Ph}} \\ \mathbf{5 2}, \mathrm{CH}_{2}-3,4,5 \text {-triMeOPh } & \mathbf{6 0}, \mathrm{CH}_{2} \mathrm{CH}_{2}-3,4-d M\end{array}$

$\begin{array}{ll}\text { 48, } \mathrm{CH}_{2}-4-\mathrm{NMe}_{2} \mathrm{Ph} & \mathbf{5 5}, \mathrm{CH}_{2}-6 \text {-quino } \\ \mathbf{5 1}, \mathrm{CH}_{2}-4-\mathrm{PrPh} & \mathbf{5 6}, \mathrm{CHMe}^{\mathrm{Ph}} \\ \mathbf{5 2}, \mathrm{CH}_{2}-3,4,5 \text {-triMeOPh } & \mathbf{6 0}\end{array}$

52, $\mathrm{CH}_{2}$-3,4,5-triMeOPh $60, \mathrm{CH}_{2} \mathrm{CH}_{2}$-3,4-diMeOPh

53, $\mathrm{CH}_{2}$-3,4-diMePh
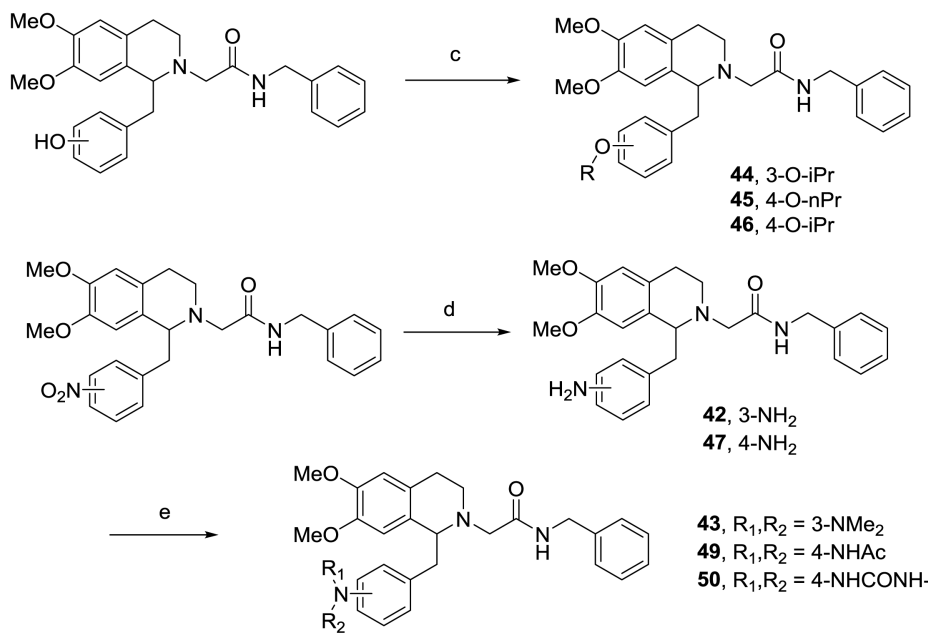

43, $\mathrm{R}_{1}, \mathrm{R}_{2}=3-\mathrm{NMe}_{2}$

49, $\mathrm{R}_{1}, \mathrm{R}_{2}=4-\mathrm{NHAC}$

50, $R_{1}, R_{2}=4-N H C O N H-n-h e x y l$

${ }^{a}$ Reagents and Conditions: (a) (i) 7, HBTU, $\operatorname{PPr}_{2} \mathrm{EtN}$, DMF; (ii) $\mathrm{POCl}_{3}$, toluene; (iii) $\mathrm{NaBH}_{4}$, $\mathrm{MeOH}$; (b) $\mathrm{BrCH}_{2} \mathrm{CONHCH}_{2} \mathrm{Ph}, \mathrm{iPr}_{2} \mathrm{EtN}, \mathrm{Bu}_{4} \mathrm{NI}$, DMF; (c) R-Br, $\mathrm{K}_{2} \mathrm{CO}_{3}$, DMF; (d) Raney Ni, $\mathrm{NH}_{2} \mathrm{NH}_{2} \cdot \mathrm{H}_{2} \mathrm{O}$, EtOH; (e) R-CHO, $\mathrm{Na}(\mathrm{AcO})_{3} \mathrm{BH}, 1,2-\mathrm{DCE}$ or Ac-Cl, $\mathrm{iPr}_{2} \mathrm{EtN}, \mathrm{CH}_{2} \mathrm{Cl}_{2}$ or n-hexyl isocyanate, toluene.

Scheme 3.

Synthesis of 1-substituted tetrahydroisoquinolines $\mathbf{4 1 - 5 6}{ }^{\mathrm{a}}$ 

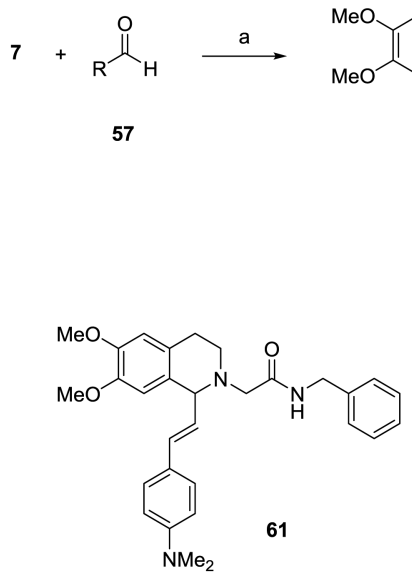

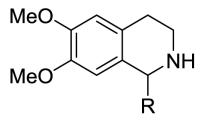

58

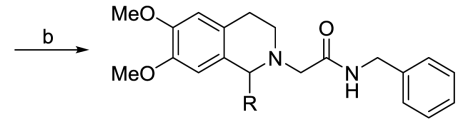

59, R=4-NMe $2 \mathrm{Ph} \quad 66$, n-heptyl

61, $\mathrm{R}=\mathrm{CHCH}-4-\mathrm{NMe}_{2}-\mathrm{Ph} 67, \mathrm{CH}_{2}$-cyclohexyl

63, $\mathrm{R}=\left(\mathrm{CH}_{2}\right)_{3} \mathrm{Ph} \quad 68,\left(\mathrm{CH}_{2}\right)_{2}$-cyclohexyl

64, $\mathrm{R}=\mathrm{nBu}$

65, $R=i B u$

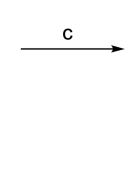

${ }^{a}$ Reagents and Conditions: (a) $\mathrm{CF}_{3} \mathrm{CO}_{2} \mathrm{H}$, toluene; (b) $\mathrm{BrCH}_{2} \mathrm{CONHCH}_{2} \mathrm{Ph}, \mathrm{Pr}_{2} \mathrm{EtN}, \mathrm{Bu}_{4} \mathrm{NI}$, DMF; (c) $\mathrm{H}_{2}, 10 \% \mathrm{Pd} / \mathrm{C}$, EtOH.

Scheme 4.

Synthesis of 1-substituted tetrahydroisoquinolines 59-69 


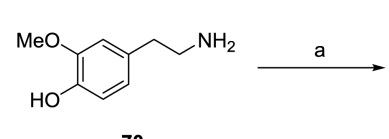

70

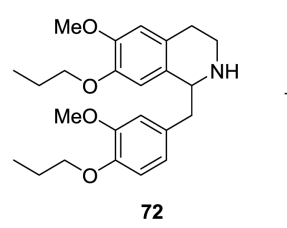

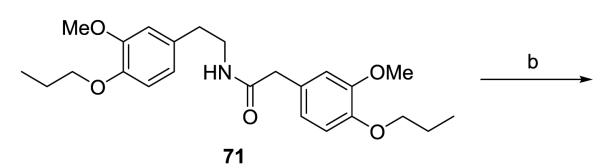

71

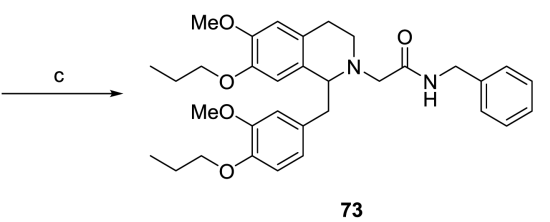

${ }^{a}$ Reagents and Conditions: (a) (i) $8 \mathbf{b}$, $\mathrm{HBTU}$, $\mathrm{iPr}_{2} \mathrm{EtN}$, DMF; (ii) 1-iodopropane, $\mathrm{K}_{2} \mathrm{CO}_{3}$, DMF; (b) (i) $\mathrm{POCl}_{3}$, toluene; (ii) $\mathrm{NaBH}_{4}, \mathrm{MeOH}$; (c) $\mathrm{BrCH}_{2} \mathrm{CONHCH}_{2} \mathrm{Ph}, \mathrm{K}_{2} \mathrm{CO}_{3}$, DMF.

\section{Scheme 5.}

Synthesis of 7-propoxy tetrahydroisoquinoline $\mathbf{7 3}$. $^{\mathrm{a}}$ 


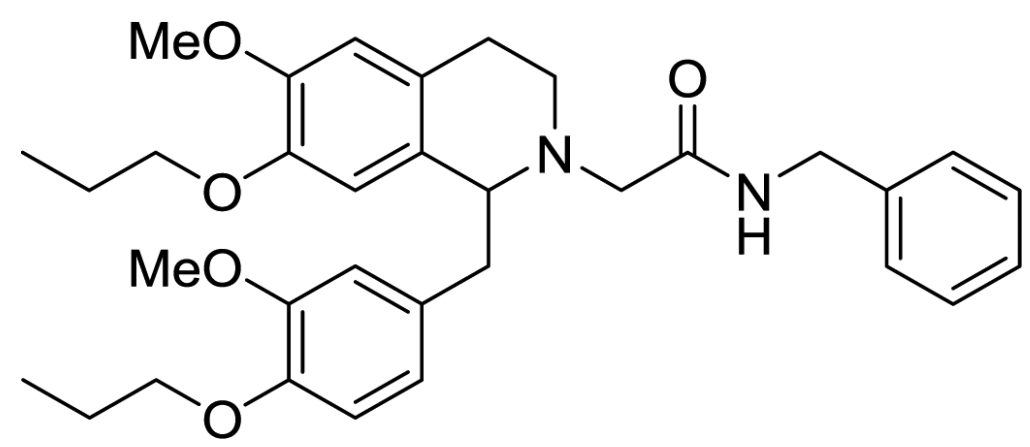

Figure 2.

7-Propoxy-1-(4-propoxy)benzyl tetrahydroisoquinoline derivative $\mathbf{7 3}$. 
D a y 1

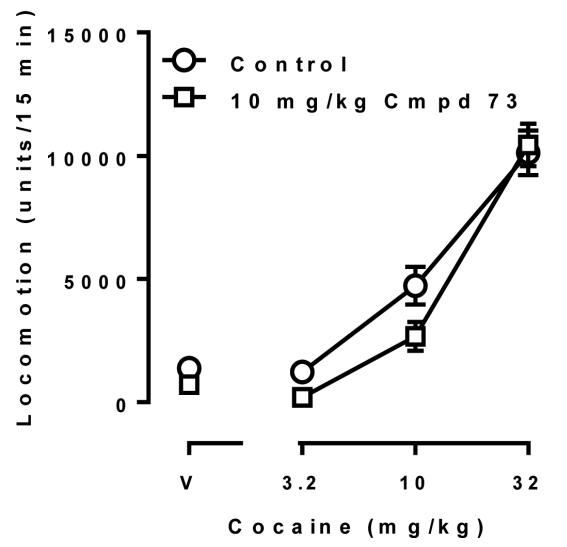

D a y 15

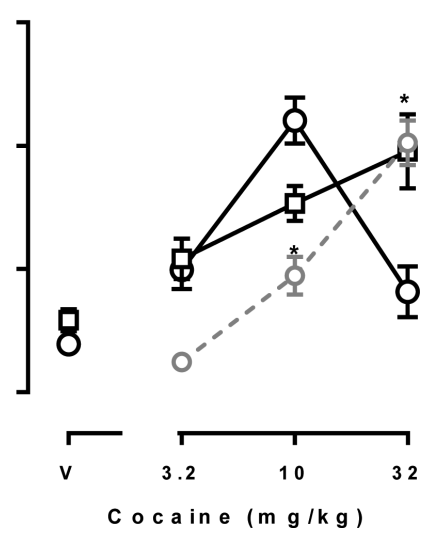

Figure 3.

Compound $\mathbf{7 3}$ attenuated the development of cocaine-induced behavioral sensitization. Left: compound 73 did not significantly alter acute cocaine-induced hyperactivity (n=8/group). Right: compound $\mathbf{7 3}$ significantly reduced the development of cocaine sensitization during the challenge test $(* \mathrm{P}<0.05$ as compared with control group). Dashed line represents the replotted data of control group in Day 1 for comparison in Day 15. Data represent the mean \pm SEM. The absence of error bars indicates that the variability is contained within the data point. V, vehicle. 
Table 1

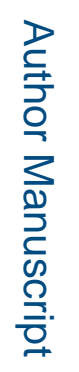

Effect of benzyl substitution on OX antagonism

\begin{tabular}{|c|c|c|c|c|c|}
\hline Number & $\mathbf{R}_{1}$ & $\mathbf{R}_{\mathbf{2}}$ & $\operatorname{Ke}\left(\mathbf{O X}_{1}, \mathrm{nM}\right)^{b}$ & $\mathrm{Ke}\left(\mathrm{OX}_{2}, \mathrm{nM}\right)^{c}$ & $\mathrm{OX}_{2} / \mathrm{OX}_{1}$ \\
\hline 11 & $\mathrm{OMe}$ & $\mathrm{OMe}$ & $199 \pm 47$ & $>10,000$ & $>50.3$ \\
\hline 12 & $\mathrm{OMe}$ & $\mathrm{OH}$ & $419 \pm 64$ & $>10,000$ & $>24$ \\
\hline 13 & $\mathrm{OMe}$ & O-n-Butyl & $48 \pm 27$ & $2000 \pm 860$ & 42 \\
\hline 14 & $\mathrm{OMe}$ & O-n-Hexyl & $120 \pm 20$ & $>10,000$ & $>83$ \\
\hline 15 & $\mathrm{OMe}$ & $\mathrm{O}-\left(\mathrm{CH}_{2}\right)_{2}$-piperidinyl & $>10,000^{d}$ & $a$ & \\
\hline 16 & $\mathrm{OMe}$ & $\mathrm{OCO}\left(\mathrm{CH}_{2}\right)_{2} \mathrm{CH}_{3}$ & $43.5 \pm 3.7$ & $2080 \pm 600$ & 48 \\
\hline 17 & $\mathrm{OMe}$ & $\mathrm{OSO}_{2} \mathrm{Me}$ & $480 \pm 180$ & $a$ & \\
\hline 18 & $\mathrm{OMe}$ & OBenzyl & $399 \pm 22$ & $a$ & \\
\hline 19 & $\mathrm{OMe}$ & $\mathrm{O}-\left(\mathrm{CH}_{2}\right)_{4}-\mathrm{OPh}$ & $385 \pm 96$ & $a$ & \\
\hline 20 & $\mathrm{OMe}$ & $\mathrm{OSO}_{2}(4-\mathrm{Me}) \mathrm{Ph}$ & $>10,000$ & $a$ & \\
\hline 21 & $\mathrm{OMe}$ & $\mathrm{OCH}_{2}$-2-Pyridyl & $153 \pm 43$ & $a$ & \\
\hline 22 & $\mathrm{OMe}$ & $\mathrm{OCH}_{2}$-3-Pyridyl & $250 \pm 120$ & $a$ & \\
\hline 23 & $\mathrm{OMe}$ & $\mathrm{OSO}_{2} \mathrm{Ph}$ & $1820 \pm 680$ & $a$ & \\
\hline 26 & $\mathrm{NO}_{2}$ & $\mathrm{OMe}$ & $1500 \pm 230$ & $a$ & \\
\hline 28 & $\mathrm{NMe}_{2}$ & $\mathrm{OMe}$ & $12.7 \pm 2.8$ & $970 \pm 350$ & 76.7 \\
\hline 29 & NHEt & $\mathrm{OMe}$ & $309 \pm 39$ & $>10,000$ & $>32$ \\
\hline 30 & $\mathrm{NEt}_{2}$ & $\mathrm{OMe}$ & $208 \pm 38$ & $>10,000$ & $>48$ \\
\hline 31 & NH-n-Propyl & $\mathrm{OMe}$ & $920 \pm 140$ & $>10,000$ & $>11$ \\
\hline 32 & $\mathrm{~N}(\mathrm{n} \text {-Propyl })_{2}$ & $\mathrm{OMe}$ & $857 \pm 380^{d}$ & $a$ & \\
\hline 33 & NH-Benzyl & $\mathrm{OMe}$ & $>10,000^{d}$ & $a$ & \\
\hline 34 & NHAc & $\mathrm{OMe}$ & $>10,000^{d}$ & $a$ & \\
\hline 35 & $\mathrm{NHCO}\left(\mathrm{CH}_{2}\right)_{2} \mathrm{CH}_{3}$ & $\mathrm{OMe}$ & $320 \pm 30$ & $a$ & \\
\hline 36 & $\mathrm{NO}_{2}$ & $\mathrm{OH}$ & $>10,000^{d}$ & $a$ & \\
\hline 37 & $\mathrm{NH}_{2}$ & $\mathrm{OH}$ & $>10,000^{d}$ & $a$ & \\
\hline 38 & \multicolumn{2}{|c|}{ 2-Methyl-5-benzoxazole } & $2620 \pm 870^{d}$ & $a$ & \\
\hline
\end{tabular}

ACS Chem Neurosci. Author manuscript; available in PMC 2016 April 15. 
${ }^{c}$ Values are the mean \pm SEM of at least two independent experiments performed in duplicate; for compounds with $\mathrm{Ke}<100 \mathrm{nM}_{\text {at }} \mathrm{OX}_{1}$ at least three independent experiments in duplicate were performed.

${ }^{d}$ Values are the mean \pm SEM of two independent experiments performed in duplicate. 
Table 2

Mono-substituted benzylic substituents at the 1-position and their effect on OX antagonism

\begin{tabular}{|c|c|c|c|c|c|}
\hline Number & $\mathbf{R}_{\mathbf{1}}$ & $\mathbf{R}_{\mathbf{2}}$ & $\operatorname{Ke}\left(\mathrm{OX}_{1}, \mathrm{nM}\right)^{b}$ & $\operatorname{Ke}\left(\mathrm{OX}_{2}, \mathrm{nM}\right)^{c}$ & $\mathrm{OX}_{2} / \mathrm{OX}_{1}$ \\
\hline 11 & $\mathrm{OMe}$ & $\mathrm{OMe}$ & $199 \pm 47$ & $>10,000$ & $>50.3$ \\
\hline 41 & O-Isopropyl & $\mathrm{H}$ & $1470 \pm 70$ & $>10,000$ & $>6.8$ \\
\hline 42 & $\mathrm{NO}_{2}$ & $\mathrm{H}$ & $>10,000$ & $1200 \pm 160$ & $<0.12$ \\
\hline 43 & $\mathrm{NH}_{2}$ & $\mathrm{H}$ & $1310 \pm 90$ & $a$ & \\
\hline 44 & $\mathrm{NMe}_{2}$ & $\mathrm{H}$ & $75.3 \pm 1.3$ & $660 \pm 160$ & 8.8 \\
\hline 45 & $\mathrm{H}$ & O-n-Propyl & $370 \pm 50$ & $>10,000$ & $>27$ \\
\hline 46 & $\mathrm{H}$ & O-Isopropyl & $489 \pm 68$ & $>10,000$ & $>20$ \\
\hline 47 & $\mathrm{H}$ & $\mathrm{NH}_{2}$ & $>10,000^{d}$ & $a$ & \\
\hline 48 & $\mathrm{H}$ & $\mathrm{NMe}_{2}$ & $253 \pm 85$ & $>10,000$ & $>40$ \\
\hline 49 & $\mathrm{H}$ & NHAc & $>10,000^{d}$ & $a$ & \\
\hline 50 & $\mathrm{H}$ & NHCONH-n-hexyl & $>10,000^{d}$ & $a$ & \\
\hline 51 & $\mathrm{H}$ & Isopropyl & $85 \pm 21$ & $>10,000$ & $>118$ \\
\hline
\end{tabular}

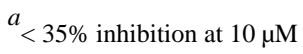

${ }^{b}$ Values are the mean \pm SEM of at least three independent experiments performed in duplicate

${ }^{c}$ Values are the mean \pm SEM of at least two independent experiments in performed duplicate; for compounds with $\mathrm{Ke}<100 \mathrm{nM}_{\text {at }} \mathrm{OX}_{1}$ at least three independent experiments in duplicate were performed.

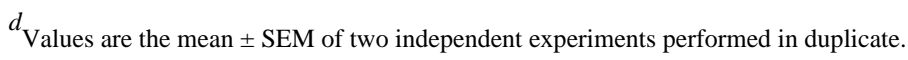


Table 3

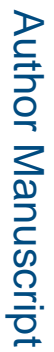

Other substituents at the 1-position and their effect on OX antagonism

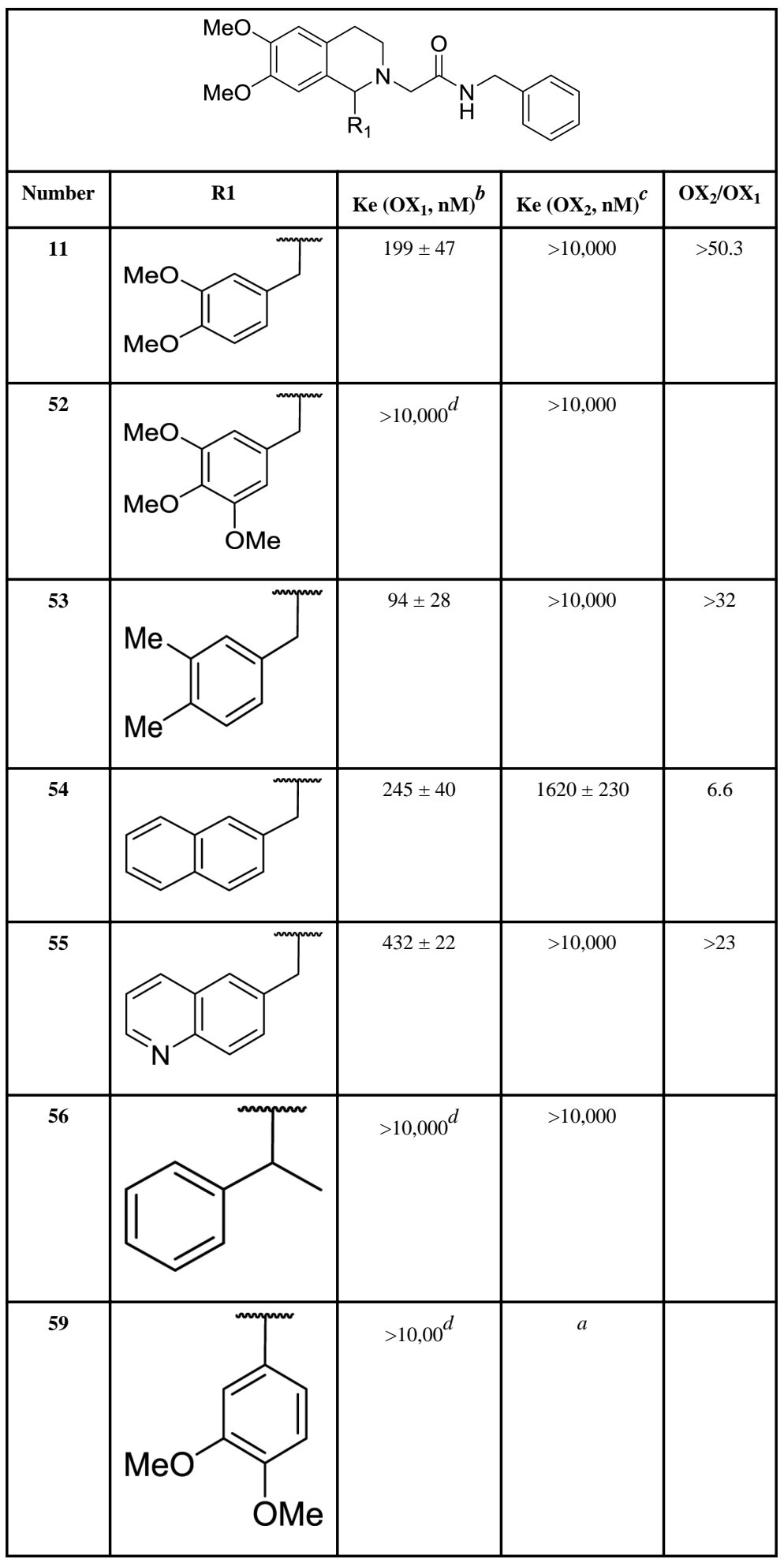

ACS Chem Neurosci. Author manuscript; available in PMC 2016 April 15. 


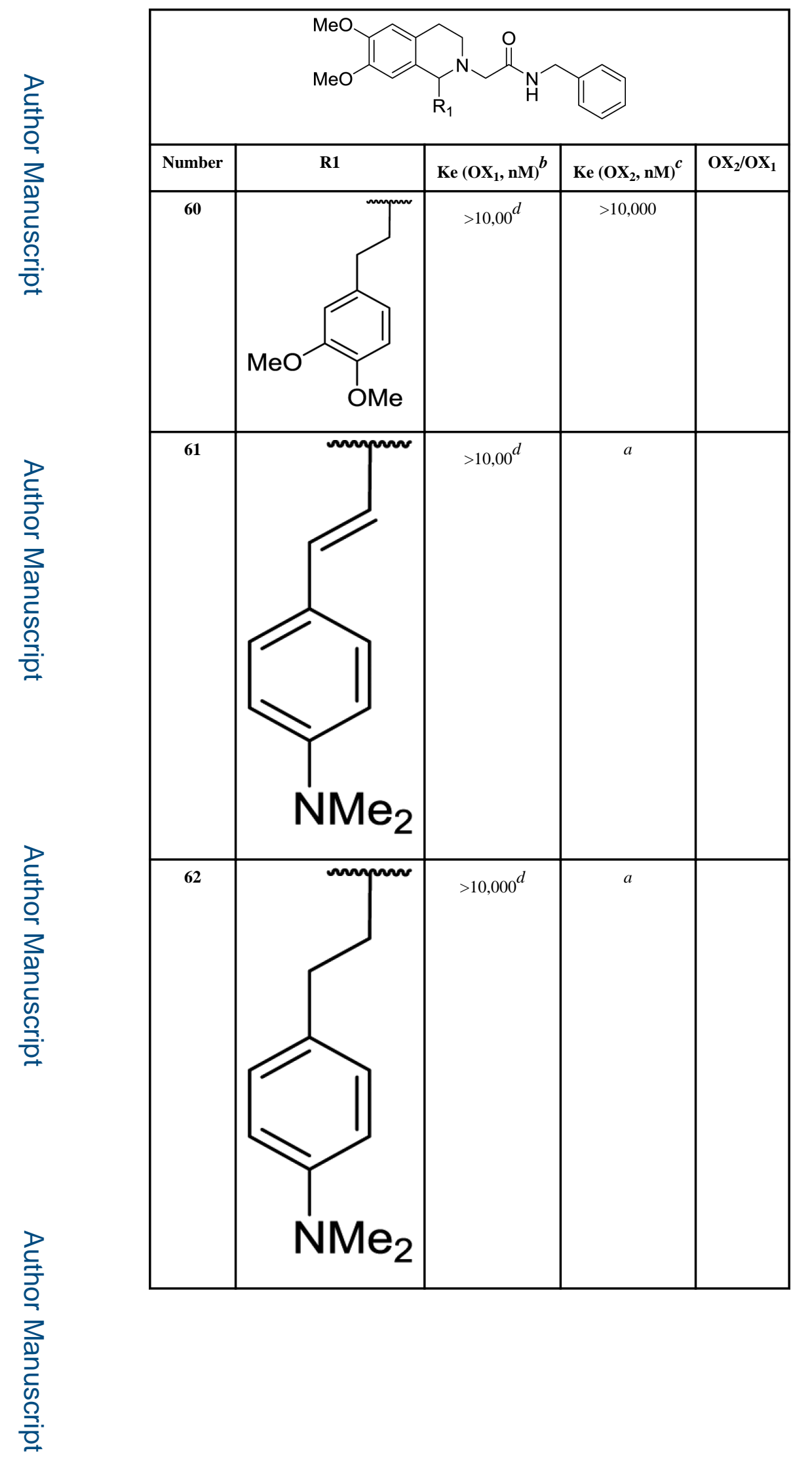

ACS Chem Neurosci. Author manuscript; available in PMC 2016 April 15. 


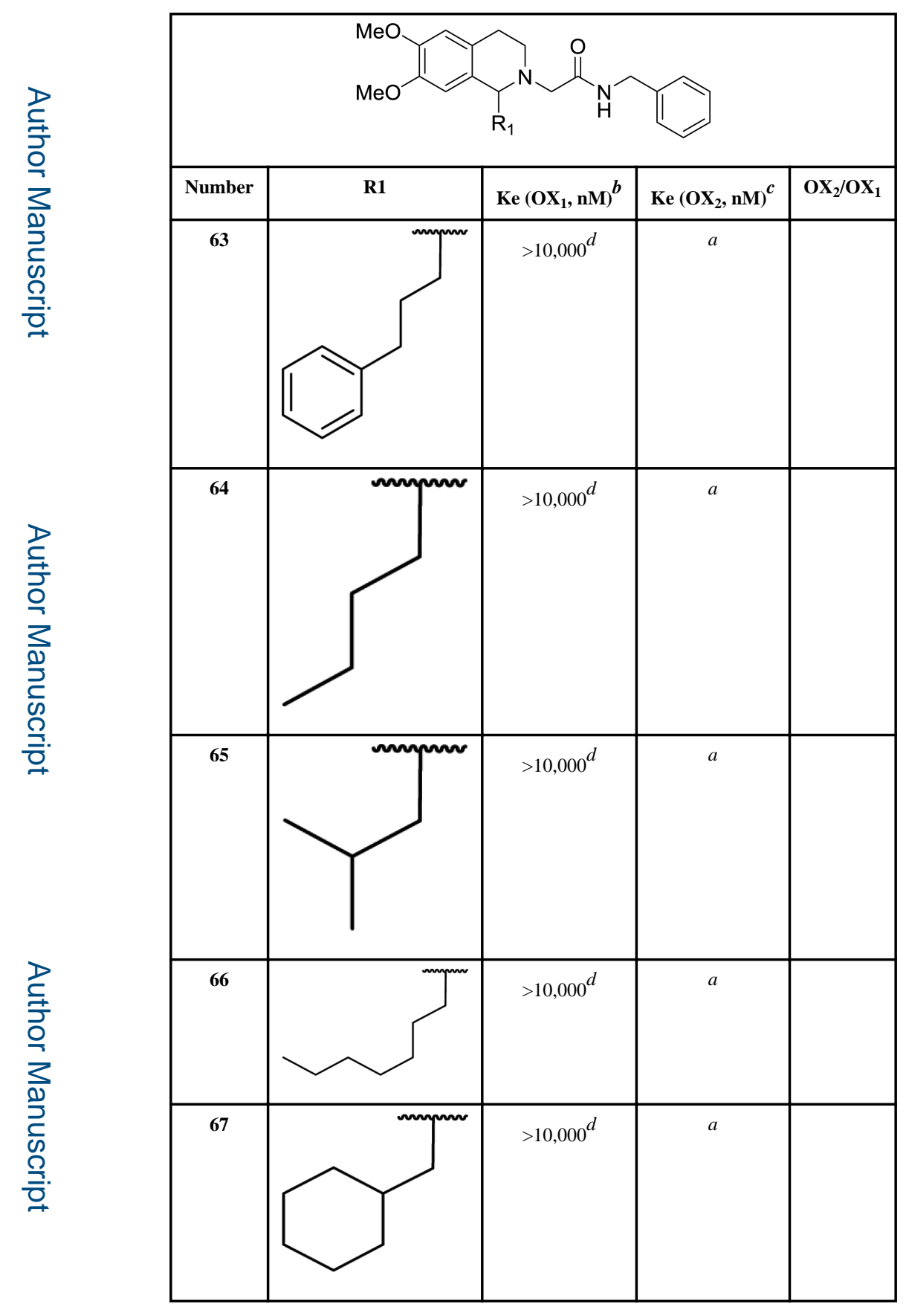

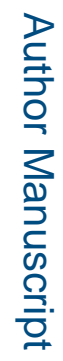




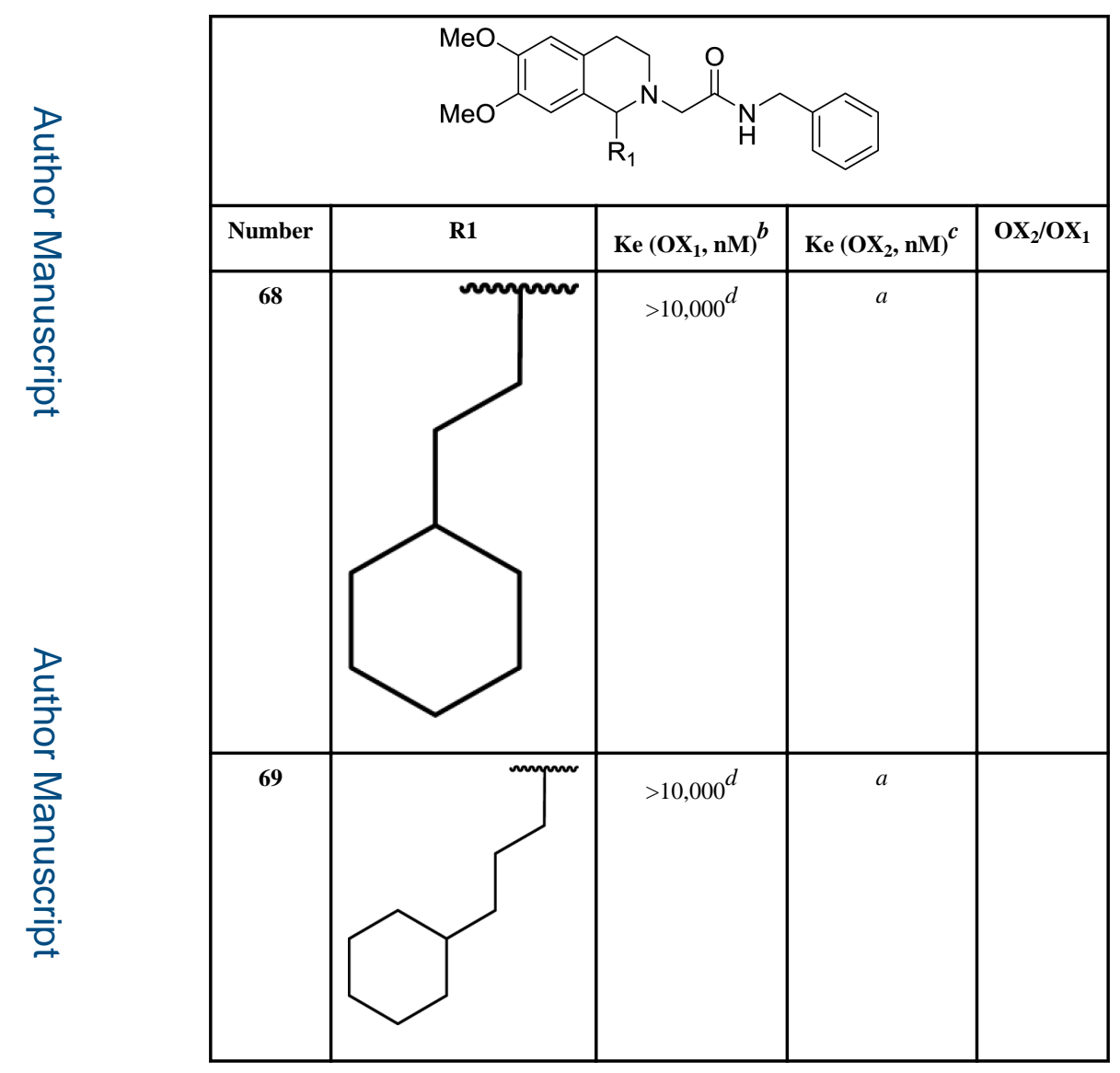

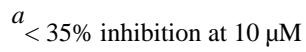

${ }^{b}$ Values are the mean \pm SEM of at least three independent experiments performed in duplicate

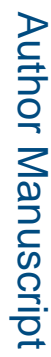

${ }^{c}$ Values are the mean \pm SEM of at least two independent experiments in performed duplicate; for compounds with $\mathrm{Ke}<100 \mathrm{nM}_{\text {at }} \mathrm{OX}_{1}$ at least three independent experiments in duplicate were performed.

${ }^{d}$ Values are the mean \pm SEM of two independent experiments performed in duplicate. 